Installation Restoration Research Program

\title{
Vapor-Phase Transport of Explosives Compounds in Soils
}

R. Ravikrishna, Sally L. Yost, Cynthia B. Price, Charolett A. Hayes, Kalliat T. Valsaraj, and James M. Brannon

US Army Corps of Engineers ${ }_{\circledast}$

Engineer Research and Development Center

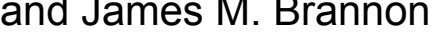


The contents of this report are not to be used for advertising, publication, or promotional purposes. Citation of trade names does not constitute an official endorsement or approval of the use of such commercial products.

The findings of this report are not to be construed as an official Department of the Army position, unless so designated by other authorized documents. 


\section{Vapor-Phase Transport of Explosives Compounds in Soils}

by R. Ravikrishna, Kalliat T. Valsaraj

Louisiana State University

Gordon A. and Mary Cain Department of Chemical Engineering

Baton Rouge, LA 70803

Sally L. Yost, Cynthia B. Price, Charolett A. Hayes, James M. Brannon

Environmental Laboratory

U.S. Army Engineer Research and Development Center 3909 Halls Ferry Road

Vicksburg, MS 39180-6199

Final report

Approved for public release; distribution is unlimited 


\section{Contents}

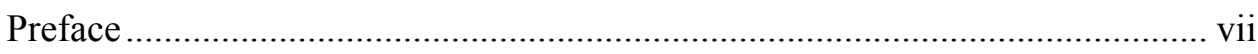

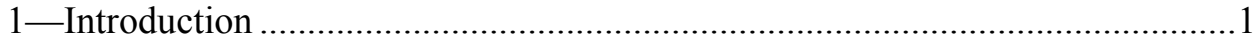

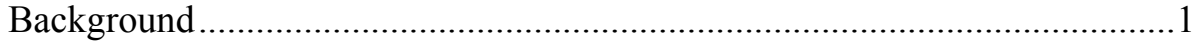

Modeling of Vapor-Phase Transport of Explosives.......................................

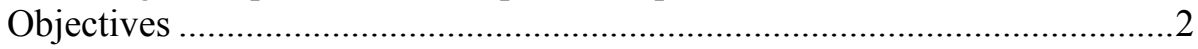

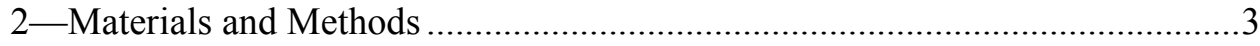

Soils 3

Transport of UXO Chemical Signatures from Soils ..................................... 3

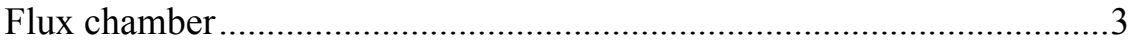

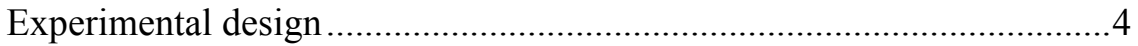

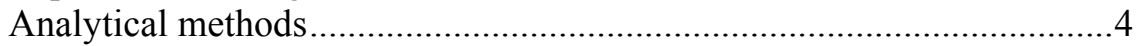

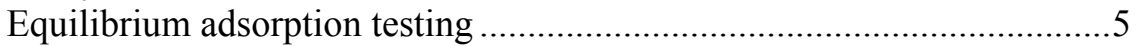

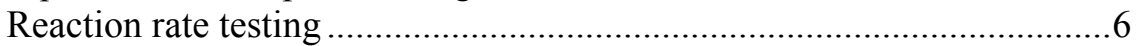

Transport of Explosives Chemicals from Buried Sources ..............................6

Mathematical Model .......................................................................................

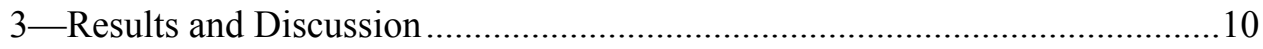

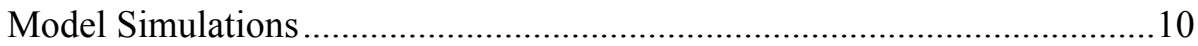

Case $1 \quad 10$

Case $2 \quad 10$

Case $3 \quad 11$

Case $4 \quad 11$

Transport of UXO Chemicals from Soils .....................................................11

Experimental soil/water adsorption constants ......................................11

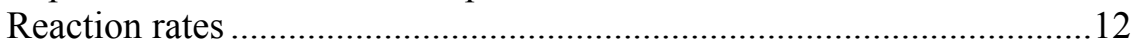

Experimental results and model comparison.........................................13

Effect of soil temperature on flux from soils.........................................25

Explosive Chemical Signature Transport from Buried Sources ....................28

Application of the Model to Soil Samples Collected Near Buried

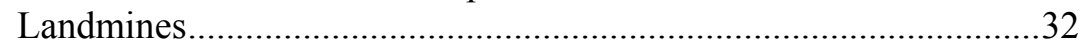

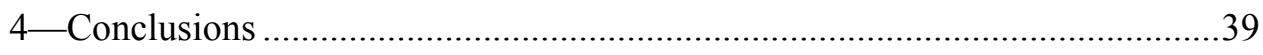

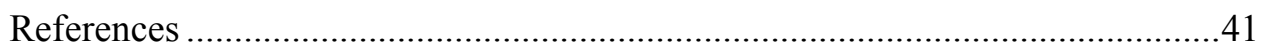




\section{List of Figures}

Figure 1. Flux of 2,4-DNT from three soils...........................................14

Figure 2. Flux of 2,6-DNT from three soils............................................15

Figure 3. Flux of 1,3-DNB from three soils .......................................... 16

Figure 4. Comparison of experimental and model fit for cases 1 and 2 for $2,4-D N T$ at 20 - and $100-\mathrm{ml} / \mathrm{min}$ airflow rate from LAAP-C soil.

Figure 5. Comparison of experimental and model fit for cases 1 and 2 for 2,6-DNT at 20- and 100- $\mathrm{ml} / \mathrm{min}$ airflow rate from LAAP-C soil.

Figure 6. Comparison of experimental and model fit for cases 1 and 2 for $1,3-\mathrm{DNB}$ at 20 - and $100-\mathrm{ml} / \mathrm{min}$ airflow rate from LAAP-C soil.

Figure 7. Experimental data for 2,4-DNT, 2,6-DNT, and 1,3-DNB for all three soils for case 3

Figure 8. Comparison of experimental fluxes of 2,4-DNT, 2,6-DNT, and 1,3-DNB for case 3 data with LAAP-C soil for 20 - and $100-\mathrm{ml} / \mathrm{min}$ airflow rates

Figure 9. Comparison of experimental and model fit for 2,4-DNT, 2,6-DNT, and 1,3-DNB for case 4 for 20- and 100-ml/min airflow rates, LAAP-C soil, 20-percent soil moisture with humid air

Figure 10. Effect of temperature on the flux of 2,4-DNT from LAAP-C soil....

Figure 11. Comparison of experimental and modeled soil concentrations of 2,4-DNT, 2,6-DNT, and 1,3-DNB from a buried source, soil moisture of 5 percent with vaporphase diffusion

Figure 12. Comparison of experimental and modeled soil concentrations of 2,4-DNT, 2,6-DNT, and 1,3-DNB from a buried source, soil moisture of 20 percent with aqueousphase diffusion 
Figure 13. Comparison of experimental and model fit soil concentrations of 2,4-DNT, 2,6-DNT, 1,3-DNB, and TNT from buried TMA-5 type landmine, Fort Leonard Wood site, 41 days following burial.

Figure 14. Comparison of experimental and model fit soil concentrations of 2,4-DNT, 2,6-DNT, 1,3-DNB, and TNT from buried TMA-5 type landmine, Fort Leonard Wood site, 270 days following burial .37

Figure A1. Experimental soil concentrations of 2,4-DNT as a function of position with respect to source at $4-\mathrm{cm}$ depth

Figure A2. Experimental soil concentrations of 2,4-DNT as a function of position with respect to source at $15-\mathrm{cm}$ depth

Figure A3. Experimental soil concentrations of 2,6-DNT as a function of position with respect to source at $4-\mathrm{cm}$ depth.

Figure A4. Experimental soil concentrations of 2,6-DNT as a function of position with respect to source at $15-\mathrm{cm}$ depth

Figure A5. Experimental soil concentrations of 1,3-DNB as a function of position with respect to source at $4-\mathrm{cm}$ depth.

Figure A6. Experimental soil concentrations of 1,3-DNB as a function of position with respect to source at $15-\mathrm{cm}$ depth

Figure A7. Experimental soil concentrations of 1,3,5-TNB as a function of position with respect to source at $4-\mathrm{cm}$ depth.

Figure A8. Experimental soil concentrations of 1,3,5-TNB as a function of position with respect to source at $15-\mathrm{cm}$ depth

\section{List of Tables}

Table 1. Physical Characteristics of Soils .................................................

Table 2. Relevant Properties of Explosives Compounds ...........................5

Table 3. Initial Soils Loading with Explosives Compounds ......................5

Table 4. Soil Properties for Simulation ….............................................10

Table 5. Soil-Water Adsorption Coefficients for 2,4-DNT, 2,6-

DNT, and 1,3-DNB in three soils at $24{ }^{\circ} \mathrm{C}$ .12 
Table 6. First-Order Reaction Rate Constants for Yokena Clay

Soil

Table 7. Adjustable Parameter for Comparison with Experimental Fluxes from Cases 1 and 2 for the 20-ml/min Airflow

Rate

Table 8. Adjustable Parameter for Comparison with Experimental Fluxes from Cases 1 and 2 for LAAP-C Soil for the 100-ml/min Airflow Rate

Table 9. Fit $K_{S A}$ and $k_{1}$ Values for Modeling Experimental Data in Case 3 from LAAP-C Soil . .25

Table 10. Fit $K_{A W}$ Values to Model Experimental Data in Case 4 from LAAP-C Soil

Table 11. Adjustable Parameters for Comparison with Laboratory Flux Experiments and Buried Chemical Experiments with LAAP-C Soil.... .32

Table 12. Comparison of Air Concentrations Calculated from the Buried Source Experimental Data and Corresponding Model Simulations

Table 13. Model Fit Parameters for the Comparison of Landmine Data with Model Simulations. 38

Table A1. Initial and Final Concentration in Soils as a Function of Temperature and Moisture

Table A2. Mass of Explosives from Buried Explosives at 5-Percent Moisture and 4-cm Burial Depth.

Table A3. Mass of Explosives from Buried Explosives at 5-Percent Soil Moisture and 15-cm Burial Depth

Table A4. Mass of Explosives from Buried Explosives at 20-Percent Soil Moisture and 4-cm Burial Depth

Table A5. Mass of Explosives from Buried Explosives at 20-Percent Soil Moisture and 15-cm Burial Depth 


\section{Preface}

The U.S. Army Engineer Research and Development Center (ERDC), Environmental Laboratory (EL), Vicksburg, MS, in conjunction with the Gordon A. and Mary Cain Department of Chemical Engineering, Louisiana State University (LSU), Baton Rouge, LA, prepared this report. The experimental data were generated at the ERDC, and the modeling was conducted at LSU. The research was sponsored by Headquarters, U.S. Army Corps of Engineers (HQUSACE), Installation Restoration Research Program (IRRP), Buried Unexploded Ordnance Detection Thrust Area. The Work Area was entitled Characterization and Mobilization of UXO. Dr. Clem Myer was the IRRP Coordinator at the Directorate of Research and Development, HQUSACE, and the IRRP Program Manager was Dr. M. John Cullinane, EL, ERDC.

The report was written by R. Ravikrishna and Kalliat T. Valsaraj, LSU, and Sally L. Yost, Cynthia B. Price, Charolett A. Hayes, and James M. Brannon, EL, ERDC.

This report was reviewed by Drs. Judith C. Pennington and Patrick Deliman, EL, ERDC. The study was conducted under the direct supervision of Dr. Richard E. Price, Chief, Environmental Processes and Engineering Division, EL, and Dr. Edwin A. Theriot, Director, EL.

At the time of publication of this report, Director of ERDC was Dr. James R. Houston. Commander and Executive Director was COL John W. Morris III, EN.

This report should be cited as follows:

Ravikrishna, R., Yost, S. L., Price, C. B., Hayes, C. A., Valsaraj, K. T., and Brannon, J. M. (2002). "Vapor-phase transport of explosives compounds in soils," ERDC/EL TR-02-26, U.S. Army Engineer Research and Development Center, Vicksburg, MS.

The contents of this report are not to be used for advertising, publication, or promotional purposes. Citation of trade names does not constitute an official endorsement or approval of the use of such commercial products. 


\section{Introduction}

\section{Background}

Military test and training ranges contain large numbers of unexploded ordnance (UXO). The detection and clearing of UXO at such sites is currently the Army's highest priority environmental restoration problem. Chemical signatures emanating from UXO potentially offer a means of detection, discrimination between UXO and innocuous clutter, or refinement in classification of detected UXO. The characterization and remediation of sites containing UXO using currently available technology are often hazardous and prohibitively expensive due to the extraordinarily high level of false detections. Before the utility of new chemical detectors can be evaluated, methods for determining the strength of explosives chemical signatures under various environmental and soil conditions are required.

The efficacy of chemical sensors and their potential usefulness for detecting buried UXO are difficult to determine without understanding how explosives chemical signatures are transported through soil. Soil conditions may result in no detectable explosives signature at the soil surface due to explosives degradation in the soil (Price, Brannon, and Hayes 1997; Price et al. 2001). The probability of detecting explosives signatures is further complicated by the low vapor pressure of 2,4,6-trinitrotoluene (TNT), hexahydro-1,3,5-trinitro-1,3,5-triazine (RDX), and octahydro-1,3,5,7-tetranitro-1,3,5,7-tetrazocine (HMX) (summarized in McGrath 1995). The vapor pressure of RDX and HMX is so low that signatures from spiked soils could not be detected even with the use of radioisotopes. TNT forms a significant fraction of explosives in UXO because of its use alone or as a component of military formulations in munitions. Manufacturing impurities in TNT such as 2,4-dinitrotoluene (2,4-DNT), 2,6-dinitrotoluene (2,6-DNT), 1,3-dinitrobenzene (1,3-DNB), and 1,3,5-trinitrobenzene (1,3,5-TNB) have higher vapor pressures than TNT and offer a potentially better chemical tracer for detection of explosives from UXO (Brannon and Pennington, In Press; Phelan and Webb 1997). The compounds 2,4-DNT and 1,3-DNB were found in higher concentrations in the equilibrium vapor of TNT and were transported more rapidly in the soil (George et al. 1999).

Documentation exists on the fate and transport of explosives residues from contaminated soils and groundwater under saturated conditions (McGrath 1995; Brannon and Myers 1997; Brannon and Pennington, In Press). Field measurements of chemical transport from buried landmines also have been conducted (Jenkins et al. 2000; George et al. 1999; Jenkins, Leggett, and Ranney 1999). 
However, descriptions for processes controlling the migration of explosives chemical signatures through soil from UXO and other sources under unsaturated conditions are limited (George et al. 1999, Phelan, Rodacy, and Barnett 2001; Phelan and Webb 1997) and must be understood to develop mathematical models to predict their vapor-phase movement. These models will aid in the calibration and evaluation of existing and future sensors by attempting to predict the strength of chemical signatures at the detector.

\section{Modeling of Vapor-Phase Transport of Explosives}

The fate and transport of explosives in the air-filled pores within soil affect both the potential detection of buried ordnance by chemical sensors and vadose zone transport of explosives residues (McGrath 1995). The transport characteristics of explosives vapors through soils affect the sensitivity levels that sensors must attain to detect chemical signatures for a given munitions depth. Transport characteristics also affect how chemical concentrations will migrate in the vadose zone independently of water-phase transport. Experimental and modeling methods for examining the flux of polyaromatic hydrocarbons from sediment into the air have been developed (Valsaraj et al. 1999, 1997; Ravikrishna et al. 1998). Results have shown that transport from the sediment particles to the air are affected by moisture content, air relative humidity, air velocity, and temperature. Documents have also been published concerning the explosives source term for UXO (Price et al. 2000) and a conceptual model for fate and transport of explosives through soils (Brannon et al. 1999).

The modeling and experimental methods used for examining the flux of polyaromatic hydrocarbons can be modified and adapted for examining the transport of explosives from soils under various conditions of soil moisture, temperature, and relative humidity. These parameters control the flux of nonpolar organic compounds from sediment particles into the air and provide a basis for evaluation of explosives residues vapor transport (Valsaraj et al. 1999, 1997; Ravikrishna et al. 1998).

\section{Objectives}

The objectives of this study were to quantify chemical signature transport through soils under various environmental conditions in unsaturated soils and to develop a model for chemical signature transport in unsaturated soils. 


\section{Materials and Methods}

\section{Soils}

Two aquifer soils obtained from Louisiana Army Ammunition Plant, Shreveport, LA (LAAP-C and LAAP-D), and one surface soil (Yokena clay) from the Mississippi River floodplain were used as test matrices in the experiments to study UXO chemical signature transport. These soils provided a wide range of physical and chemical characteristics (Table 1). Each soil was air-dried, ground, and sieved before storing at room temperature. After spiking, soils were placed on a pan in a thin layer under a hood to allow the acetone to evaporate, then tumbled overnight to ensure complete mixing.

\begin{tabular}{|c|c|c|c|}
\hline \multicolumn{4}{|c|}{$\begin{array}{l}\text { Table } 1 \\
\text { Physical Characteristics of Soils }\end{array}$} \\
\hline Soil Property & LAAP-C & LAAP-D & Yokena Clay \\
\hline $\mid \overline{P e r c e n t ~ s a n d ~}$ & 77 & 27 & 13.75 \\
\hline Percent silt & 11 & 41 & 37.54 \\
\hline Percent clay & 12 & 32 & 48.75 \\
\hline Textural classification & Sandy loam & Clay loam & Clay \\
\hline Percent total organic carbon & 0.08 & 0.20 & 2.4 \\
\hline Cation exchange capacity, meq/100 g & 6.6 & 15.5 & 38.9 \\
\hline Bulk density, $\mathrm{g} / \mathrm{cm}^{3}$ & 1.43 & 0.88 & 0.86 \\
\hline
\end{tabular}

\section{Transport of UXO Chemical Signatures from Soils}

\section{Flux chamber}

These experiments were designed to measure and model evaporative fluxes of the test explosive chemicals from soils. The test soils were spiked with the chemicals and placed in a flux chamber with air flowing across the surface of the soil. A modified version of a flux chamber designed by Spencer et al. (1979) was used. The two-part chamber was constructed of anodized aluminum. The bottom portion held soil at a depth of $2.54 \mathrm{~cm}$ with a surface area of $30 \mathrm{~cm}^{2}$. The top portion was designed with channels to provide a 2-mm air space over the sediment well to allow uniform airflow across the soil surface. O-rings and threaded fasteners were used to seal the compartments together for an airtight fit. Laboratory house air, channeled through Gilmont flow meters to ensure constant flow rate, was passed through the chamber entrance ports over the surface of the sediment. Stainless steel air sampling traps were made from tubing and 
contained 0.2 g Tenax TA (25-30 mesh). Traps were attached to the exit ports of the chambers to collect explosives compounds released into the air stream.

\section{Experimental design}

The experiments were designed to compare volatile emissions under varying air relative humidity (r. h.) ( 0 and 98 percent), soil moisture content (5 and 20 percent), soil temperature $\left(14\right.$ and $\left.24{ }^{\circ} \mathrm{C}\right)$ and airflow rate $(20$ and $100 \mathrm{ml} / \mathrm{min}$ ). The $100-\mathrm{ml} / \mathrm{min}$ experiments were conducted at 5- and 20-percent soil moisture contents and with 0 - and 98-percent $r$. h. conditions, but with one soil only, LAAP-C. Air humidity was controlled using an in-line bubble trap to add moisture vapor to the passing air. Moisture contents of each soil were determined, and deionized water was added to obtain the desired soil moisture content. A recirculating water bath (Remcor Products Company, IL, model CFF550) was set to maintain a constant $14{ }^{\circ} \mathrm{C}$ for the low temperature experiment, while room temperature provided the desired $24{ }^{\circ} \mathrm{C}$ ambient temperature.

Humid airflow was established at the two desired flow rates of 20 and $100 \mathrm{ml} / \mathrm{min}$, and passed over the soils for a 21-day period. The humid air was then switched to dry air for another 21-day period. Air samples were taken at 24, $72,168,336$ and $504 \mathrm{hr}$ by replacing the Tenax trap with a fresh trap. The traps were extracted with $5 \mathrm{ml}$ acetonitrile and analyzed for the mass of contaminant trapped $(\Delta m) .1$ Knowing the duration of sampling $(\Delta t)$ and the soil-air interface area of the chamber $\left(A_{\mathrm{c}}\right)$, the flux rates $\left(N_{\mathrm{A}}\right)$ were determined from $N_{\mathrm{A}}=\left(\Delta m / A_{\mathrm{c}}\right.$ $\Delta t)$.

In all flux measurement experiments, the soils were spiked with a mixture of TNT, 2,4-DNT, 2,6-DNT, 1,3,5-TNB, and 1,3-DNB. Samples of $800 \mathrm{~g}$ of the different soils were spiked with $50 \mathrm{ml}$ of an acetone solution containing approximately $10 \mathrm{mg} / \mathrm{L}$ of each of the explosives. The spiked soils were placed under a hood to allow the acetone to evaporate, then tumbled overnight to ensure complete mixing. Table 2 lists the physicochemical properties of the compounds considered in this study. Table 3 lists the loading of three of the compounds spiked in the flux experiments. These three compounds were chosen for comparison with the model since their fluxes were consistently measurable.

\section{Analytical methods}

Soils in the flux chambers were analyzed initially and at the end of each experiment to determine if explosives degradation had occurred. Air sampling traps were extracted for $24 \mathrm{hr}$ with acetonitrile before analysis. At the conclusion of an experiment, the plate at the top of the flux apparatus was rinsed with acetonitrile to determine if any residues remained on the chamber surface. Analyses of soils were performed by high-performance liquid chromatography (HPLC) using SW-846 Method 8330 (U.S. Environmental Protection Agency

1 For convenience, symbols are listed in the notation (Appendix B). 


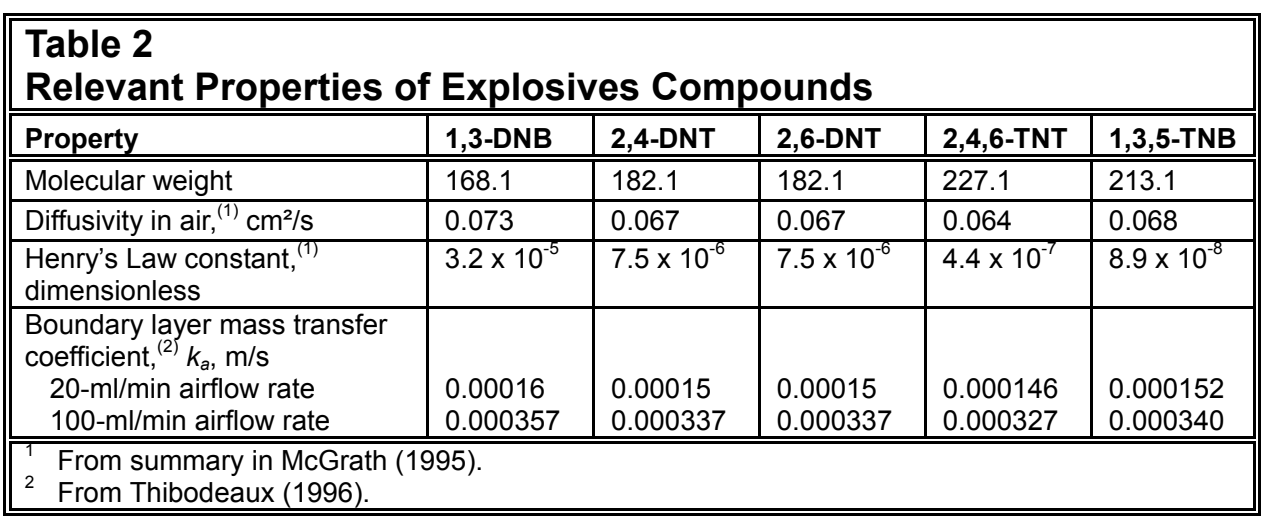

\begin{tabular}{|c|c|c|c|}
\hline \multicolumn{4}{|c|}{$\begin{array}{l}\text { Table } 3 \\
\text { Initial Soils Loading with Explosives Compounds }\end{array}$} \\
\hline \multirow[b]{2}{*}{ Soil } & \multicolumn{3}{|c|}{ Looading, mg/kg } \\
\hline & 1,3-DNB & 2,4-DNT & 2,6-DNT \\
\hline \multicolumn{4}{|c|}{ 20-ml/min experiments } \\
\hline LAAP-C & 7.4 & 10.5 & 8.4 \\
\hline LAAP-D & 9.2 & 11.0 & 9.0 \\
\hline Yokena clay & 9.1 & 9.3 & 9.4 \\
\hline \multicolumn{4}{|c|}{ 100-ml/min experiments } \\
\hline LAAP-C & 9.74 & 10.4 & 9.36 \\
\hline
\end{tabular}

(U.S. EPA) 1994). Analyses of sampling traps, acetonitrile extracts, and acetonitrile rinses of flux chamber surfaces were preformed by gas chromatograph using SW 846, update IV-B Method 8095 (U.S. EPA 2000).

\section{Equilibrium adsorption testing}

One of the most critical parameters in the transport of chemicals in subsurface soils is equilibrium partitioning of the chemical between soil and water. Equilibrium adsorption testing was conducted with LAAP-C, LAAP-D, and Yokena clay soils with a 1:4 ratio of soil to water (4 $\mathrm{g}$ of soil to $16 \mathrm{ml}$ water) and five concentrations of contaminant $(10,7.5,5,2.5$, and $1 \mu \mathrm{g} / \mathrm{ml})$. The LAAP-C test was spiked with 2,6-DNT; the LAAP-D test was spiked with 2,6-DNT and 2,4-DNT in separate runs; the Yokena clay was spiked with a mixture of contaminants (TNT, 2,4-DNT, 1,3,5-TNB, 1,3-DNB, and 2,6-DNT). Tests were placed on a reciprocating shaker at 280 excursions per minute for $24 \mathrm{hr}$. After shaking, tests were centrifuged at 7,000 relative centrifugal speed for $30 \mathrm{~min}$. The aqueous phase was removed and frozen until analyzed. Analytes included 2,4-DNT, 2,6-DNT, 1,3-DNB, 1,3,5-TNB, and 2,4,6-TNT, 2,6-DANT, 2,4-DANT, and 4,4-Azoxy. The aqueous samples from the Yokena clay were preserved with ethylene diamine tetraacetic acid to a final concentration of $5 \mu \mathrm{g} / \mathrm{ml}$. The testing was carried out in duplicate for each experimental unit. 


\section{Reaction rate testing}

Disappearance or degradation due to reaction within the soil matrix is another important parameter in the subsurface transport of chemicals. These reactions may be due to metabolism by microbial organisms present in the soil or reactions on the soil surface. The three soils (Yokena clay, LAAP-C, and LAAP-D) were spiked with a mixture of TNT, 1,3-DNB, 2,4-DNT, 2,6-DNT, and $1,3,5-\mathrm{TNB}$ at a concentration of $10 \mathrm{mg} / \mathrm{kg}$. Spiking was done by misting the soil with the contaminant solution and then tumbling for $24 \mathrm{hr}$. After spiking, the soils were divided into batches and brought to two different moistures, 5 percent and 20 percent by weight. Samples were weighed in 5-g increments and loaded into 20 -ml amber glass vials. Sufficient vials were loaded so that each soil was duplicated at four different conditions; 5-percent moisture at $14{ }^{\circ} \mathrm{C}, 5$-percent moisture at $24{ }^{\circ} \mathrm{C}, 20$-percent moisture at $14{ }^{\circ} \mathrm{C}$, and 20-percent moisture at $24{ }^{\circ} \mathrm{C}$. The LAAP-C and LAAP-D treatments were sampled at 7, 14, and 28 days, while the Yokena clay treatments were sampled at $6 \mathrm{hr}, 20 \mathrm{hr}, 2$ days, 7 days, and 14 days. In addition to the time-series sampling, initial samples were taken of each soil at the 5- and 20-percent moisture level for HPLC analysis.

\section{Transport of Explosives Chemicals from Buried Sources}

Another series of experiments was conducted to evaluate the transport of explosives from a controlled system similar to that of buried munitions. To determine the effects of soil moisture and burial depth on chemical signature movement, four tests were conducted using soil at 5- and 20-percent moisture contents and explosives buried at depths of $15 \mathrm{~cm}$ (6 in.) and $4 \mathrm{~cm}$ (1.6 in.) below the soil surface. Soil obtained from LAAP-C was used for the four soil conditions tested. Bulk soil samples were brought to 5- and 20-percent moisture content with distilled deionized water. Four 37.85-L (10-gal) containers composed of high-density polyethylene with measurements of $38.5 \mathrm{~cm}$ height by $39.4 \mathrm{~cm}$ outside diameter (OD) were used. Packing the soil into the container was necessary to obtain vertical cores that could be sectioned incrementally.

The explosives were introduced by adding a mixture of $100 \mathrm{mg}$ each of TNT, 1,3-DNB, 1,4,5-TNB, 2,4-DNT, and 2,6-DNT to the surface of soil $15 \mathrm{~cm}$ deep through a stainless steel tube placed centrally in each container. Soil in one container was at 5-percent moisture; soil in the other was at 20-percent moisture. Approximately $2.54 \mathrm{~cm}$ ( $1 \mathrm{in}$.) of soil was packed around the tube. The tube was then removed and the explosives were visually inspected to ensure that they had remained in place. Soil was then packed over and around the explosive plug. Additional soil was added and packed to a depth of $15 \mathrm{~cm}$ over the mixture giving a total depth of $30 \mathrm{~cm}$. Identical procedures were used to place the explosives in the remaining two containers with the exception that the soils were initially packed to a depth of $26 \mathrm{~cm}$. An additional $4 \mathrm{~cm}$ of soil was packed over the compounds.

The containers were sealed and allowed to sit at room temperature $\left(\sim 24{ }^{\circ} \mathrm{C}\right)$ for 120 days. Thin-walled stainless steel tubing, $1.9 \mathrm{~cm}(0.75 \mathrm{in}$.) OD, was used 
to sample the soils. Eight horizontal cores both directly over or to the side of the explosives mixture were made in the 20-percent moisture tests. The stainless cores were sectioned every $1.5 \mathrm{~cm}$ from the soil surface giving approximately 19 vertical samples per horizontal core. Due to the looser consistency of the 5-percent moisture soil, only six horizontal cores were taken in each container for approximately 17 vertical segments for each core. Ten milliliters of acetonitrile was added to each section, and samples were stored in the freezer. Twenty samples from each container were selected and analyzed using SW-846 8095 (U.S. EPA 2000).

\section{Mathematical Model}

A general model describing the contaminant fate and transport in porous media is a diffusion-reaction equation:

$$
R_{f} \cdot \frac{\partial C_{A}}{\partial t}=\nabla \bullet\left(D_{e f f} \nabla C_{A}\right)-\left(-r_{A}\right)
$$

where

$$
\begin{aligned}
R_{f} & =\text { retardation factor } \\
C_{A} & =\text { concentration of chemical in pore air } \\
t & =\text { time } \\
D_{e f f} & =\text { effective diffusivity, } \mathrm{m}^{2} / \mathrm{s} \\
-r_{A} & =\text { reaction term }
\end{aligned}
$$

Diffusion in the soil pore air is assumed to be the dominant mechanism of mass transport within the soil. The reaction term, $-r_{A}$, is added for generality to accommodate disappearance of chemical that may occur due to biodegradation or reaction within the soil. The model also neglects chemical loss by the mechanism of "wicking" or vapor-phase advective transport of the chemical that may occur as a result of water evaporation.

If only the vertical transport in the z-direction is considered, Equation 1 is simplified to Equation 2, which is the governing differential equation for the pore air concentration of the contaminant, $C_{A}(z, t)$, as a function of depth, $z$, and time, $t$. Here it is assumed that the rate of degradation is first-order and, hence, $-r_{A}=$ $k_{1} C_{A}$.

$$
\frac{\partial C_{A}}{\partial t}=\frac{D_{e f f}}{R_{f}} \frac{\partial^{2} C_{A}}{\partial z^{2}}-k_{1} C_{A}
$$

where $k_{1}$ is the first-order constant for disappearance rate of chemical in soil. 
The following boundary conditions are applicable when a contaminated soil is exposed to air as applied to the experimental data from the flux experiments conducted with surface soils. At the soil-air interface, a thin film offers a mass transfer resistance. The boundary condition here at $z=0$ (surface) is described by:

$$
k_{a} C_{A}=D_{e f f} \frac{\partial C_{A}}{\partial z}
$$

where $k_{a}$ is the air-side mass transfer coefficient. At depths far away from the soil-air interface, $z=\infty$, the chemical concentration in the soil is relatively unaffected by the transport dynamics at the air-soil interface; therefore, this semiinfinite boundary condition can be set as $C_{A}=C_{A}^{0}$ where $C_{A}^{0}$ is the initial equilibrium concentration of chemical in pore air.

The analytical solution to Equation 2 (Choy and Reible 2000) gives $C_{A}(z, t)$. The flux is calculated by multiplying the surface overall mass transfer coefficient, $k_{a}$, and the vapor-phase contaminant concentration at the surface, $C_{A}(0, t)$, and the resultant expression for flux, $N_{A}(t)$, is shown in Equation 4.

$$
N_{A}(t)=C_{A}^{0} k_{a} e^{-k_{1} t} \cdot \exp \left(\frac{k_{a}^{2} t}{D_{e f f} R_{f}}\right) \cdot \operatorname{erfc}\left(k_{a} \sqrt{\frac{t}{D_{e f f} R_{f}}}\right)
$$

where $\operatorname{erfc}$ is the complementary error function. In Equation $4, C_{A}^{0}$, the initial equilibrium concentration of the contaminant in the pore air, is given by $W_{S}^{0} \rho_{b} / R_{f}$ where $W_{S}^{0}$ is the initial loading of the contaminant $(\mathrm{kg} / \mathrm{kg})$ and $\rho_{b}$ is the bulk density of the soil $\left(\mathrm{kg} / \mathrm{m}^{3}\right)$.

The model described by Equation 1 assumes local equilibrium with respect to the contaminant in the pore spaces. Further, the surface flux depends on the soilside and air-side resistances offered to transport of the contaminant (Valsaraj et al. 1999). The soil-side resistance is dependent on the retardation of the contaminant on the soil surface due to adsorption and the effective diffusivity of the contaminant in the porous media. The retardation factor is given by $\gamma_{a}+\rho_{b} K_{S A}$, where $K_{S A}$ is the soil-air partition constant $(\mathrm{L} / \mathrm{kg})$ and $\gamma_{a}$ is the air-filled porosity $\left(\mathrm{m}^{3} / \mathrm{m}^{3}\right)$. The retardation factor is proportional to the partition constant of the contaminant between soil and air $\left(K_{S A}\right)$. In the absence of direct measurements, $K_{S A}$ can be estimated for wet soils ( $>5$-percent soil moisture content) using Equation 5 (Valsaraj et al. 1997):

$$
K_{S A}=\frac{K_{S W}}{K_{A W}}
$$


where

$$
\begin{aligned}
K_{S W}= & \text { soil-water partition constant, } \mathrm{L} / \mathrm{kg} \\
K_{A W}= & \text { air-water partition constant, Henry's Law constant, molar } \\
& \text { concentration ratio, dimensionless }
\end{aligned}
$$

The soil-water partition constants, $K_{S W}$, were directly measured for the compounds of interest in separate batch experiments. In the absence of measured data, the values of the Henry's Law constant for the compounds of interest were obtained from the ratio of the saturated vapor pressure and solubility of explosives in water. The uncertainty in the Henry's Law constant values directly translates to the uncertainty in the soil-air partition constant.

The effective diffusivity, $D_{\text {eff }}$, was computed using the expression, $D_{A} \gamma_{a}^{10 / 3} /$ $\gamma_{T}^{2}$, where $D_{A}$ is the diffusivity of contaminant $A$ in air, $\gamma_{a}$ is the air-filled porosity, and $\gamma_{T}$ is the total porosity (Choy and Reible 2000). The values of airfilled porosity used in the simulation were calculated using the measured values of the initial soil moisture content, total soil porosity, and soil bulk density. The mass transfer coefficient, $k_{a}$, quantifies the air-side resistance offered by the film for mass transfer between the soil surface and the air flowing over the surface. The $k_{a}$ was estimated using the boundary layer theory, $0.664 \mathrm{Re}^{0.33} \mathrm{Sc}^{0.5}\left(D_{A} / d\right)$, where Re is the Reynolds Number, Sc is the Schmidt number, and $d$ is the length of the airflow path. The Re is given by $d \cdot v / v$, where $v$ is the average flow velocity, $v$ is the kinematic viscosity of air, and $\mathrm{Sc}$ is given by $v / D_{A}$. All parameters were assumed to be constant during the simulation.

Wicking can be an important transport mechanism when soil moisture is continuously replenished from beneath the top layers of soil during surface drying. The laboratory experiments described in this manuscript were performed with a very thin layer of soil $(2.54 \mathrm{~cm})$ that had low moisture content ( 5 or 20 percent) and no water replenishment from below.

The losses from any possible wicking can be estimated by $k_{a d v} \cdot C_{a i r}{ }^{0}$, where $k_{a d v}$ is the advective velocity that may be induced by wicking, and $C_{a i r}{ }^{0}$ is the equilibrium vapor-phase concentration of the chemical in the soil. The advective velocity of pore air saturated with water vapor was calculated from a previous study (Valsaraj et al. 1997) and corrected for the difference in airflow rates used in both studies based on soil to air mass transfer coefficients in the literature (Thibodeaux 1996), which was $0.034 \mathrm{~cm}^{3} / \mathrm{cm}^{2} / \mathrm{hr}$. The advective fluxes thus computed for the three chemicals discussed in this report ranged from $7.4 \times 10^{-6}$ to $0.025 \mathrm{ng} / \mathrm{cm}^{2} / \mathrm{hr}$. The experimental fluxes measured at times below $72 \mathrm{hr}$ (time period when steady-state water evaporation is expected to occur) ranged from 0.0083 to $17.2 \mathrm{ng} / \mathrm{cm}^{2} / \mathrm{hr}$. The ratios of the computed advective fluxes to the corresponding measured experimental fluxes ranged from 0.00044 to 0.05 . In the worst case, the advective fluxes were 5 percent of the measured fluxes. This analysis shows that for chemicals that exhibit very low vapor pressures and very high partition constants, wicking was not a significant mechanism for vaporphase transport and was, therefore, neglected in the transport model described herein. 


\section{Results and Discussion}

\section{Model Simulations}

Experimental data analyzed using the model was classified under four cases (Ravikrishna et al. 2002) on the basis of the experimental conditions (initial soil moisture content and relative humidity of air passing over the soil surface). The porosity values used in each case of the simulation are summarized in Table 4.

\begin{tabular}{|c|c|c|c|c|c|}
\hline \multicolumn{6}{|c|}{$\begin{array}{l}\text { Table } 4 \\
\text { Soil Properties for Simulation }\end{array}$} \\
\hline Experiment & $\begin{array}{l}\text { Initial Soil } \\
\text { Moisture, \% }\end{array}$ & $\begin{array}{l}\text { Air Relative } \\
\text { Humidity }\end{array}$ & $\begin{array}{l}\text { Air-Filled } \\
\text { Porosity, } \gamma_{a} \\
\end{array}$ & $\begin{array}{l}\text { Water-Filled } \\
\text { Porosity, } \gamma_{w} \\
\end{array}$ & $\begin{array}{l}\text { Total } \\
\text { Porosity, } \gamma_{\mathrm{T}}\end{array}$ \\
\hline Case 1 & 5 & $\begin{array}{l}\text { humid } \\
\end{array}$ & $\begin{array}{l}0.23 \\
\end{array}$ & $\begin{array}{l}0.08 \\
\end{array}$ & 0.31 \\
\hline Case 2 & 20 & dry & 0.16 & 0.15 & 0.31 \\
\hline Case 3 & 5 & dry & 0.31 & 0 & 0.31 \\
\hline Case 4 & 20 & humid & 0 & 0.31 & 0.31 \\
\hline
\end{tabular}

\section{Case 1}

The initial moisture content of the soil was 5 percent and the relative humidity of the air passing over the soil surface was 100 percent. With humid air passing over the soil, no evaporation was expected. The soil pore air was expected to retain the initial moisture content. The initial air-filled porosity was calculated to be 0.23 and was maintained at that value throughout the simulation period. At 5-percent soil moisture content, the soil was considered wet and, therefore, the $K_{S A}$ was estimated from $K_{S W}$ and $K_{A W}$ as per Equation 4.

\section{Case 2}

The initial moisture content of the soil was 20 percent, and the relative humidity of the air passing over the soil surface was 0 percent. Since the air passing over the soil was dry, evaporation was expected. Soil moisture filled almost all of the soil pores initially, but with moisture loss to air, the air-filled porosity was expected to increase. Earlier reports of evaporation rates from similar experiments (Valsaraj et al. 1997) showed that initially water loss occurs very rapidly and complete water loss takes much longer. The air-filled porosity would increase as a function of time during this period, but in the absence of any transient, measured data, the air-filled porosity was set as an average of the initial 
(zero) and the final expected value (total porosity). For the duration of the experiment, the soil was presumed to retain enough moisture to be considered wet, and the $K_{S A}$ was estimated from $K_{S W}$ and $K_{A W}$ as per Equation 4.

\section{Case 3}

The initial moisture content of the soil was 5 percent, and the relative humidity of the air passing over the soil surface was 0 percent. The moisture from the pore air space was expected to decrease within a very short period of time and, therefore, the value of the air-filled porosity was set equal to that of the total porosity throughout the simulation period. The rapid drying creates the possibility of dry-off of the soil surface. In this case, $K_{S A}$ cannot be approximated as $K_{S W} / H_{C}$ (where $H_{C}=$ Henry's Law constant) and was not directly measured either. $K_{S A}$ was used as an adjustable parameter in the model for this case.

\section{Case 4}

The initial moisture content of the soil was 20 percent, and humid air was passed over the soil during the entire course of the experiment. Initially, the soil pore spaces were all filled with water, and this condition persisted throughout the entire experiment. This implies that the diffusion through pore water is the predominant transport mechanism rather than the diffusion through pore air. Equation 2 remains the governing differential equation, but $C_{A}$ is the pore air concentration instead of pore water concentration. The initial pore water concentration, $C_{A}^{0}$, is given by $W_{S}^{0} / K_{S W}$, where $K_{S W}$ is the measured soil-water equilibrium partition constant. At the soil-air interface, a correction factor of $K_{A W}$ (the air-water equilibrium constant, or the Henry's Law constant) is applied to the overall mass transfer coefficient, $k_{a}$, to account for the evaporation at the soilair interface. The effective diffusivity, $D_{\text {eff, }}$ is recomputed using water-filled porosity and the diffusivity of the chemical in water. The retardation factor, $R_{f}$, was computed as $\gamma_{w}+K_{S W} \rho_{b}$, where $\gamma_{w}=$ water-filled porosity.

\section{Transport of UXO Chemicals from Soils}

\section{Experimental soil/water adsorption constants}

The two aquifer soils from LAAP were high in sand, ranging from 27 to 77 percent sand and low in organic carbon (Table 1). Silt and clay were present in all samples, although in lower amounts in the LAAP-C soil. Cation exchange capacity (CEC) was also relatively low, ranging from 6.6 to $15.5 \mathrm{meq} / 100 \mathrm{~g}$. The Yokena clay surface soil was high in clay, organic carbon, and CEC compared to the aquifer soils.

The experimentally measured soil/water partition constants $\left(K_{S W}\right)$ for 2,4-DNT, 2,6-DNT, and 1,3-DNB are listed in Table 5. Soil/water partition constants for TNT are presented elsewhere (Pennington et al. 1999). The $K_{S W}$ values for the Yokena clay surface soil were larger than those for the 


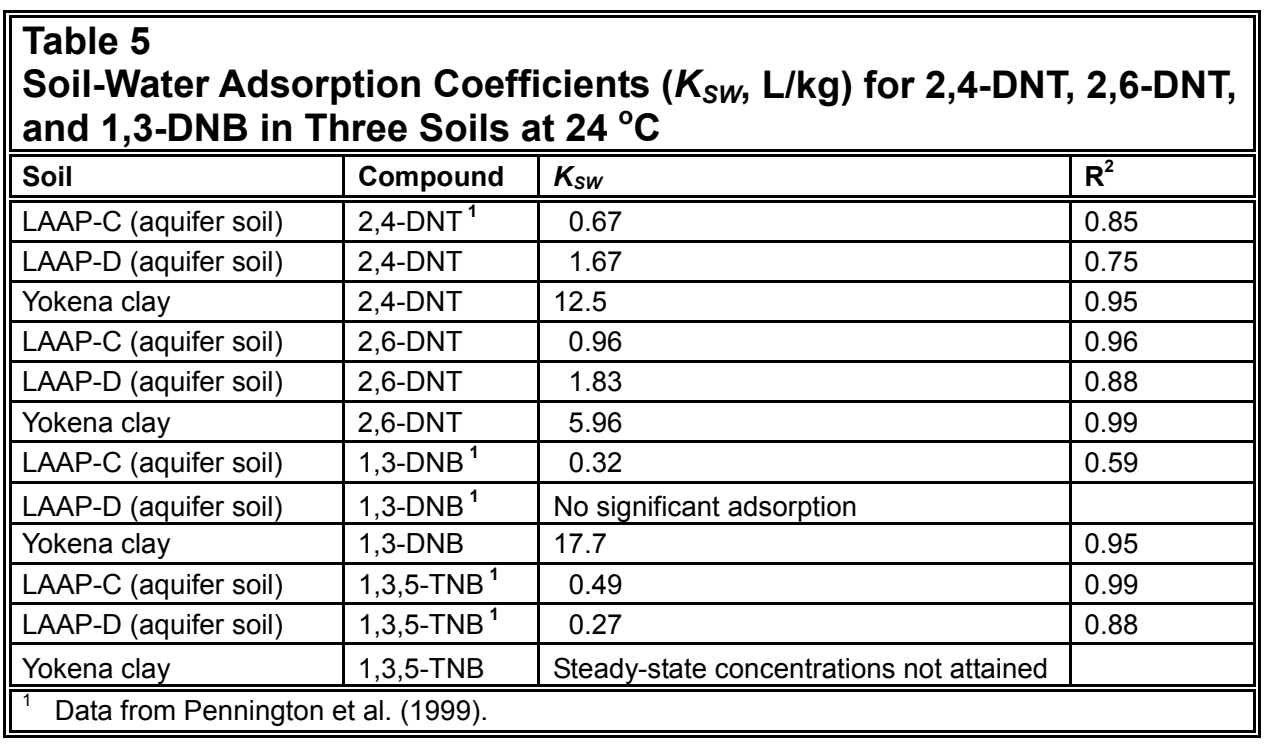

aquifer soils. Previous work on a common UXO fill explosive, TNT, reported a strong correlation between $K_{S W}$ and the CEC and clay content of the soil (Pennington and Patrick 1990; Haderlein, Weissmahr, and Schwarzenbach 1996). In the present work, the $K_{S W}$ for all four compounds increased with CEC, clay content, and organic carbon fraction of the soils. Sorption of these compounds is clearly higher in the surface soil (Yokena clay) than in aquifer soils (LAAP-C and LAAP-D).

\section{Reaction rates}

Concentrations of explosives remained essentially unchanged in the aquifer soils regardless of the temperature or moisture regime (Appendix A, Tables A1 and A2). This held true for 1,3,5-TNB, 1,3-DNB, TNT, 2,4-DNT, and 2,6-DNT in the aquifer soils. Initial and final explosives concentrations for the Yokena clay soil are summarized in Table A3. Results ranged from no change in soil concentrations over the 14 days of incubation to complete disappearance of the tested compound.

The rate of processes that remove TNT and its transformation products from solution was modeled using pseudo-first-order kinetics, which take the form $\ln \left(C_{0} / C\right)=k_{1} \bullet t$, where $C$ is the chemical concentration of the reacting substance, $(\mathrm{mg} / \mathrm{L}), C_{0}$ is the concentration of the reactant at time $0, k_{1}$ is the pseudo-firstorder rate constant $\left(\mathrm{hr}^{-1}\right)$, and $t$ is time (hr). Half-life $\left(t_{1 / 2}\right)$ was calculated using $t_{1 / 2}=0.693 / k_{1}$.

The tested compounds generally disappeared from the soil under both the 5and 20-percent moisture regime at $24{ }^{\circ} \mathrm{C}$ (Table 6) in the Yokena clay soil. Halflives were much shorter at higher soil moisture levels. At the 5-percent moisture level, half-lives of 1,3-DNB and 2,6-DNT could not be determined because no significant change in soil concentrations were observed over the course of the 


\begin{tabular}{|c|c|c|c|c|c|c|c|c|}
\hline \multicolumn{9}{|c|}{$\begin{array}{l}\text { Table } 6 \\
\text { First-Order Reaction Rate Constants }\left(K, \mathrm{hr}^{-1}\right) \text { for Yokena Clay Soil }\end{array}$} \\
\hline \multirow[b]{3}{*}{ Compound } & \multicolumn{4}{|c|}{$14^{\circ} \mathrm{C}$} & \multicolumn{4}{|c|}{$24^{\circ} \mathrm{C}$} \\
\hline & \multicolumn{2}{|c|}{$\begin{array}{l}\text { 5-Percent } \\
\text { Moisture }\end{array}$} & \multicolumn{2}{|c|}{$\begin{array}{c}\text { 20-Percent } \\
\text { Moisture }\end{array}$} & \multicolumn{2}{|c|}{$\begin{array}{c}\text { 5-Percent } \\
\text { Moisture }\end{array}$} & \multicolumn{2}{|c|}{$\begin{array}{c}\begin{array}{c}\text { 20-Percent } \\
\text { Moisture }\end{array} \\
\end{array}$} \\
\hline & $K, \mathrm{hr}^{-1}$ & $r^{2}$ & $K, \mathrm{hr}^{-1}$ & $r^{2}$ & $K, \mathrm{hr}^{-1}$ & $r^{2}$ & $K, \mathrm{hr}^{-1}$ & $r^{2}$ \\
\hline 1,3,5-TNB & 0.0017 & 0.51 & 0.027 & 0.988 & 0.0005 & 0.79 & 0.093 & 0.94 \\
\hline 1,3-DNB & $\mathrm{NSC}^{1}$ & & 0.012 & 0.91 & NSC & & 0.137 & 0.92 \\
\hline \begin{tabular}{l|l} 
TNT \\
\end{tabular} & 0.0009 & 0.56 & 0.033 & 0.989 & 0.0007 & 0.81 & 0.122 & 0.94 \\
\hline 2,6-DNT & NSC & & NSC & & NSC & & 0.011 & 0.99 \\
\hline 2,4-DNT & NSC & & 0.005 & 0.99 & 0.0005 & 0.86 & 0.011 & 0.91 \\
\hline
\end{tabular}

experiment. Where significant changes occurred in soil concentrations, removal of the explosives contaminants generally conformed to first-order kinetics (Table 6). This suggests that when modeling stability of these compounds in soils, first-order kinetics can be used to describe removal that results from the sum of all soil reactions. Values of $r^{2}$ were especially high under the 20-percent moisture regime, exceeding $r^{2}=0.91$ for compounds where soil concentrations decreased. At the 20-percent moisture regime, the tested compounds were more stable at $14{ }^{\circ} \mathrm{C}$ than at $24{ }^{\circ} \mathrm{C}$. Half-lives at $24{ }^{\circ} \mathrm{C}$ were less than half of that measured at $14{ }^{\circ} \mathrm{C}$. These results show that both temperature and moisture affect the stability of 1,3,5-TNB, 1,3-DNB, TNT, 2,4-DNT, and 2,6-DNT in the Yokena clay soil. Higher temperature and moisture resulted in decreased stability of these compounds, which can affect their signature transport.

\section{Experimental results and model comparison}

Cases 1 and 2, 20-ml/min flow rate experiments. Figures 1-3 show the comparison of experimental fluxes and the corresponding model simulations for 2,4-DNT, 2,6-DNT, and 1,3-DNB, respectively, at $24{ }^{\circ} \mathrm{C}$ in three different soils for cases 1 and 2, and at the airflow rate of $20 \mathrm{ml} / \mathrm{min}$. These three compounds were chosen for comparison since the data set was most complete for these. Figure 1 shows the flux of 2,4-DNT from LAAP-C, LAAP-D, and Yokena clay soils. The experimental flux values are represented by discrete symbols while lines represent the simulation curves. The experimental data show the flux of 2,4-DNT decreasing gradually with time and quickly reaching steady-state. Initially, the flux is air-phase-resistance controlled. Very quickly the flux becomes soil-side-resistance controlled, and diffusion through the soil pores dominates. Thus, the initial flux can be given by $N_{A}(t)=k_{a} C_{A}{ }^{0}$ and as $t$ becomes large, the long-term flux is proportional to $1 / t^{1 / 2}$. Any deviation from this behavior is indicative of processes other than diffusion also being significant. Figures 2 and 3 show similar trends in the experimental fluxes of 2,6-DNT and 1,3-DNB, respectively, for cases 1 and 2 for the three soils.

The model curves in each case shown in Figures 1-3 were not a priori simulations, but best fits of the experimental data using one variable fit parameter the soil-air partition constant, $K_{S A}$. The best fit for each data set was obtained by 


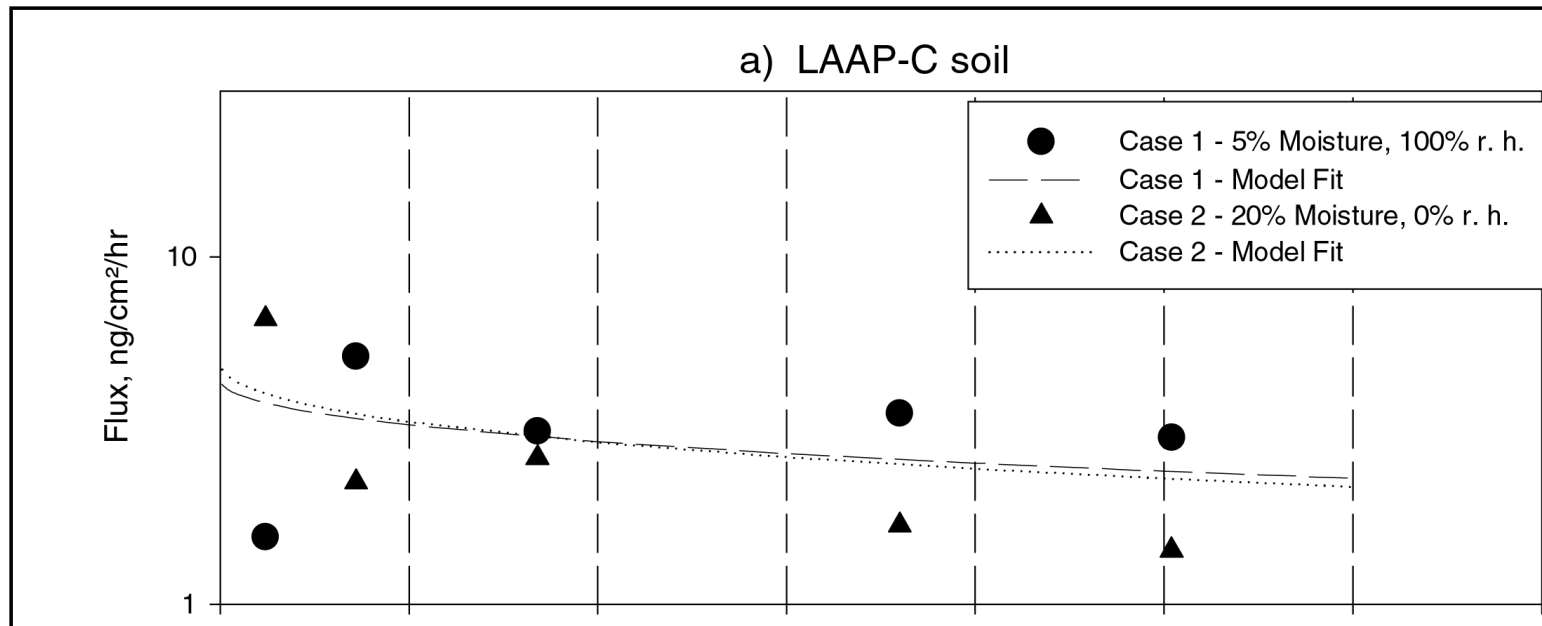

b) LAAP-D soil

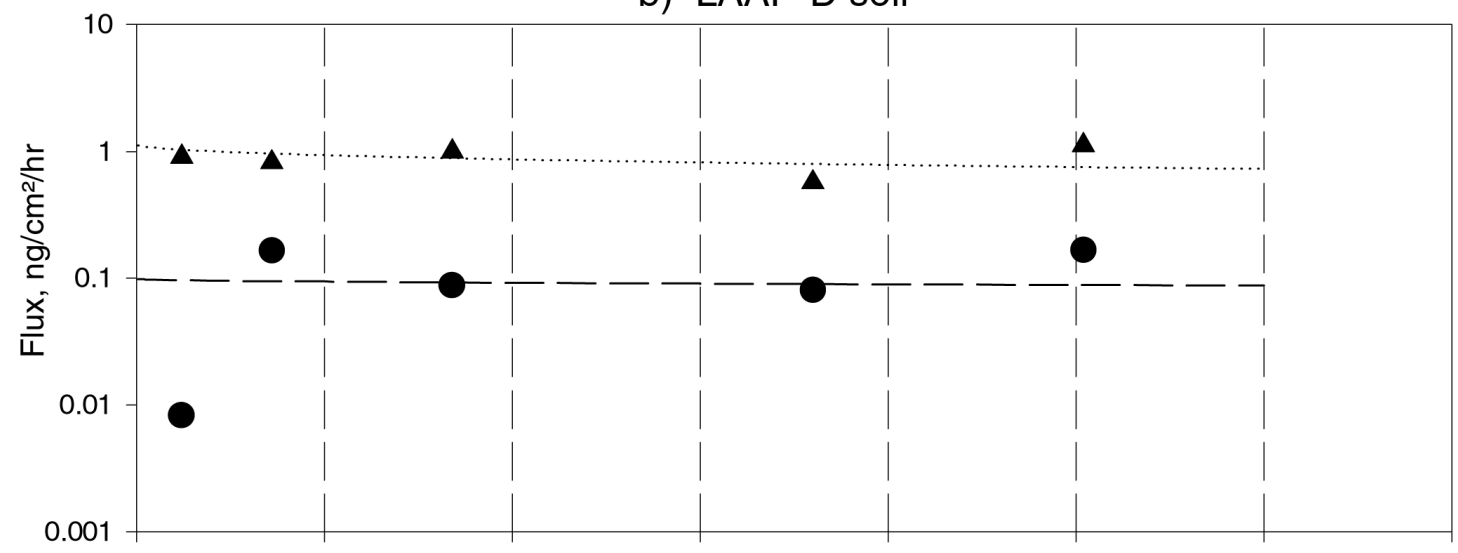

c) Yokena clay soil

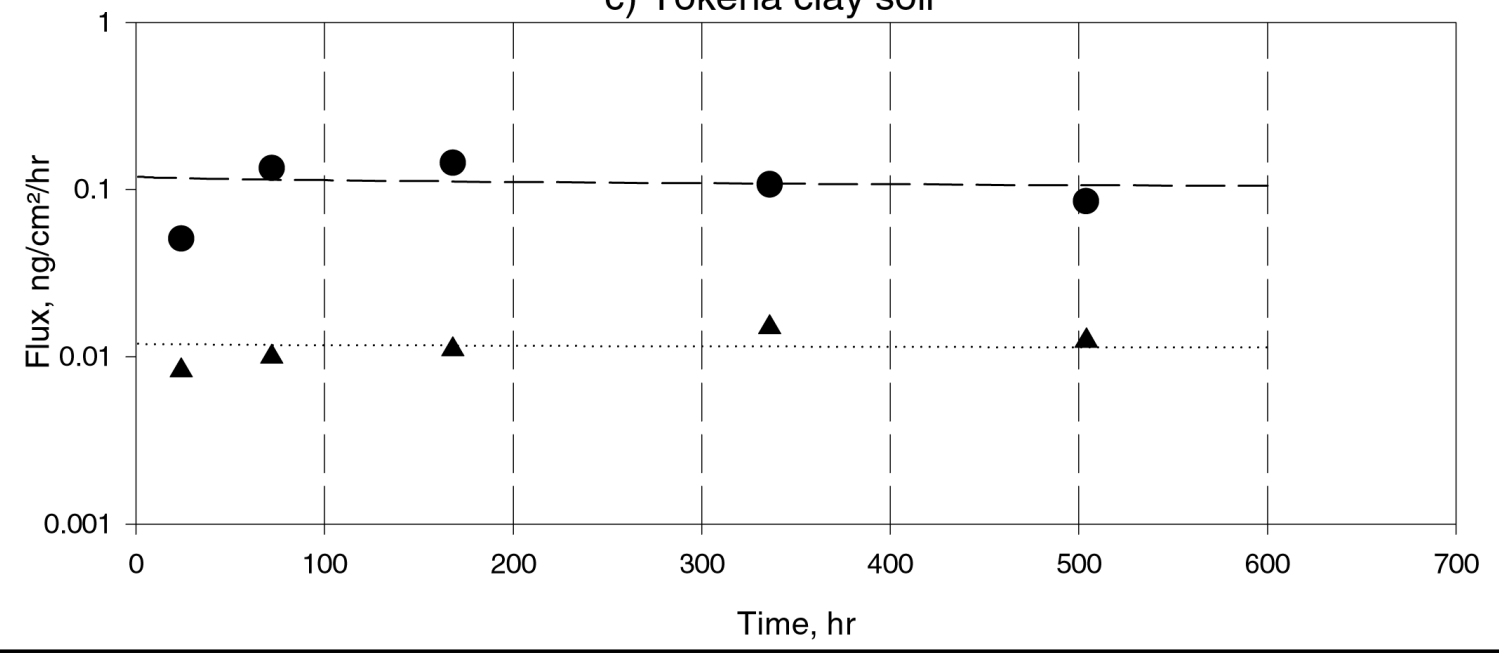

Figure 1. Flux of 2,4-DNT from three soils. Comparison of experimental data and model fits for cases 1 and 2 at $20-\mathrm{ml} / \mathrm{min}$ airflow rate 


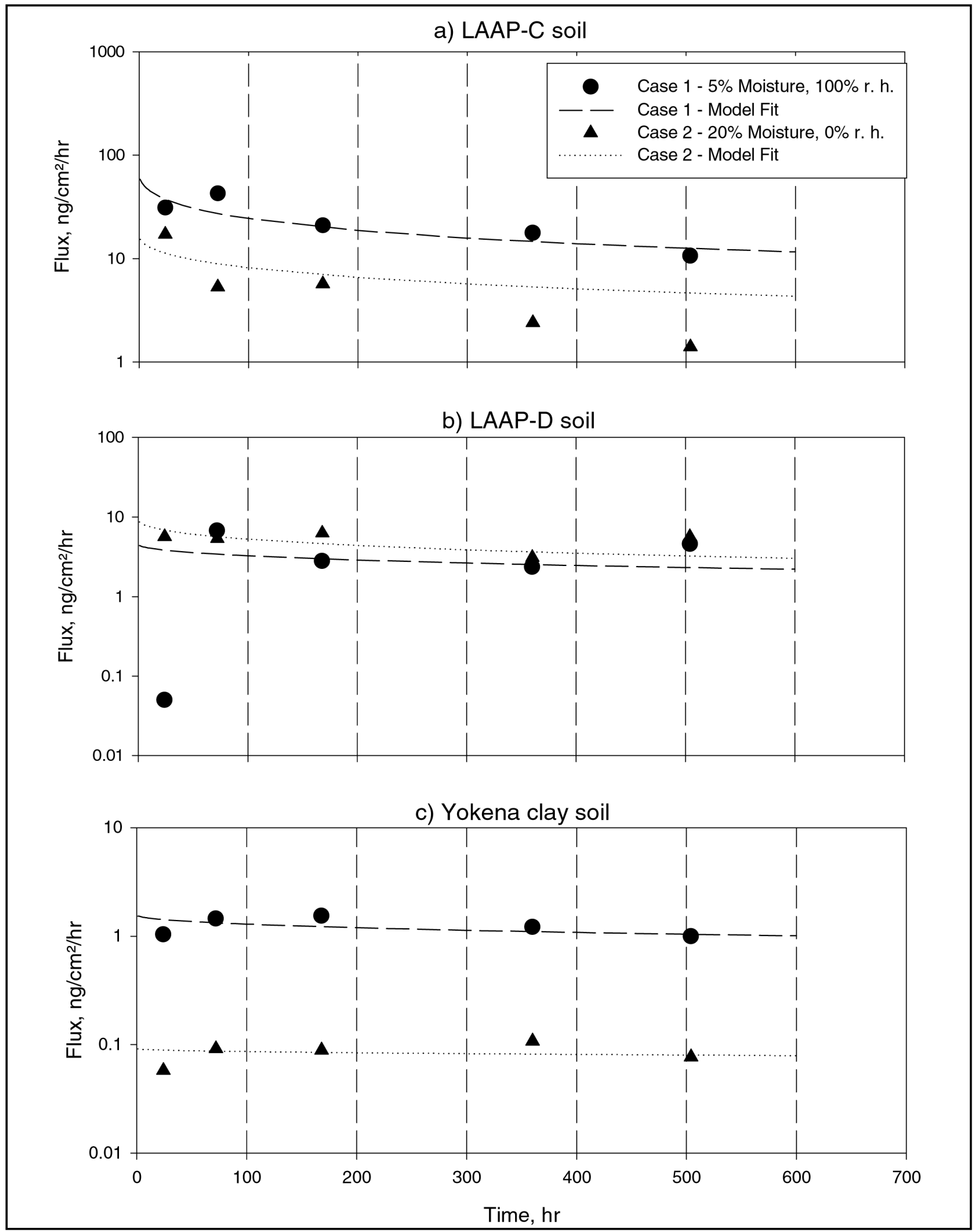

Figure 2. Flux of 2,6-DNT from three soils. Comparison of experimental data and model fits for cases 1 and 2 at $20-\mathrm{ml} / \mathrm{min}$ airflow rate 


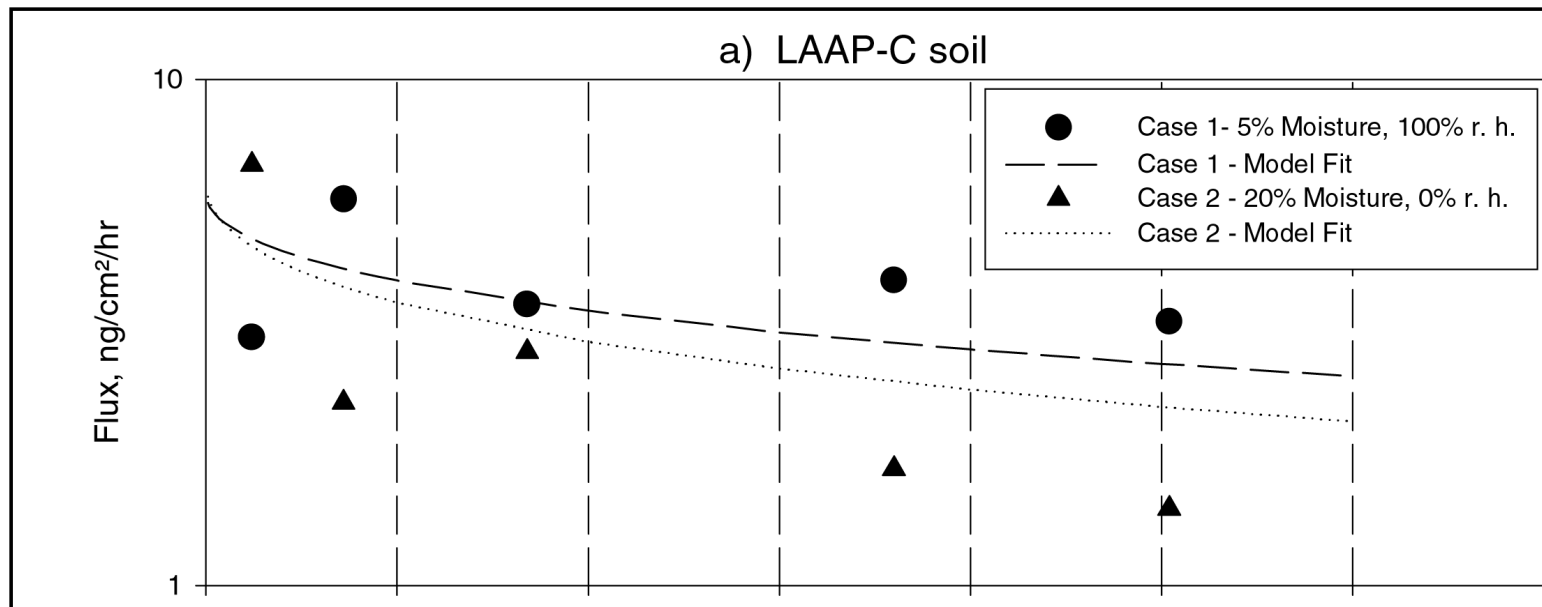

b) LAAP-D soil

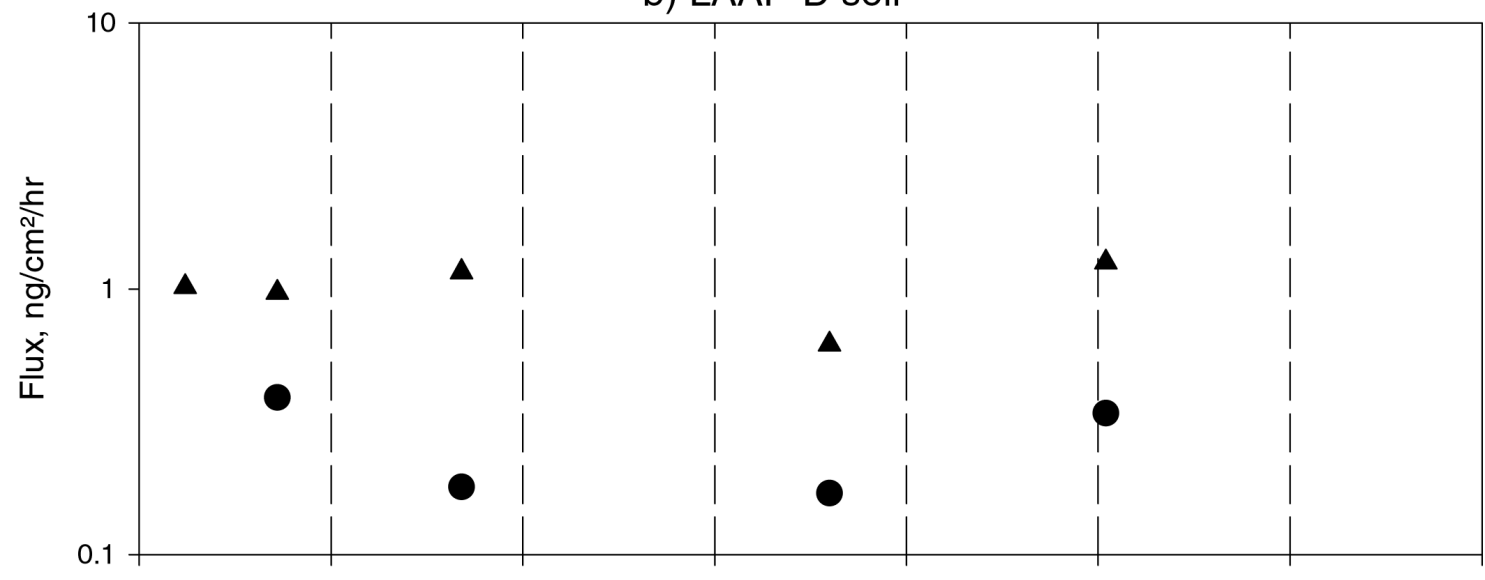

c) Yokena clay soil

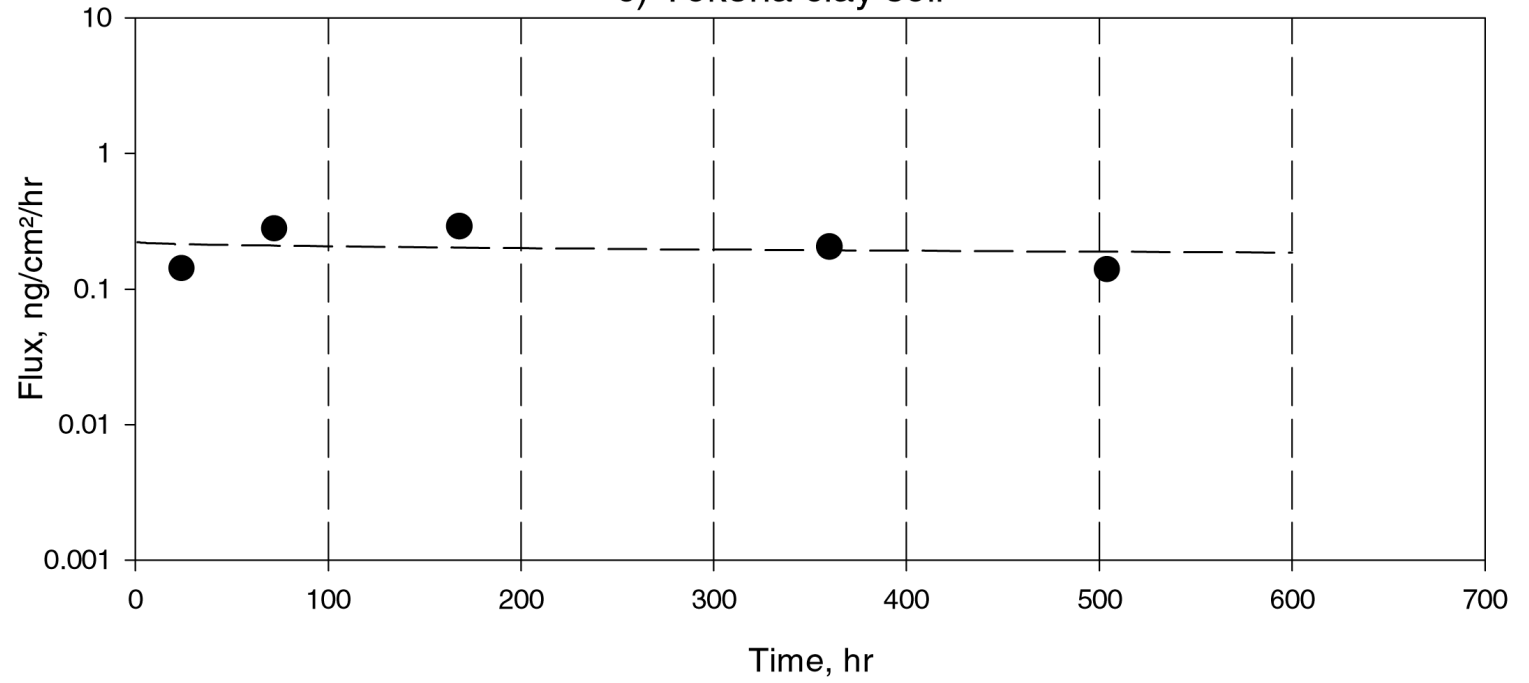

Figure 3. Flux of 1,3-DNB from three soils. Comparison of experimental data and model fits for cases 1 and 2 at $20-\mathrm{ml} / \mathrm{min}$ airflow rate 
adjusting the $K_{S A}$ value until the sum of squares quantity between the experimental data and model fit was a minimum. The model fit curves show a trend similar to that of the experimental data. The effectiveness of the model to simulate the experimental fluxes can be evaluated by comparing the experimentally determined and fit model parameters, in this case, $K_{S A}$. Table 7 shows this comparison of the $K_{S A}$ values for cases 1 and 2 for the three compounds and the three soil types. The average difference between the fit and the a priori estimation of $K_{S A}$ is within an order of magnitude for all compounds. The $K_{S W}$ values used to estimate $K_{S A}$ were those measured in the batch experiments, and, hence, the variation in $K_{S A}$ is a direct result of the variation in reported $K_{A W}$ values (Henry's Law constant).

\begin{tabular}{|c|c|c|c|c|c|c|}
\hline $\begin{array}{l}\text { Table } 7 \\
\text { Adjust } \\
\text { from C }\end{array}$ & $\begin{array}{l}\text { ramet } \\
\text { and } 2\end{array}$ & $\begin{array}{l}\text { for Co } \\
\text { the } 2\end{array}$ & $\begin{array}{l}\text { arison } \\
\mathrm{l} / \mathrm{min}\end{array}$ & $\begin{array}{l}\text { th Exp } \\
\text { flow R }\end{array}$ & nenta & uxes \\
\hline Partition & & P-C & & $\overline{P-D}$ & & ia Clay \\
\hline Constant & Case 1 & Case 2 & Case 1 & Case 2 & Case 1 & Case 2 \\
\hline & & & 2,4-DNT & & & \\
\hline 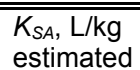 & $8.9 \mathrm{e}+4$ & $8.9 e+4$ & $2.2 \mathrm{e}+5$ & $2.2 \mathrm{e}+5$ & $1.7 \mathrm{e}+6$ & $1.7 \mathrm{e}+6$ \\
\hline $\begin{array}{l}K_{S A}, L / k g \\
\text { fit }\end{array}$ & $1.2 \mathrm{e}+5$ & $1.1 \mathrm{e}+5$ & $5.5 \mathrm{e}+6$ & $4.8 e+5$ & $4.2 \mathrm{e}+6$ & $4.2 \mathrm{e}+7$ \\
\hline & & & 2,6 -DNT & & & \\
\hline $\begin{array}{l}\bar{K}_{S A}, \mathrm{~L} / \mathrm{kg} \\
\text { estimated }\end{array}$ & $1.3 e+5$ & $1.3 e+5$ & $2.4 \mathrm{e}+5$ & $2.4 e+5$ & $7.9 e+5$ & $7.9 \mathrm{e}+5$ \\
\hline $\begin{array}{l}K_{S A}, \mathrm{~L} / \mathrm{kg} \\
\mathrm{fit}\end{array}$ & $6.4 \mathrm{e}+3$ & $2.5 e+4$ & $9.6 e+4$ & $4.7 e+4$ & $3.2 \mathrm{e}+5$ & $5.5 \mathrm{e}+6$ \\
\hline & & & 1,3-DNB & & & \\
\hline $\begin{array}{l}K_{S A}, \mathrm{~L} / \mathrm{kg} \\
\text { estimated }\end{array}$ & 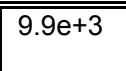 & $99.9 \mathrm{e}+3$ & $\mathrm{NA}^{\prime}$ & NA & $5.5 \mathrm{e}+5$ & $25.5 \mathrm{e}+5$ \\
\hline $\begin{array}{l}K_{S A}, L / k g \\
\text { fit }\end{array}$ & $6.1 \mathrm{e}+4$ & $6.9 \mathrm{e}+4$ & $\mathrm{NP}^{2}$ & $\mathrm{NP}$ & $2.3 e+6$ & $\mathrm{ND}^{3}$ \\
\hline
\end{tabular}

Cases 1 and 2, 100-ml/min airflow experiments. Figures 4-6 show the experimental fluxes for 2,4-DNT, 2,6-DNT, and 1,3-DNB, respectively, from LAAP-C soil at 100- and 20-ml/min airflow rates for cases 1 and 2. The figures also show a comparison with the model. The model simulations were fit to the experimental data by varying the value of $K_{S A}$. In general, the experimental fluxes were higher in the $100-\mathrm{ml} / \mathrm{min}$ airflow rate experiment than in the $20-\mathrm{ml} / \mathrm{min}$ experiment for the three compounds. This is expected since the increased airflow rate implies a higher mass transfer coefficient at the soil-air interface that reduces the overall resistance for mass transfer from the bulk to air.

For the last two data points of case 2 in Figures 4-6, the experimental flux for higher airflow rate is smaller than that for the lower airflow rate. This anomalous trend may be explained by the fact that in case 2, dry air is passing over the surface of 20-percent moist soil. Over $400 \mathrm{hr}$, this surface tends to dry, increasing the partition constant, which results in lower flux. Case 1 represents constant conditions with respect to the effective diffusivity and the partition constant; 


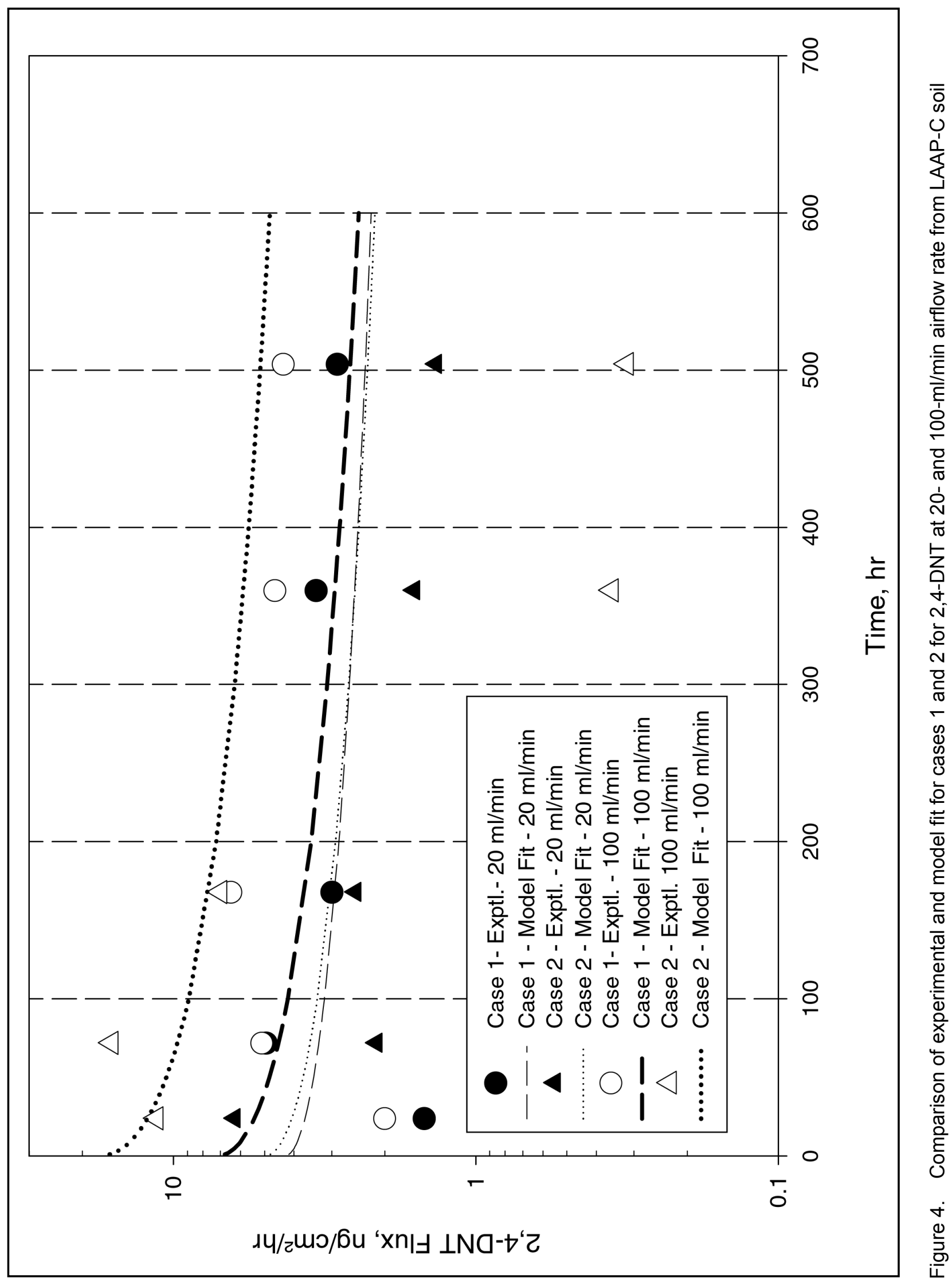




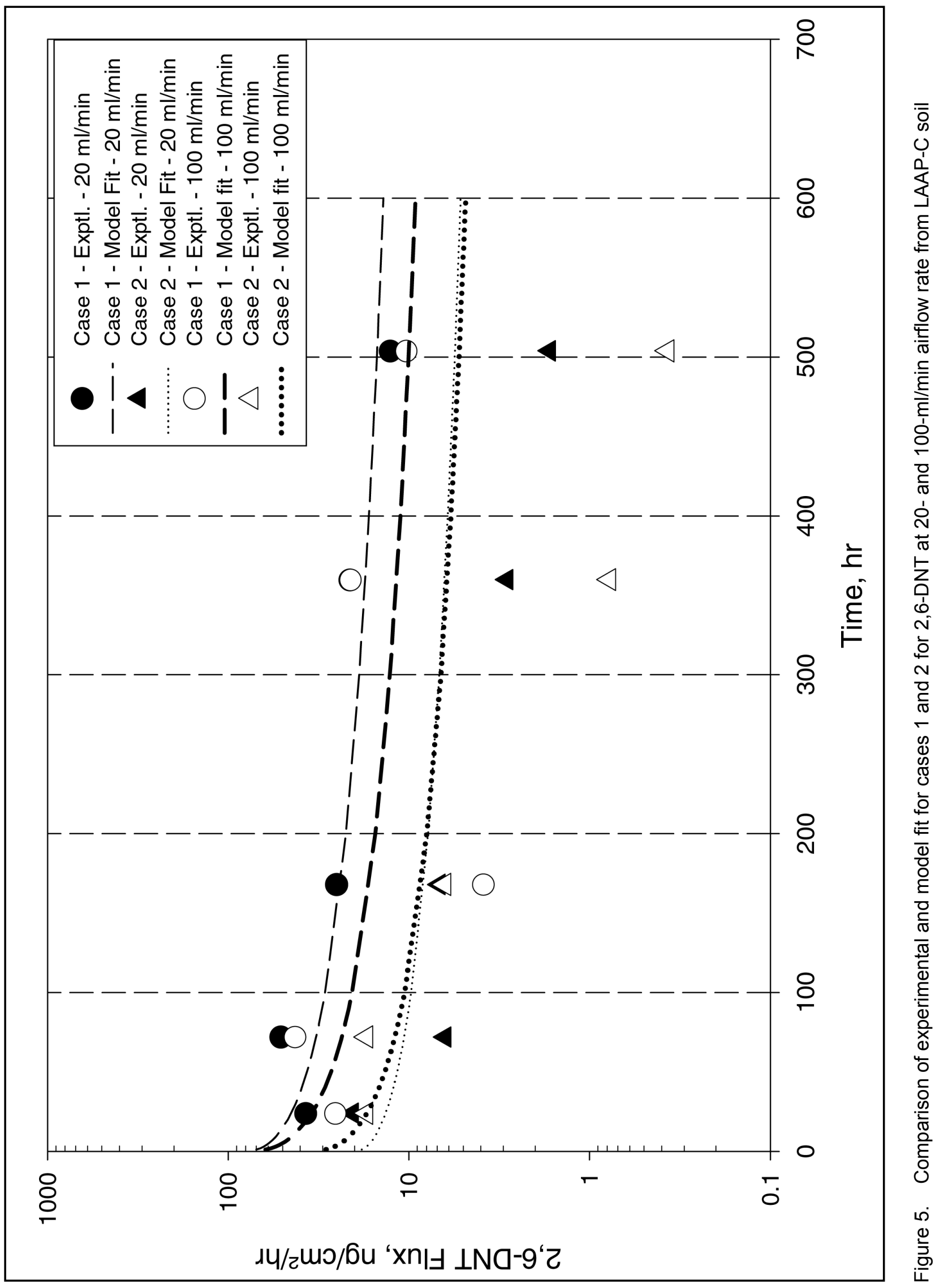




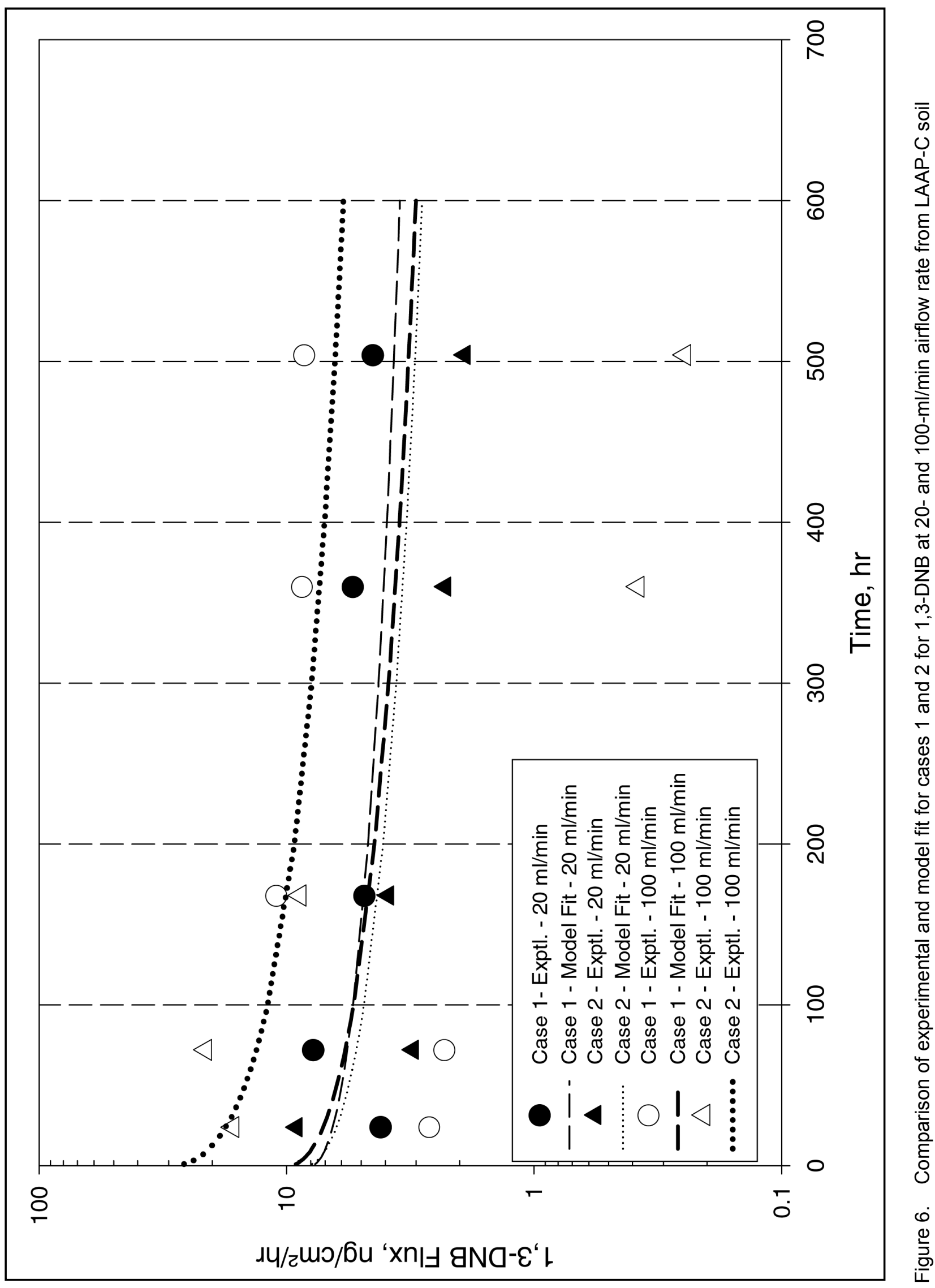


therefore, such anomalous behavior is not observed. The model simulations were fit to the experimental data using $K_{S A}$ as the adjustable parameter. The comparison of the estimated and the fit $K_{S A}$ values for both flow rates is shown in Table 8 . The differences between the fit $K_{S A}$ values in both cases and the estimated $K_{S A}$ values were discussed earlier (Valsaraj et al. 1999) and were attributed to the uncertainty in the reported values of $K_{A W}$. All parameters used to simulate the two different fit cases were the same except for the air-side mass transfer coefficient and the fit $K_{S A}$ value. The difference in the fit $K_{S A}$ values between the two flow rate experiments is less than one order of magnitude. This difference represents the degree of validity of the initial approach to fit the experimental values by varying $K_{S A}$. If this approach is correct, the difference between the fit $K_{S A}$ values in both cases (20- and 100- $\mathrm{ml} / \mathrm{min}$ airflow rates) should be insignificant. However, a small difference in the fit $K_{S A}$ values was observed for both cases. The difference was significant for case 1 , where no change in operating conditions over the duration of the experiment occurred.

\begin{tabular}{|c|c|c|}
\hline \multicolumn{3}{|c|}{$\begin{array}{l}\text { Table } 8 \\
\text { Adjustable Parameter for Comparison with Experimental Fluxes, } \\
K_{S A}(\text { L/kg), from Cases } 1 \text { and } 2 \text { for LAAP-C Soil for the } 100-\mathrm{ml} / \mathrm{min} \\
\text { Airflow Rate }\end{array}$} \\
\hline Parameter & Case 1 & Case 2 \\
\hline \multicolumn{3}{|c|}{ 2,4-DNT } \\
\hline Estimated & $8.9 \mathrm{e}+4$ & $8.9 \mathrm{e}+4$ \\
\hline Model fit - $20 \mathrm{ml} / \mathrm{min}$ & $1.2 \mathrm{e}+5$ & $9.7 \mathrm{e}+4$ \\
\hline Model fit - $100 \mathrm{ml} / \mathrm{min}$ & $1.6 \mathrm{e}+5$ & $2.9 \mathrm{e}+4$ \\
\hline \multicolumn{3}{|c|}{ 2,6-DNT } \\
\hline Estimated & $1.3 \mathrm{e}+5$ & $1.3 \mathrm{e}+5$ \\
\hline Model fit - $20 \mathrm{ml} / \mathrm{min}$ & $6.4 \mathrm{e}+3$ & $2.5 \mathrm{e}+4$ \\
\hline Model fit - $100 \mathrm{ml} / \mathrm{min}$ & $1.5 \mathrm{e}+4$ & $3.2 \mathrm{e}+4$ \\
\hline \multicolumn{3}{|c|}{ 1,3-DNB } \\
\hline Estimated & $9.9 \mathrm{e}+3$ & $9.9 \mathrm{e}+3$ \\
\hline Model fit - $20 \mathrm{ml} / \mathrm{min}$ & $6.1 \mathrm{e}+4$ & $6.9 \mathrm{e}+4$ \\
\hline Model fit - $100 \mathrm{ml} / \mathrm{min}$ & $1.1 \mathrm{e}+5$ & $2.0 \mathrm{e}+4$ \\
\hline
\end{tabular}

Case 3, 20- and 100-ml/min airflow rate experiments. Figure 7 shows the experimental data for case 3 with the airflow rate at $20 \mathrm{ml} / \mathrm{min}$. The fluxes show a distinct sharp downward gradient with time not characteristic of a $1 / t^{1 / 2}$ dependence for purely diffusive transport as observed in the cases 1 and 2 (shown in Figures 1-3). This behavior is uniformly observed for all three compounds and for the three soil types. This trend is not indicative of an equilibrium state in the soil as seen in Figures 1-3. It is more representative of a dynamic rate-controlled (kinetic) phenomenon. Two hypotheses arise out of these observations.

The first hypothesis is that the soil is drying at a certain rate that is dependent on the airflow rate. The initial moisture content ( 5 percent) was near the lower limit of the "wet" soil criteria ( $>5$ percent moisture content) for soil-air partition constants described earlier. The soil partition constant increases as soil moisture decreases below 5 percent and continues to decrease until the soil moisture level reaches the "dry" state and is constant for soil moisture levels below 0.1 percent. 


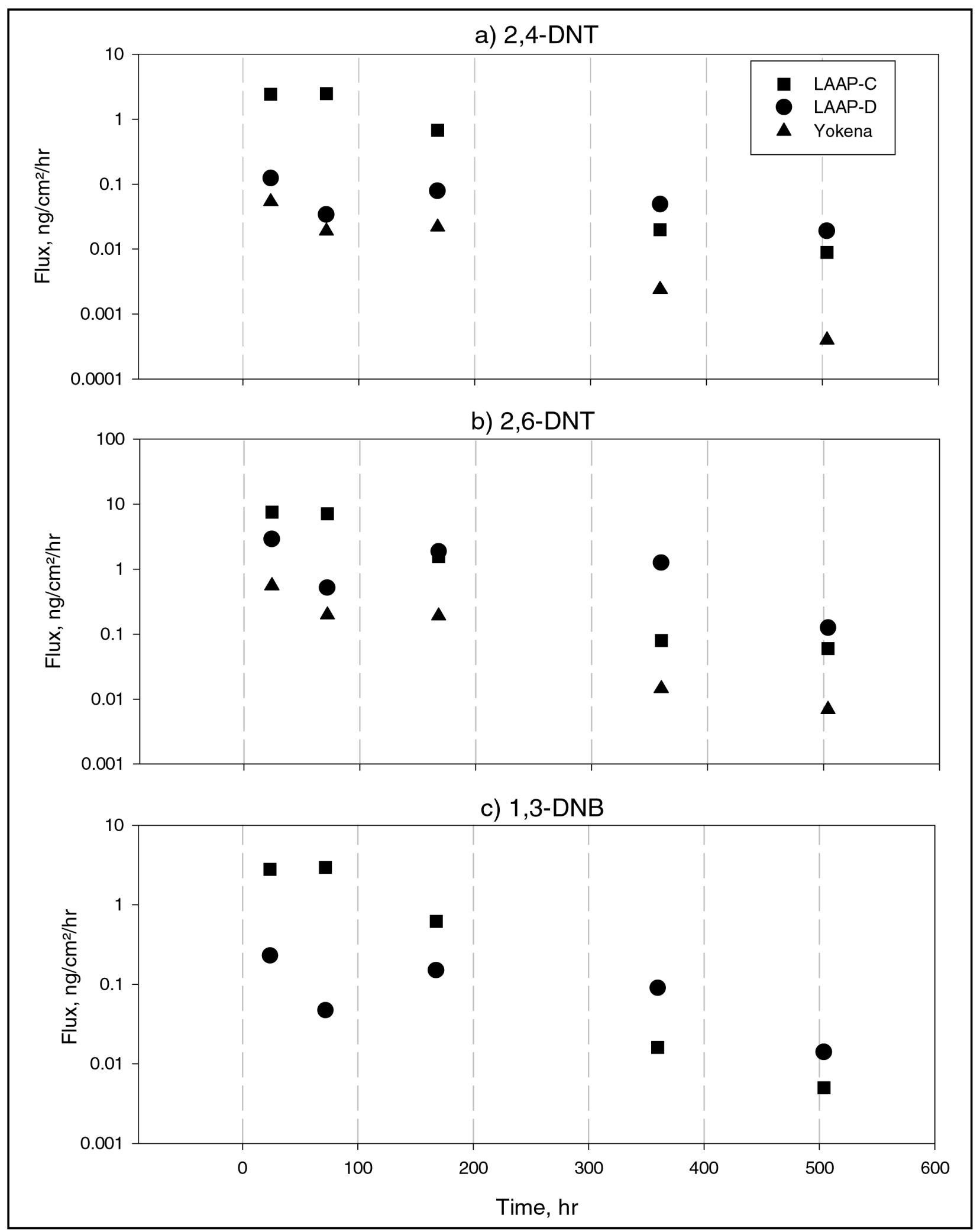

Figure 7. Experimental data for 2,4-DNT, 2,6-DNT, and 1,3-DNB for all three soils for case 3 
The rate of decrease of the partition constant in the damp zone between the "dry" and the "wet" zone is not well characterized and depends on the drying rate of the soil, which is dependent on the flow rate of air and initial moisture content. Therefore, decreasing flux measurements might represent successive stages of increasing partition constant as the soil is still undergoing loss of moisture in the "damp" regime due to the low moisture content and the low airflow rate ( $20 \mathrm{ml} / \mathrm{min}$ ). The experiment was concluded before the flux measurements attained a plateau indicative of an equilibrium state (i.e., completion of the drying process), when an equilibrium partition constant of the dry soil could have been extracted by fitting the dry flux data. Experiments performed at higher airflow rates can provide more qualitative information for the UXO soil-air partitioning in the dry soils in the time scales of the experiments performed.

A second hypothesis is that the soil is dry enough to cause a surface reaction to degrade the UXO compound. Such a loss via reaction can be coupled with purely diffusive transport to model the transport process. The gradient in the flux data observed may be representative of the surface reaction kinetics on dry soils. Since no batch experiments were performed to evaluate the reaction kinetics on dry soil, to verify or evaluate this hypothesis at this stage is not possible. The system is surmised to tend towards a new equilibrium state not captured in the time scale of the experiment. Previously reported oligomerization reactions occur on dry mineral surfaces of soils with very low organic carbon. This phenomenon has been observed by Karimi-Loftabad, Pickard, and Gray (1996) for polyaromatic hydrocarbons on dry soils.

Figure 8 presents the comparison of the experimental data for case 3 (5-percent soil moisture and dry air over the soil) for LAAP-C soil both at 20 and $100 \mathrm{ml} / \mathrm{min}$, represented by symbols joined by continuous and broken lines, respectively. A significant observation between the two sets of data is that for the $100-\mathrm{ml} / \mathrm{min}$ airflow rate case, the flux drops after the first data point and then remains almost constant for the duration of the experiment, while in the $20-\mathrm{ml} / \mathrm{min}$ experiment, the flux drops continuously, but at a slower rate. In both cases, the fluxes tend towards the same level at the last interval of experimental measurement. These observations suggest that the first hypothesis, that of a transient stage of soil moisture resulting in a dynamic increase in the soil-air partition constant, is more credible than the possibility of reaction. In conjunction with this, the behavior of the experimental data in case 3 at $20 \mathrm{ml} / \mathrm{min}$ is more likely due to slow continuous drying of the soil surface across its length. Table 9 lists the $K_{S A}$ fit values that apply for the closest possible match with the experimental data. These values are much higher than those obtained from the damp and wet soil cases. The $K_{S A}$ values listed for the $20-\mathrm{ml} / \mathrm{min}$ experiments are listed along with a $k_{1}$ value that was used as a fit parameter to fit the apparent kinetics in the data.

Case 4, 20- and 100-ml/min airflow experiments. Figure 9 shows the experimental data and model fit for case 4 with 20-percent soil moisture and humid air over the soil at 20 and $100 \mathrm{ml} / \mathrm{min}$. The transport of the contaminants within the soil is primarily by diffusion in the pore water followed by evaporation at the pore water-air interface at the soil surface. The properties of the soil are expected to be constant over the entire duration of the experiment since the physical properties of the soil do not change. This is also illustrated by the 


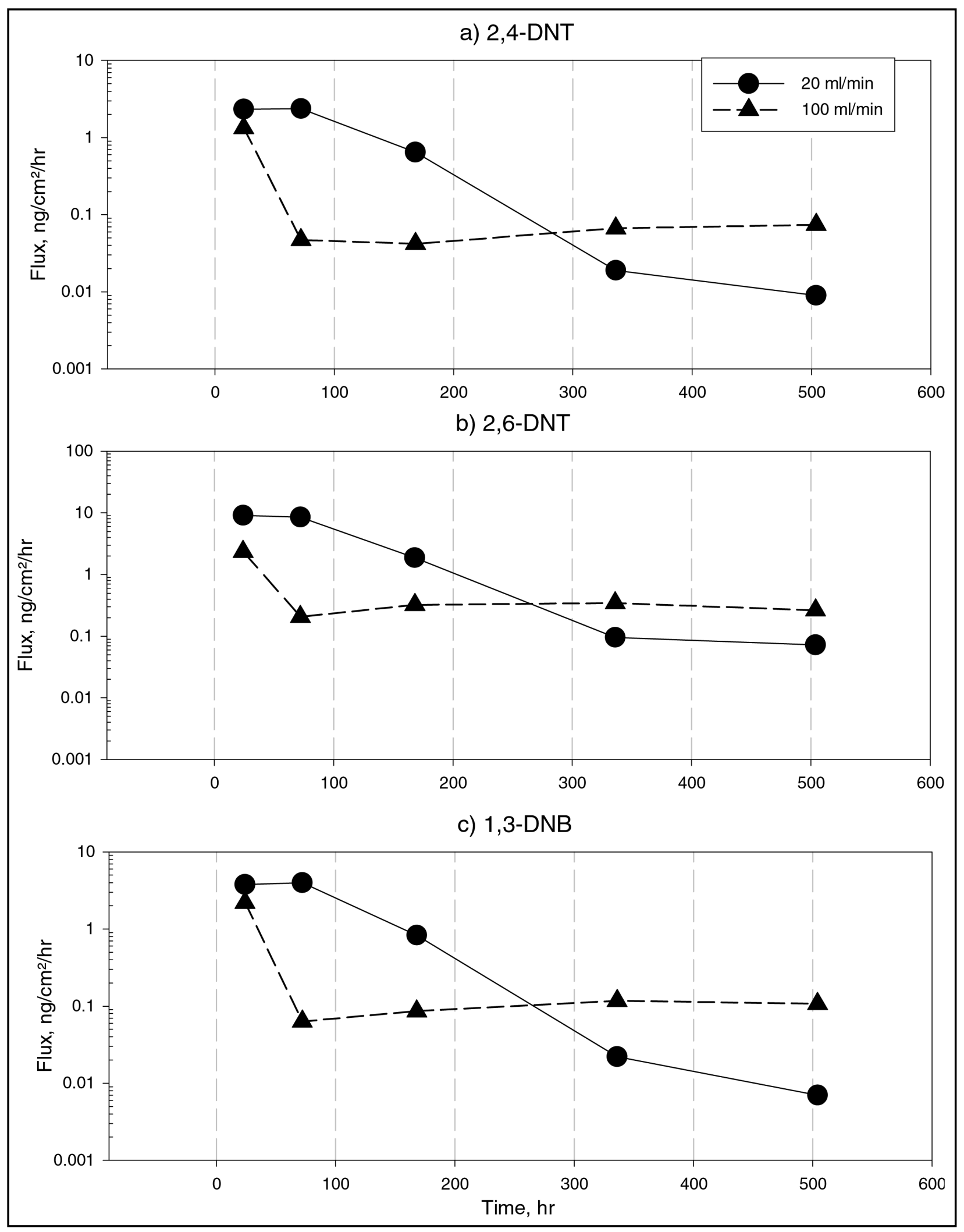

Figure 8. Comparison of experimental fluxes of 2,4-DNT, 2,6-DNT, and 1,3-DNB for case 3 data with LAAP-C soil for 20 - and $100-\mathrm{ml} / \mathrm{min}$ airflow rates 


\begin{tabular}{|c|c|c|}
\hline $\begin{array}{l}\text { Table } 9 \\
\text { Fit } K_{S A} \text { an } \\
\text { from LAA }\end{array}$ & for Mod & tal Data in Case 3 \\
\hline Airflow Rate & $K_{S A}, \mathrm{~L} / \mathbf{k g}$ & $k_{1}, \mathrm{~s}^{-1}$ \\
\hline & & \\
\hline $20 \mathrm{ml} / \mathrm{min}$ & $8.9 e+4$ & $4.7 e-6$ \\
\hline $100 \mathrm{ml} / \mathrm{min}$ & $3.2 \mathrm{e}+6$ & 0 \\
\hline & & \\
\hline $20 \mathrm{ml} / \mathrm{min}$ & $4.8 \mathrm{e}+4$ & $3.1 \mathrm{e}-6$ \\
\hline $100 \mathrm{ml} / \mathrm{min}$ & $1.3 e+6$ & 0 \\
\hline & & \\
\hline $20 \mathrm{ml} / \mathrm{min}$ & $9.9 e+3$ & $1.0 e-5$ \\
\hline $100 \mathrm{ml} / \mathrm{min}$ & $1.3 e+6$ & 0 \\
\hline
\end{tabular}

experimental fluxes that show very little dynamics. The fluxes at $100 \mathrm{ml} / \mathrm{min}$ are higher than those at $20 \mathrm{ml} / \mathrm{min}$ for almost all the experimental measurements in this case. The model fits were obtained by varying the air-water equilibrium constant values, $K_{A W}$, which appear in the overall air-side mass transfer coefficient. The fit and the reported values of $K_{A W}$ are listed in Table 10. The limited variation indicates the validity of the model for these conditions.

\section{Effect of soil temperature on flux from soils}

Since temperature is an important variable among the various Department of Defense sites contaminated with explosives residues, a set of experiments was conducted to study the effects of soil temperature on flux to air. Figure 10 shows the comparison of 2,4-DNT fluxes from LAAP-C soil samples at two different temperatures, $14{ }^{\circ} \mathrm{C}$ and $24{ }^{\circ} \mathrm{C}$ (room temperature) for case 2 . The flux was $0.51 \mathrm{ng} / \mathrm{cm}^{2} / \mathrm{hr}$ at $14{ }^{\circ} \mathrm{C}$ and $6.63 \mathrm{ng} / \mathrm{cm}^{2} / \mathrm{hr}$ at $24{ }^{\circ} \mathrm{C}$ after $24 \mathrm{hr}$ and slowly decreasing to $0.11 \mathrm{ng} / \mathrm{cm}^{2} / \mathrm{hr}$ at $14{ }^{\circ} \mathrm{C}$ and $1.43 \mathrm{ng} / \mathrm{cm}^{2} / \mathrm{hr}$ at $24{ }^{\circ} \mathrm{C}$ after $504 \mathrm{hr}$. The flux at $14{ }^{\circ} \mathrm{C}$ was uniformly lower than that at $24^{\circ} \mathrm{C}$. Figure 10 also shows the model fit curves for the experimental data for both temperatures. The model simulation for the $24^{\circ} \mathrm{C}$ case was described earlier in this section. The model fit to the data at $14{ }^{\circ} \mathrm{C}$ was performed with the $K_{S A}$ obtained at $24{ }^{\circ} \mathrm{C}$ as a starting value. Changing $K_{S A}$ and minimizing the residual sum of square of errors generated a correct fit. A correction factor of $\left(T_{2} / T_{1}\right)^{7 / 4}$, where $T$ is temperature $\left({ }^{\circ} \mathrm{K}\right)$, was used to adjust the diffusivity to the lower temperature (Thibodeaux 1996). The fit $K_{S A}$ for $2,4-D N T$ on LAAP-C soil at $14{ }^{\circ} \mathrm{C}$ was $10^{7} \mathrm{~L} / \mathrm{kg}$ as compared to $1.2 \times 10^{5} \mathrm{~L} / \mathrm{kg}$ at $24{ }^{\circ} \mathrm{C}$. The trend of higher partitioning constant at lower temperature was compared to the data obtained for a different compound (phenanthrene) on a different soil, but with comparable moisture contents. The heat of desorption from soil to air, $\Delta H_{\text {desorp }}$, was calculated using the ClausiusClapeyron equation

$$
\frac{d(\ln P)}{d T}=-\frac{\Delta H_{\text {desorp }}}{R T^{2}}
$$




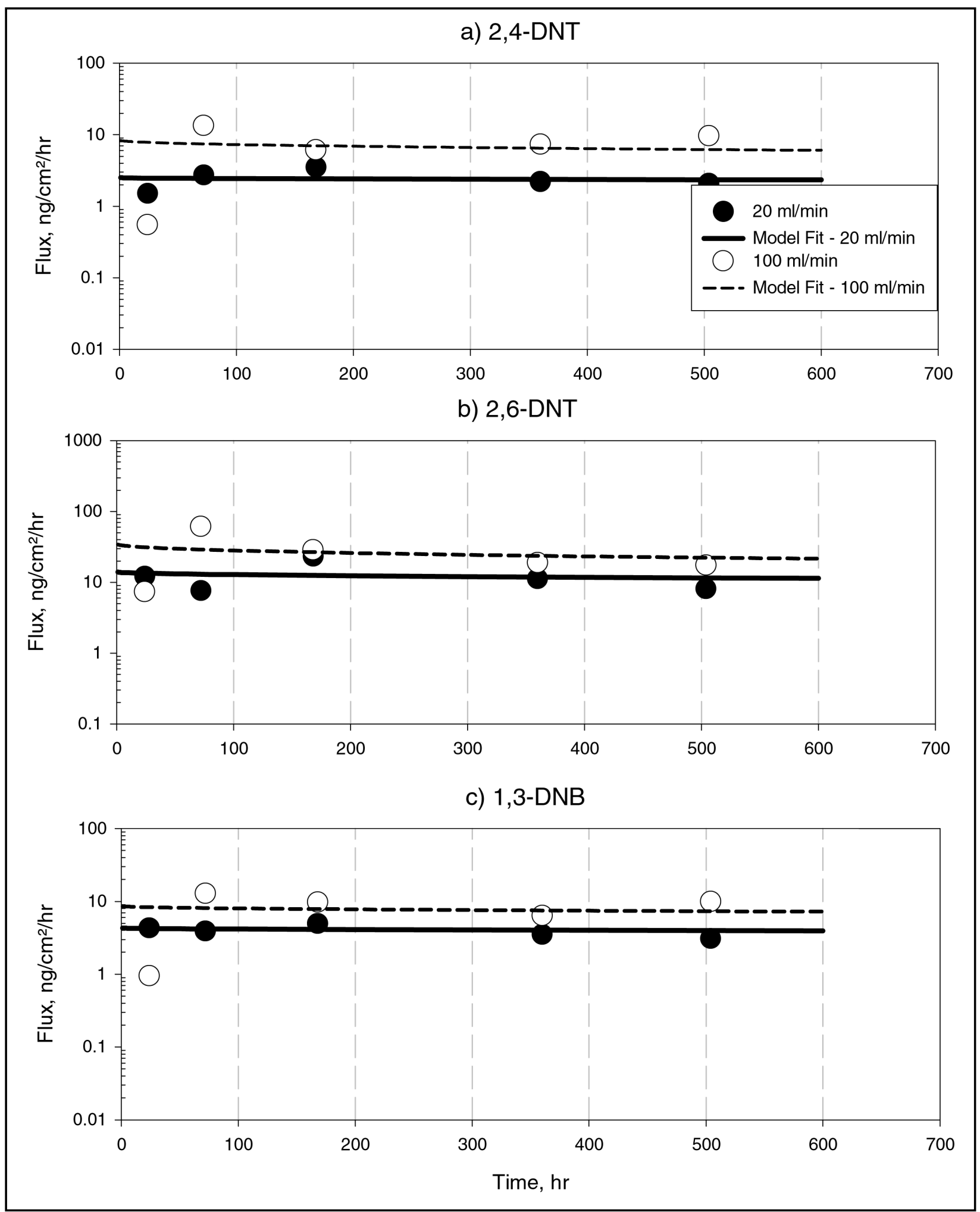

Figure 9. Comparison of experimental and model fit for 2,4-DNT, 2,6-DNT, and 1,3-DNB for case 4 for 20 - and 100-ml/min airflow rates, LAAP-C soil, 20-percent soil moisture with humid air 


\begin{tabular}{|c|c|}
\hline \multicolumn{2}{|c|}{$\begin{array}{l}\text { Table } 10 \\
\text { Fit } K_{A W} \text { Values (or Henry's Law constant) to Model Experimental } \\
\text { Data in Case } 4 \text { from LAAP-C Soil }\end{array}$} \\
\hline Parameter & $K_{A W}$ \\
\hline \multicolumn{2}{|c|}{ "2,4-DNT } \\
\hline Reported & $7.5 \mathrm{e}-6$ \\
\hline Model fit, $20 \mathrm{ml} / \mathrm{min}$ & $4.1 \mathrm{e}-6$ \\
\hline Model fit, $100 \mathrm{ml} / \mathrm{min}$ & $1.3 e-5$ \\
\hline \multicolumn{2}{|c|}{ 2,6-DNT } \\
\hline Reported & $\overline{77.5 e-6}$ \\
\hline Model fit, $20 \mathrm{ml} / \mathrm{min}$ & $6.9 e-6$ \\
\hline Model fit, $100 \mathrm{ml} / \mathrm{min}$ & $7.7 \mathrm{e}-6$ \\
\hline \multicolumn{2}{|c|}{ 1,3-DNB } \\
\hline Reported & $\begin{array}{l}.2 \mathrm{e}-5 \\
\end{array}$ \\
\hline Model fit, $20 \mathrm{ml} / \mathrm{min}$ & $4.0 \mathrm{e}-6$ \\
\hline Model fit, $100 \mathrm{ml} / \mathrm{min}$ & $3.6 e-6$ \\
\hline
\end{tabular}

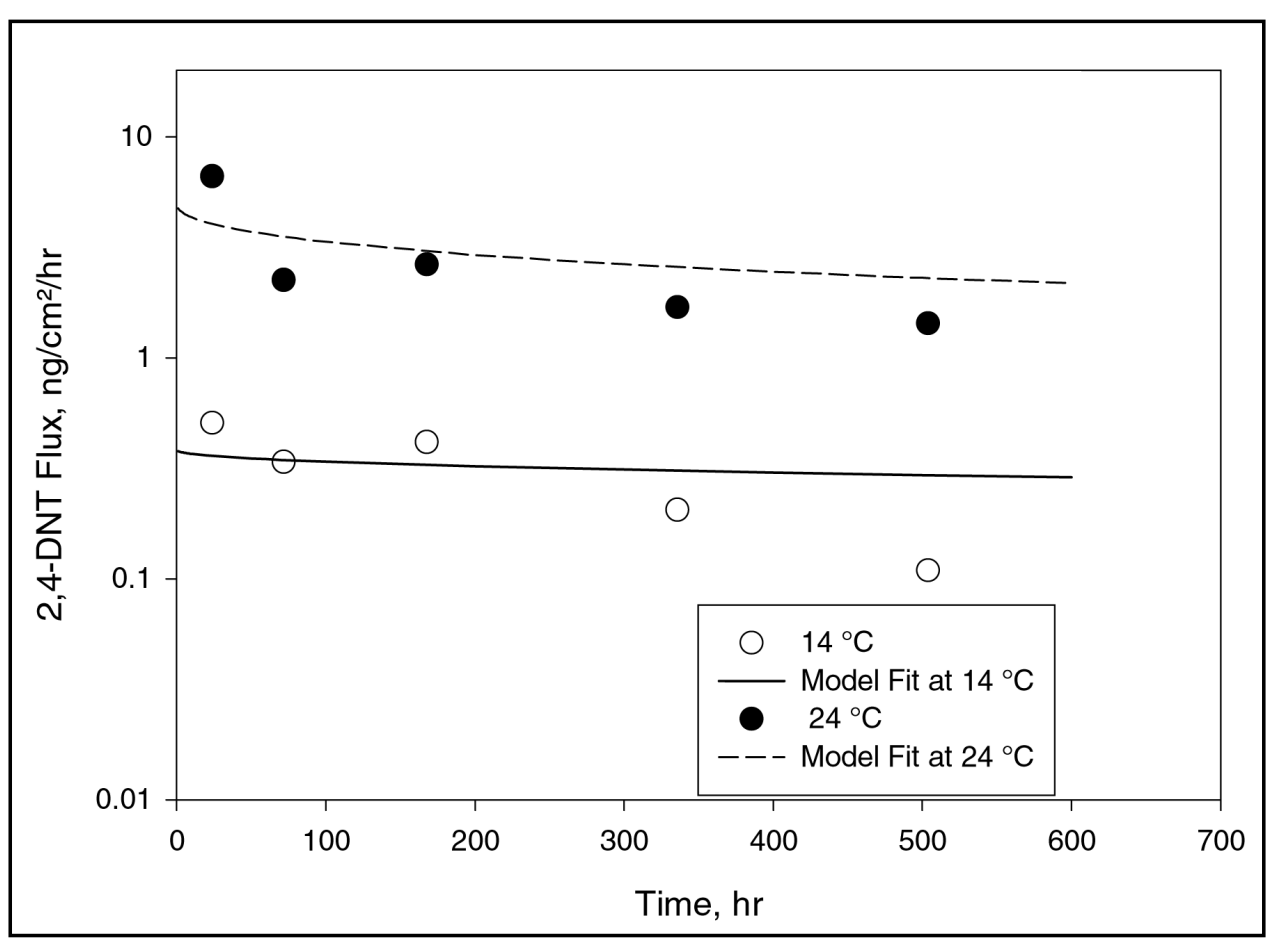

Figure 10. Effect of temperature on the flux of 2,4-DNT from LAAP-C soil (case 2: 20-percent poisture content with dry air passing over the soil)

where $P$ is the equilibrium vapor pressure $(\mathrm{Pa})$ calculated using Equation 7

$$
P=\frac{W_{S} R T}{K_{S A} M}
$$

and 


$$
\begin{aligned}
R & =\text { universal gas constant } \\
M & =\text { molecular mass }
\end{aligned}
$$

A large value for $\Delta H_{\text {desorp }}$ of $187 \mathrm{~kJ} / \mathrm{mol}$ was obtained from Equation 6 and indicated that desorption was endothermic. The heat of desorption for phenanthrene measured by DeSeze (2000) was also endothermic (average value of $\Delta H_{\text {desorp }}$ for wet soil was $90 \pm 4 \mathrm{~kJ} / \mathrm{mol}$ ). This suggests that the effects of temperature on $K_{S A}$ and flux for UXO are similar to those reported for other types of compounds and are predictable using Equation 4 with appropriate temperature correction for $K_{S A}$.

\section{Explosive Chemical Signature Transport from Buried Sources}

In these experiments, explosive chemical signature transport from a buried source was evaluated by measuring soil concentrations around and above the buried source. Soil concentration measurements were acquired by sampling around the buried source in the experiments described earlier. The raw experimental data consisted of soil concentration measurements at a certain depth and at a certain distance from the central axis of the container. The lateral sampling plane was considered to be symmetrical and, therefore, the measurements do not indicate the radial direction of measurement about the central axis. The raw experimental data are plotted in Figures A1-A8. These curves are based on the raw data that were transformed by interpolation and smoothing to obtain surface plots. These plots are of the soil concentrations for all four of the explosive chemicals used in this study (2,4-DNT, 2,6-DNT, 1,4-DNB, and 1,3,5-TNB) with two different soil conditions ( 5 percent and 20 percent soil moisture content) and two different source depths ( $4 \mathrm{~cm}$ and $15.24 \mathrm{~cm}$ ). The Cartesian coordinates $X=0$ and $Y=4.0 \mathrm{~cm}$ on the figures corresponds to the source depth of $4 \mathrm{~cm}$ in the experimental data. The soil concentrations are higher nearer the source and decrease away from the source. In the plots corresponding to the source depth at $15.24 \mathrm{~cm}$, the source coordinates are $X=0, Y=15.24 \mathrm{~cm}$. The highest soil concentrations are found closer to that source at around $Y=16 \mathrm{~cm}$ and decrease away from the source. In both cases, the soil concentration decreases with increasing absolute distance away from the source. This is due to the diffusion arising from the concentration gradients that exist in the soil matrix. Expectedly, the surface soil concentrations are higher in the case where the source is at $4 \mathrm{~cm}$ than when the source is at a depth of $15.24 \mathrm{~cm}$ from the surface. Also, the soil concentrations at the surface immediately above the buried source were higher than on the surface a few centimeters away from the central axis of burial. Soil concentration measurements are listed and plotted to a depth of about $24 \mathrm{~cm}$ in both cases, and, therefore, no peaks are seen beyond $Y=20 \mathrm{~cm}$ on the plot. Deeper measurements were obtained, but are not shown here since the interest is primarily in the migration of the chemical signature towards the surface. The 5and 20-percent moisture data do not differ qualitatively or quantitatively. This was not unexpected because reaction rate tests for the LAAP-C soil showed similar results. The migration patterns of the explosive chemical seem similar in both cases. The raw data is also arranged in Tables A4-A7. 
To model the transport of the chemical vapor signature away from the source, the Cartesian coordinates corresponding to the experimental measurements were converted to absolute distances. The quantity, $r$, the absolute distance from the source, was calculated by the following equation:

$$
r=\left[\left(X-X_{0}\right)^{2}+\left(Y-Y_{0}\right)^{2}\right]^{1 / 2}
$$

where

$$
\begin{gathered}
X_{0} \text { and } Y_{0}=\text { source coordinates } \\
X \text { and } Y=\text { sample coordinates }
\end{gathered}
$$

Plotting the experimental soil concentrations as a function of $r$, one can obtain the two-dimensional plot to represent the transport of the chemical from its source. In this analysis, $r=0$ represents the point at the source. The chemical source was assumed to be a point source since the plug containing the explosive chemicals was much smaller in relation to the dimensions of the container.

FEMLAB, a commercially available software from COMSOL $^{\circledR}$, was initially used to attempt to simulate a test case. This program uses the same diffusion model described earlier in Equation 2 and follows a finite element method to solve for mobile phase concentrations in space. The program offers the modeling capabilities of complex geometries and can generate surface plots that are visually instructive. However, this program did not provide a simple method to perform curve fitting. An alternative, simpler analytical model that was more amenable to fitting a parameter was also considered for the specific task of comparing and fitting the experimental data to the model. This one-dimensional model tracks the concentration in soil as a function of absolute distance away from the source and time. This model uses the same differential equation (shown in Equation 2 with $k_{a}$ set to zero and $r$ replacing $z$ in the differential equation), but with the following boundary conditions: at $r=0$ (i.e., the source), $C_{A}=C_{A}^{0}$, and at $r=4$ (far away from the source), $C_{A}=0$ and with the initial condition at all $r>$ $0, C_{A}=0$. Essentially, this assumes that at distances sufficiently far away from the source, the initial conditions were always maintained. The equation for the soil concentration as a function of time and space derived from Equation 2 is shown below in Equation 9:

$$
W_{S}(r, t)=K_{S A} \cdot C_{A}^{0} \cdot \operatorname{erfc}\left(\frac{r}{\sqrt{4 \alpha t}}\right)
$$

where

$$
\begin{aligned}
W_{S} & =\text { soil chemical concentration, } \mu \mathrm{g} / \mathrm{kg} \\
r & =\text { absolute distance away from the source, } \mathrm{cm} \\
t & =\text { time }, \mathrm{hr} \\
K_{S A} & =\text { soil-air partition constant, } \mathrm{L} / \mathrm{kg}
\end{aligned}
$$




$$
\begin{aligned}
C_{A}^{0}= & \text { soil vapor concentration at the source, } \mu \mathrm{g} / \mathrm{cm}^{3} \\
\alpha= & D_{\text {eff }} / R_{f}, \text { where } D_{\text {eff }} \text { and } R_{f} \text { are the effective diffusivity }\left(\mathrm{cm}^{2} / \mathrm{hr}\right) \text { and the } \\
& \text { retardation factor, respectively }
\end{aligned}
$$

For the 5-percent soil moisture case, the air-filled porosity of the soil was assumed to be constant since there could not be any significant evaporation. The loss of water vapor to the headspace in the containers was considered negligible and not to affect soil porosity significantly. For the 5-percent soil, the soil air porosity was set at 0.23 , and vapor-phase diffusion was considered to be the primary mechanism of chemical transport. The buried source was assumed to be a constant source of saturated vapor of each of the chemicals under consideration. The vapor-phase concentration at source was calculated from the reported vapor pressure and at room temperature. These computed values were 0.0021 , 0.0055 , and $0.0012 \mu \mathrm{g} / \mathrm{cm}^{3}$ for 2,4-DNT, 2,6-DNT, and 1,3-DNB, respectively.

In the 20-percent soil moisture case, diffusion in pore water was considered the primary transport mechanism since the soil pore spaces were filled with water. The water-filled porosity was set at 0.31 . In Equation 7, $K_{S A}$ was replaced by $K_{S W}, C_{A}^{0}$ was the solubility of the chemical in water, $D_{\text {eff }}$ was computed using the diffusivity of the chemical in water, and $R_{f}$ was calculated using $K_{S W}$. The saturated aqueous concentrations were 280,208 , and $533 \mu \mathrm{g} / \mathrm{cm}^{3}$ for 2,4-DNT, 2,6-DNT, and 1,3-DNB, respectively. The same model was applied to the data from two different burial depths. For the 5-percent soil moisture data, a best-fit model was applied to the experimental data by varying $K_{S A}$. Figure 11 shows the comparison between the model fit and the experimental data. The model follows the general trend shown by the experimental soil concentrations, which decrease away from the source. Table 11 lists the $K_{S A}$ for the model fit curves shown in Figure 11 and also compares these values to those obtained earlier. The $K_{S A}$ values vary over a range of two orders of magnitude. In previous experiments, Jenkins et al. (2000) measured $K_{S A}$ values for explosive chemicals and found that values varied from $3.9 \mathrm{e}+4$ to $1.0 \mathrm{e}+6 \mathrm{~L} / \mathrm{kg}$ for $2,4-\mathrm{DNT}, 2.6 \mathrm{e}+4$ to $4.1 \mathrm{e}+5 \mathrm{~L} / \mathrm{kg}$ for $2,6-\mathrm{DNT}$, and $5.34 \mathrm{e}+4$ to $2.8 \mathrm{e}+6 \mathrm{~L} / \mathrm{kg}$ for $1,3-\mathrm{DNB}$. The values measured by Jenkins et al. (2000) were for a wet soil with moisture contents greater than 10 percent and are comparable to the range of fit $K_{S A}$ values obtained from the current study. Figure 12 shows the comparison between the model and experimental soil concentrations for the 20-percent soil moisture case. The model curves were obtained by using the reported aqueous solubility and the measured $K_{S W}$ values. The experimental and the model curves match very well. The model is a good predictor of the transport of the UXO chemicals from a buried munitions source when the source concentration is known.

Table 12 lists the comparisons of the air concentrations calculated from the experimental and model fit soil concentrations. For the 5-percent soil moisture cases, the experimental air concentrations were obtained by dividing the experimental soil concentrations by the fit $K_{S A}$ values shown in Table 11. For the 20-percent soil moisture cases, the estimated $K_{S A}$ from the reported $K_{S W}$ and $K_{A W}$ was used (also shown in Table 11). For the 5-percent soil moisture case, the model directly provides the vapor-phase concentrations. For the 20-percent soil moisture case, the model solves for aqueous concentrations; therefore, at the surface the aqueous concentrations were multiplied by $K_{A W}$ to provide the air 
a) 2,4-DNT - Source $4 \mathrm{~cm}$ deep

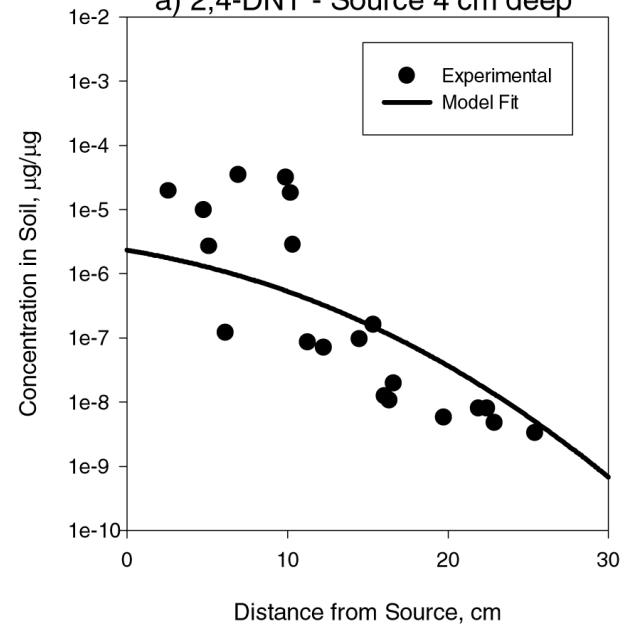

c) 2,6-DNT - Source $4 \mathrm{~cm}$ deep

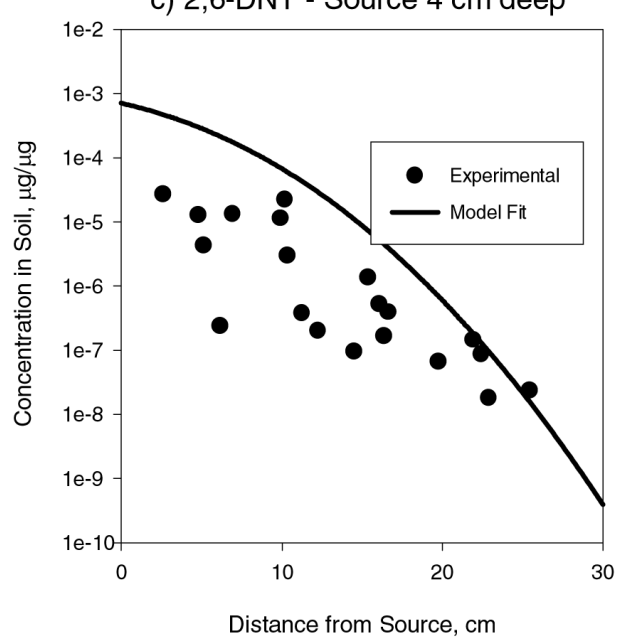

e) 1,3-DNB - Source $4 \mathrm{~cm}$ deep

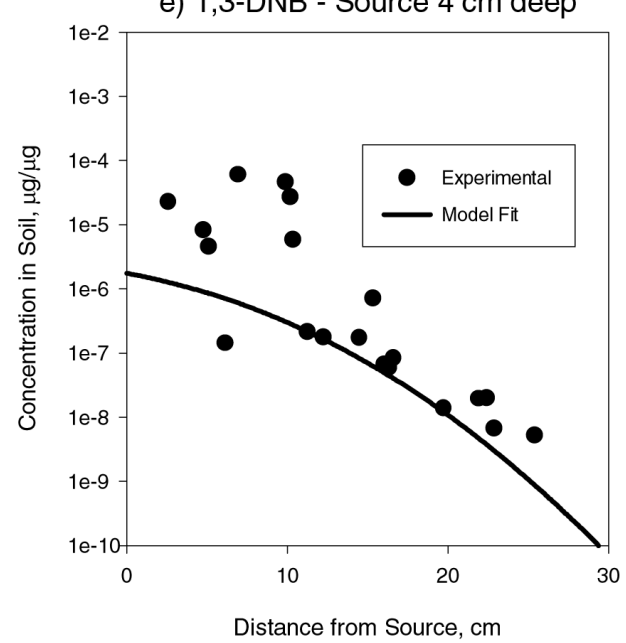

b) 2,4-DNT - Source $15 \mathrm{~cm}$ deep

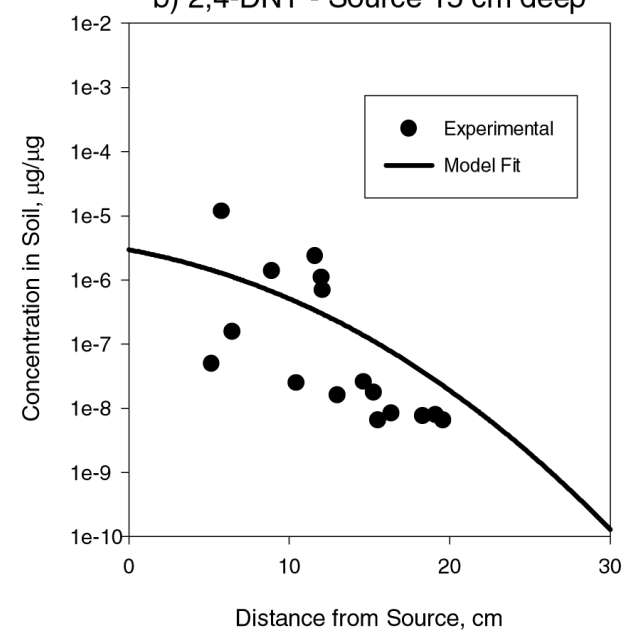

d) 2,6-DNT - Source $15 \mathrm{~cm}$ deep
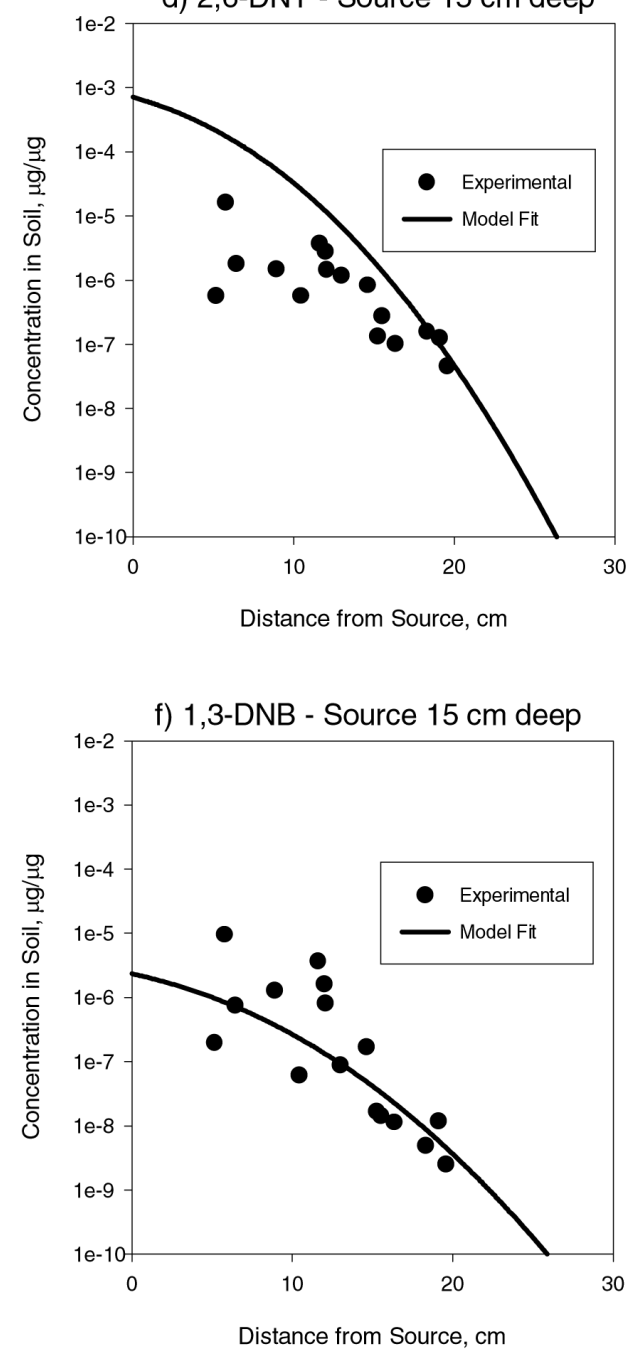

Figure 11. Comparison of experimental and modeled soil concentrations of 2,4-DNT, 2,6-DNT, and 1,3 -DNB from a buried source, soil moisture of 5 percent with vapor-phase diffusion 


\begin{tabular}{|c|c|c|}
\hline \multicolumn{3}{|c|}{$\begin{array}{l}\text { Table } 11 \\
\text { Adjustable Parameters, } K_{S A}(\mathrm{~L} / \mathrm{kg}) \text {, for Comparison with Laboratory } \\
\text { Flux Experiments and Buried Chemical Experiments with LAAP-C } \\
\text { Soil }\end{array}$} \\
\hline Parameter & Case 1 & Case 2 \\
\hline \multicolumn{3}{|c|}{ 2,4-DNT } \\
\hline Estimated & $8.9 e+4$ & $8.9 e+4$ \\
\hline Model fit - $20 \mathrm{ml} / \mathrm{min}$ & $1.2 \mathrm{e}+5$ & $9.7 e+4$ \\
\hline Model fit - $100 \mathrm{ml} / \mathrm{min}$ & $1.6 e+5$ & $2.9 e+4$ \\
\hline Model fit - Buried $(4 \mathrm{~cm})(5 \%$ soil moisture $)$ & $1.1 \mathrm{e}+3$ & - \\
\hline Model fit - Buried $(15 \mathrm{~cm})(5 \%$ soil moisture $)$ & $1.4 \mathrm{e}+3$ & - \\
\hline \multicolumn{3}{|c|}{$\begin{array}{ll}2,6-D N T \\
\end{array}$} \\
\hline Estimated & $1.3 \mathrm{e}+5$ & $1.3 e+5$ \\
\hline Model fit - $20 \mathrm{ml} / \mathrm{min}$ & $6.4 \mathrm{e}+3$ & $2.5 \mathrm{e}+4$ \\
\hline Model fit - $100 \mathrm{ml} / \mathrm{min}$ & $1.5 e+4$ & $3.2 \mathrm{e}+4$ \\
\hline Model fit - Buried $(4 \mathrm{~cm})(5 \%$ soil moisture $)$ & $2.1 \mathrm{e}+3$ & - \\
\hline Model fit - Buried $(15 \mathrm{~cm})(5 \%$ soil moisture $)$ & $3.0 \mathrm{e}+3$ & - \\
\hline \multicolumn{3}{|c|}{$\begin{array}{ll} & 1,3-\mathrm{DNB} \\
\end{array}$} \\
\hline Estimated & $9.9 e+3$ & $9.9 \mathrm{e}+3$ \\
\hline Model fit - $20 \mathrm{ml} / \mathrm{min}$ & $6.1 \mathrm{e}+4$ & $6.9 \mathrm{e}+4$ \\
\hline Model fit - $100 \mathrm{ml} / \mathrm{min}$ & $1.1 \mathrm{e}+5$ & $2.0 e+4$ \\
\hline Model fit - Buried $(4 \mathrm{~cm})(5 \%$ soil moisture $)$ & $2.0 \mathrm{e}+3$ & - \\
\hline Model fit - Buried $(15 \mathrm{~cm})(5 \%$ soil moisture $)$ & $3.4 e+3$ & - \\
\hline
\end{tabular}

concentrations. The predicted air concentrations are of the same order of magnitude, or slightly higher than, all of the measured air concentrations, except for the 5 -percent soil moisture case with the source at $4 \mathrm{~cm}$ from the surface. The measured concentrations were higher than the predicted concentration. In general, the estimation of $K_{S A}$ seemed to be the most significant factor in predicting the soil and air concentrations around a buried explosive source. The estimation of $K_{S A}$ from $K_{S W}$ and $K_{W A}$ may not be very appropriate. The $K_{S A}$ must be measured empirically for the desired soil by varying parameters such as moisture content or temperature. A gas saturation method has been used successfully in the past to measure the soil-air equilibrium partition constants for several polyaromatic hydrocarbons (DeSeze 2000). In this method, clean air with the desired relative humidity is passed through a soil column of sufficient length to facilitate equilibrium. The clean air exiting the column is sent through a plug of adsorbent material. Both the air and soil concentrations are analyzed to obtain $K_{S A}$. An alternative method, described by Jenkins et al. (2000), measured $K_{S A}$ by placing a plug of adsorbent material over contaminated soil and analyzing the plug and the soil after equilibrium is achieved.

\section{Application of the Model to Soil Samples Collected Near Buried Landmines}

The study conducted by Jenkins et al. (2000) to measure explosive-related signatures in soil samples near buried landmines provided a data set that could be used to verify the model. This study was conducted at Fort Leonard Wood, MO. 

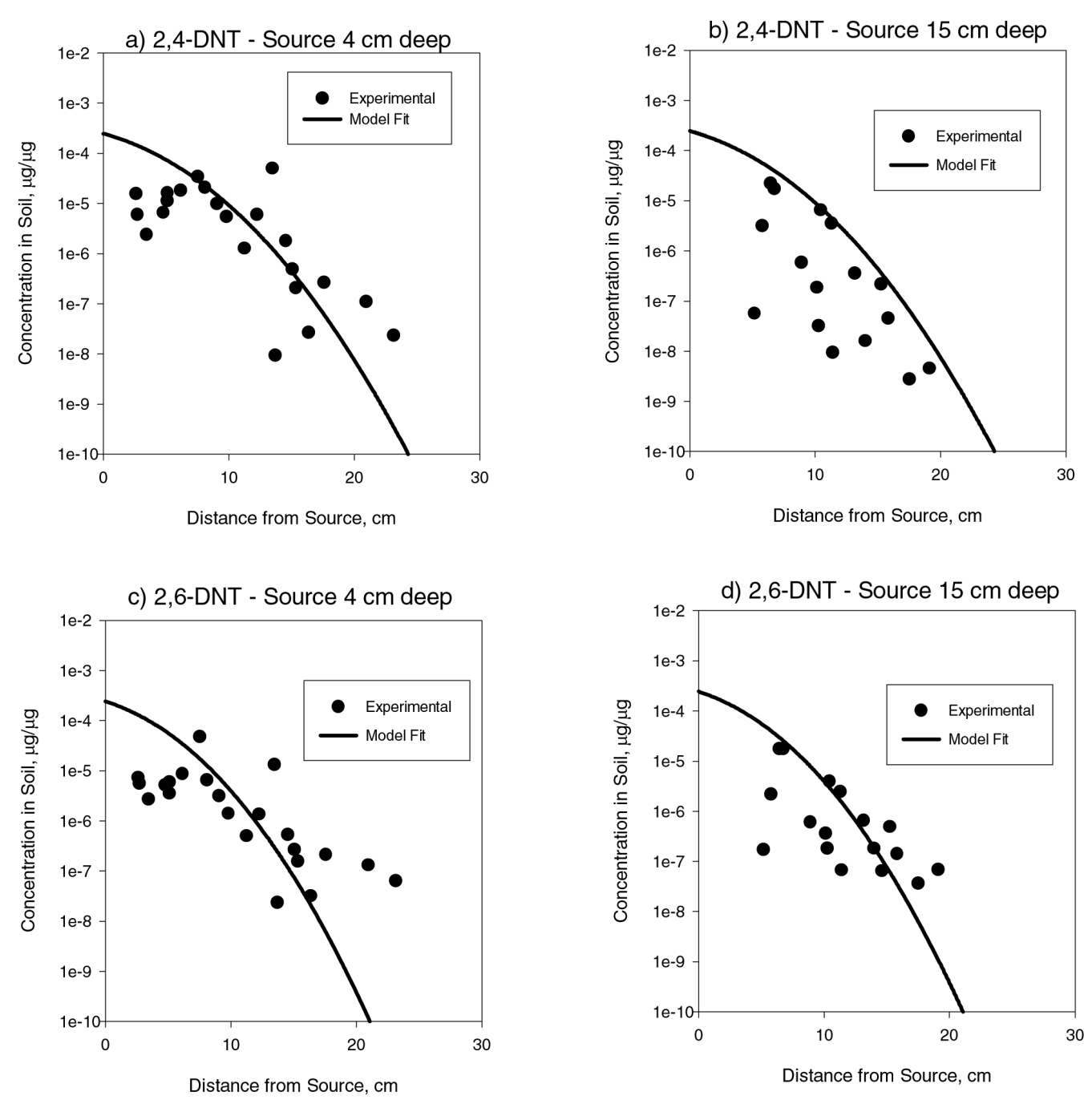

e) 1,3-DNB - Source $4 \mathrm{~cm}$ deep
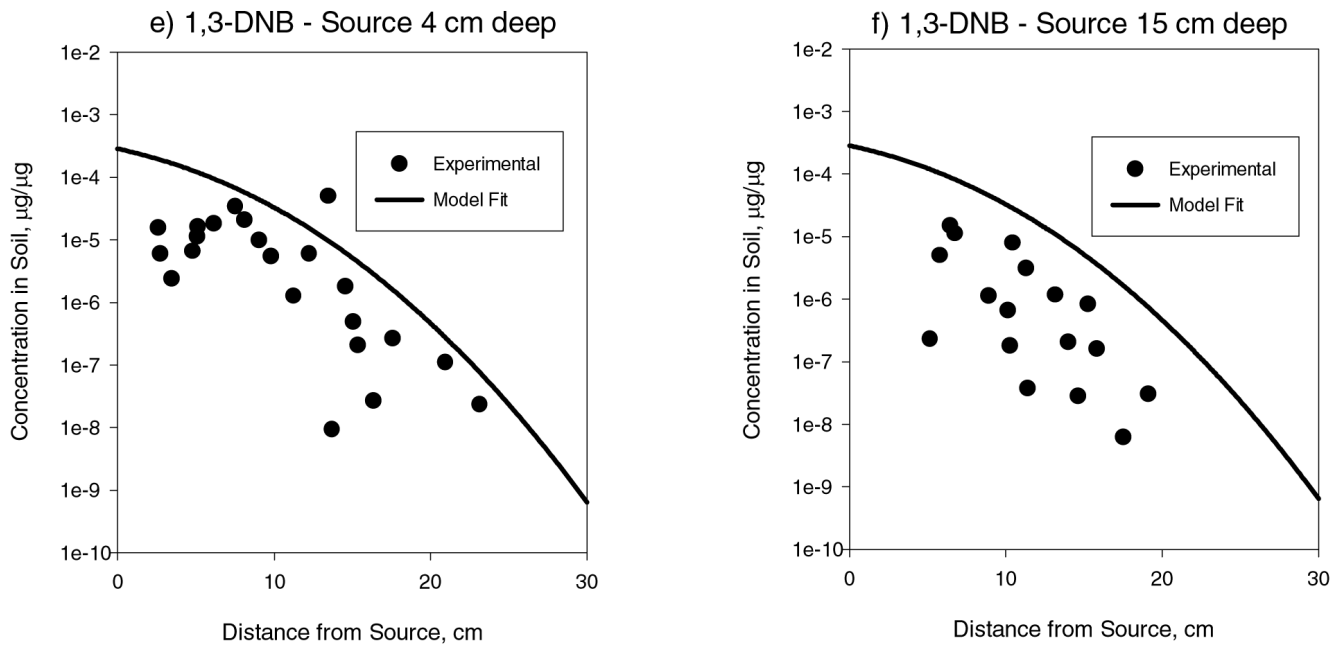

Figure 12. Comparison of experimental and modeled soil concentrations of 2,4-DNT, 2,6-DNT, and 1,3-DNB from a buried source, soil moisture of 20 percent with aqueous-phase diffusion 


\begin{tabular}{|c|c|c|c|}
\hline $\begin{array}{l}\text { Table } 12 \\
\text { Comparison } \\
\text { Source Expe } \\
\text { Simulations }\end{array}$ & $\begin{array}{l}\text { r Concentratic } \\
\text { ntal Data and }\end{array}$ & $\begin{array}{l}\text { Calculate } \\
\text { rrespondir }\end{array}$ & $\begin{array}{l}\text { the Buried } \\
\text { el }\end{array}$ \\
\hline & & Air $\mathrm{Cc}$ & ion, $\mu \mathrm{g} / \mathrm{cm}^{3}$ \\
\hline Soil Moisture, \% & Source Depth, cm & Experimental & Model \\
\hline & & & \\
\hline$\overline{55}$ & 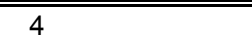 & $\bar{~} 3.17 \mathrm{e}-2$ & $\bar{~} 1.33 \mathrm{e}-3$ \\
\hline 5 & 15 & $3.59 \mathrm{e}-5$ & $8.12 \mathrm{e}-5$ \\
\hline 20 & 4 & $7.97 e-5$ & $8.49 \mathrm{e}-4$ \\
\hline 20 & 15 & $6.34 \mathrm{e}-7$ & $3.21 \mathrm{e}-6$ \\
\hline & & & \\
\hline 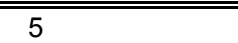 & 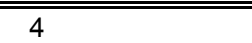 & 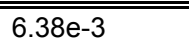 & $\begin{array}{l}2.8 e-3 \\
\end{array}$ \\
\hline 5 & 15 & $1.91 \mathrm{e}-4$ & $1.34 \mathrm{e}-5$ \\
\hline 20 & 4 & $2.77 e-5$ & $5.25 \mathrm{e}-4$ \\
\hline 20 & 15 & $1.34 \mathrm{e}-6$ & $4.06 \mathrm{e}-6$ \\
\hline & & & \\
\hline$\overline{5}$ & \begin{tabular}{c|}
4 \\
\end{tabular} & 4.01e-2 & $\begin{array}{l}6.84 \mathrm{e}-4 \\
\end{array}$ \\
\hline 5 & 15 & $9.8 e-5$ & $1.81 \mathrm{e}-5$ \\
\hline 20 & 4 & $1.14 \mathrm{e}-3$ & $9.01 \mathrm{e}-3$ \\
\hline 20 & 15 & $2.33 e-5$ & $2.83 \mathrm{e}-4$ \\
\hline
\end{tabular}

Several types of landmines were buried at different depths in soil, and core sampling was performed at several time intervals up to 472 days after the burial. The soil concentrations were measured in the collected samples and were tabulated as a function of the mine type, collection date, and collection location. Samples were collected all around the mine and also below it after the mine was removed. One of the observations made in the Jenkins study was that high concentrations of explosive chemicals were found under the mine, possibly due to leaching.

Researchers chose to compare the model simulations with two of the data sets from one mine type (TMA-5) at two different dates of sampling (August 1998 and April 1999) that were 41 and 270 days after the mines were buried. The attempt was to compare the model simulations with the measured concentrations above the depth of the mine (the TMA-5 mines were buried at a depth of $8.5 \mathrm{~cm}$ below the soil surface). Since leaching was reported below the depth of the mine, vapor transport likely occurred predominantly in an upward direction from the mine. The simple model described in the earlier section was used to simulate soil concentrations at a distance away from the source. The mine was not a symmetric source, but was $31 \mathrm{~cm}$ long, $14 \mathrm{~cm}$ wide, and $11 \mathrm{~cm}$ high. The distance from the source was computed from the nearest edge of the mine. Information about the lateral positions of the sampling cores and sampling depths in Jenkins et al. (2000) was used to obtain the coordinates of the samples. The mean depth of a sample in a core was assumed to be the depth of the sample (i.e., if a sample represented 5 to $10 \mathrm{~cm}$ of a core, the depth, or Y-coordinate, of the sample was set at $7.5 \mathrm{~cm}$ ). The porosity of the soil was computed using the particle size distribution information and was set at 0.47 . The bulk density information was not found in Jenkins et al. (2000) and hence a value of $1.43 \mathrm{~g} / \mathrm{cm}^{3}$ (based on LAAP-C soil) was assumed. The model also assumed source vaporphase concentrations based on the reported vapor pressures at room temperatures. 
The initial $K_{S A}$ values used in the simulation were the measured values reported in their study. The simulations using these parameters overpredicted the soil concentrations by several orders of magnitude within the first 2 to $5 \mathrm{~cm}$ from the source and underpredicted the soil concentrations for distances beyond $5 \mathrm{~cm}$. In other words, the orientation and curvature of the model curves cut across the experimental data at almost right angles. Adjusting the $K_{S A}$ values alone changed the curvature of the model simulation curves, but the magnitude was a few orders higher than the experimental data. Adjusting the vapor-phase concentration at the source was also necessary to obtain good fit between the model and the data. Figures 13 and 14 show the comparison between the model fit and the experimental data. The adjusted values for 2,4-DNT, 2,6-DNT, 1,3-DNB, and TNT are listed in Table 13 along with the reported values. The variation in the $K_{S A}$ does not seem out of place considering the variation observed in the measured values and the model fit in the laboratory flux experiments reported in previous sections. However, the saturated vapor concentrations input in the model fit are a few orders of magnitude different from reported values. The median air concentration of 2,4-DNT at the soil-air interface on top of a TMA-5 mine buried $8.5 \mathrm{~cm}$ was estimated on the basis of measured $K_{S A}$ to be $1.5 \times 10^{-7} \mu \mathrm{g} / \mathrm{cm}^{3}$. As a comparison, the surface concentrations estimated from the laboratory experiment with a source buried $4 \mathrm{~cm}$ and $15 \mathrm{~cm}$ under the surface were 0.0317 and $7.9 \times 10^{-5} \mu \mathrm{g} / \mathrm{cm}^{3}$, respectively.

A significant difference between the studies of buried sources conducted in the laboratory and the field study data used to test the model is the structure and strength of the explosive chemical source. In the laboratory study, the source was a small plug that was on the order of a few centimeters and was in direct contact with the soil. Therefore, the transport processes in the porous media could be easily visualized and modeled. In the case of munitions, chemical vapors are generated inside the casing and travel to the surrounding soil through the casing unless the casing is breached. This presents an additional obstacle for vapor-phase transport to soil that is not easily overcome. If a casing is breached, it cannot be considered a symmetric source and may result in asymmetrical movement of the signature in soil. The largest obstacle, however, to both modeling and detection of chemical signatures may be the lack of a consistent and known signature from UXO. This is borne out in the study of Phelan, Rodacy, and Barnett (2001) who found that the chemical signature emitted from simulated unexploded ordnance was insufficient for use in discrimination of live explosivecontaining items. A unique, persistent, distinguishing trace chemical signature emitted from UXO was not found under all test and field conditions. A necessary precursor to a good predictive model is a known source term. The model developed in this study can predict with good accuracy the transport of explosives signatures and resulting soil concentrations at a distance from the source when the source is in contact with the soil. This will be useful in both surface and vadose zone soils. 


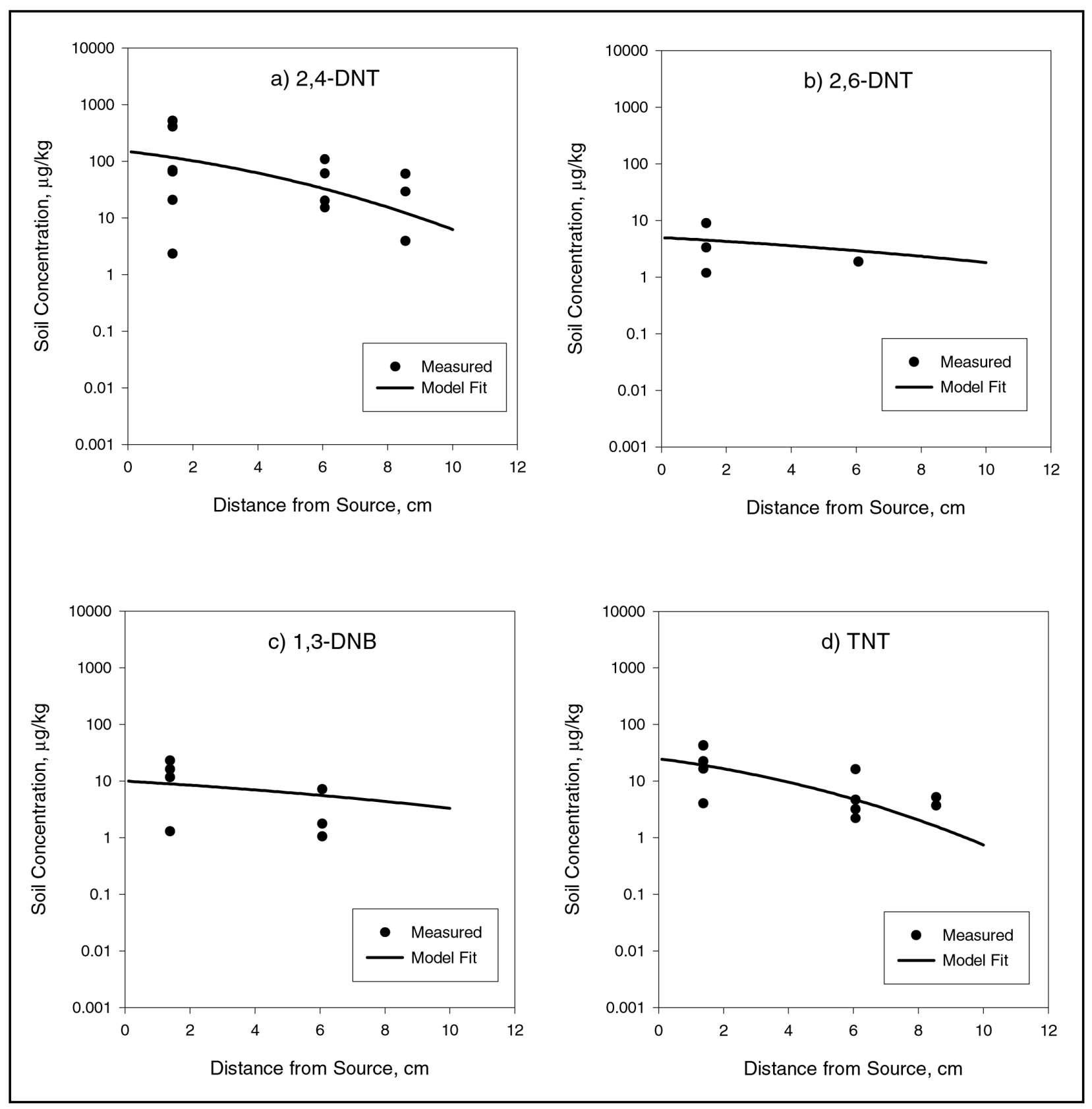

Figure 13. Comparison of experimental (data from Jenkins et al. (2000)) and model fit soil concentrations of 2,4-DNT, 2,6-DNT, 1,3-DNB, and TNT from buried TMA-5 type landmine, Fort Leonard Wood site, 41 days following burial 


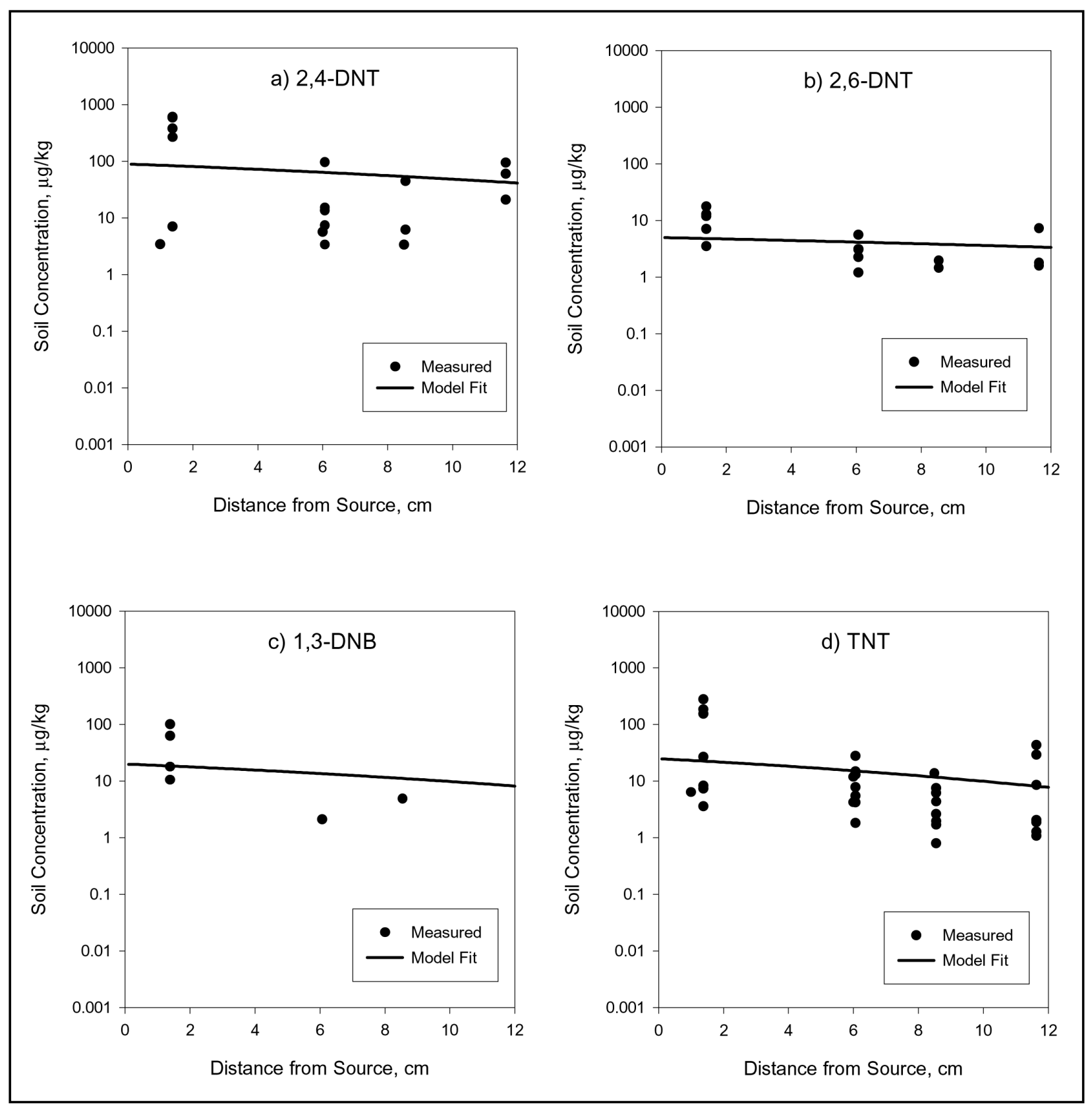

Figure 14. Comparison of experimental (data from Jenkins et al. (2000)) and model fit soil concentrations of 2,4-DNT, 2,6-DNT, 1,3-DNB, and TNT from buried TMA-5 type landmine, Fort Leonard Wood site, 270 days following burial 
Table 13

Model Fit Parameters for the Comparison of Landmine Data with Model Simulations

\begin{tabular}{||l|l|l|l|l||}
\hline \hline Parameter & 2,4-DNT & 2,6-DNT & 1,3-DNB & TNT \\
\hline \hline$K_{S A}$, L/kg, estimated & $8.6 \mathrm{e}+5$ & $1.8 \mathrm{e}+5$ & $4.6 \mathrm{e}+5$ & $9.6 \mathrm{e}+6$ \\
\hline$K_{S A}, \mathrm{~L} / \mathrm{kg}$, fit & $5.1 \mathrm{e}+3$ & $1.2 \mathrm{e}+3$ & $4.1 \mathrm{e}+3$ & $5.3 \mathrm{e}+3$ \\
\hline $\begin{array}{l}\text { Vapor concentration, } \\
\mu \mathrm{g} / \mathrm{cm}^{3}, \text { estimated }\end{array}$ & $2.1 \mathrm{e}-3$ & $5.5 \mathrm{e}-3$ & $1.2 \mathrm{e}-3$ & $6.7 \mathrm{e}-5$ \\
\hline $\begin{array}{l}\text { Vapor concentration, } \\
\mu \mathrm{g} / \mathrm{cm}^{3}, \text { fit }\end{array}$ & $3.2 \mathrm{e}-5$ & $5.1 \mathrm{e}-6$ & $5.1 \mathrm{e}-6$ & $5.2 \mathrm{e}-6$ \\
\hline
\end{tabular}




\section{Conclusions}

Increasing temperature and moisture in a surface soil decreased the stability of 1,3,5-TNB, 1,3-DNB, TNT, 2,4-DNT, and 2,6-DNT. In contrast, concentrations of explosives in the aquifer soils remained unchanged regardless of temperature and moisture. Explosives signatures in surface soils will therefore undergo greater degradation than in subsurface soils, making surface detection of signatures more difficult.

The moisture content and temperature of soils affect the flux of explosives chemical signatures from soil surfaces. The drier a soil becomes, the more the explosives signature flux decreases, probably due to increased partitioning on the soil. Fluxes of explosives signatures are relatively constant for soils with at least 5-percent moisture and that do not dry out. Increased temperature results in order of magnitude increases in explosives signature fluxes from soil. Explosive signatures from soils can be expected to increase as the soils become wetter and temperatures rise.

The compounds 2,6-DNT, 1,3-DNB, and 2,4-DNT were most likely to provide chemical signatures from soils. Of these compounds, 2,6-DNT generally provided the strongest signature. However, even the strongest 2,6-DNT signatures were relatively low, ranging from 0.1 to $<100 \mathrm{ng} / \mathrm{cm}^{2} / \mathrm{hr}$, depending upon the soil. These low signatures mean that sensors will need to be very sensitive, which may result in many false alarms because of explosives residues not associated with UXO on firing ranges. Low fluxes of even the most volatile compounds from explosives indicate that this environmental loss pathway is minimal and should not result in significant environmental exposures.

The model and process descriptors developed for prediction of explosives signature movement in soils accurately predicted signature movement in a soil with 20-percent moisture content and explosives sources buried at various depths. For drier soils, site-specific measurements of the soil-air partitioning coefficient may be needed pending development of improved Henry's Law constants. Verification of the model using an independent data set for explosives signatures around landmines showed that adjusting the vapor-phase concentration at the source was necessary to obtain a good model fit. This was needed because the casing of munitions presents a barrier to signature movement that is not easily overcome and results in an inconsistent and variable vapor emission. The model can accurately predict explosives signature movement to the surface where chemical detection can occur when the source strength is known. The model can also predict explosives signature movement and corresponding accumulation of 
explosives concentrations in vadose zone soils. The model verification phase of this study also revealed the need for improved Henry's Law constants that reflect field conditions. 


\section{References}

Brannon, J. M., and Myers, T. E. (1997). "Review of fate and transport processes of explosives," Technical Report IRRP-97-2, U. S. Army Engineer Waterways Experiment Station, Vicksburg, MS.

Brannon, J. M., and Pennington, J. C. (In Press). "Environmental fate and transport process descriptors for explosives," ERDC/EL TR-02-XX, U.S. Army Engineer Research and Development Center, Vicksburg, MS.

Brannon, J. M., Deliman, P. N., Gerald, J. A., Ruiz, C. E., Price, C. B., Hayes, C., Yost, S., and Qasim, M. (1999). "Conceptual model and processes descriptor formulations for fate and transport of UXO," Technical Report IRRP-99-1, U.S. Army Engineer Waterways Experiment Station, Vicksburg, MS.

Choy, B., and Reible, D. D. (2000). Diffusion models of environmental transport. Lewis Publishers, Boca Raton, FL.

DeSeze, G. (2000). "Sediment-air partitioning of hydrophobic organic chemicals," Ph.D. Thesis, Louisiana State University, Baton Rouge, LA.

George, V., Jenkins, T. F., Leggett, D. C., Cragin, J. H., Phelan, J., Oxley, J., and Pennington, J. C. (1999). "Progress to data on determining the vapor signature of a buried land mine," Proceedings of the SPIE $13^{\text {th }}$ Annual International Symposium on Aerospace/Defense Sensing, Simulation and Controls, 5-9 April 1999, Orlando, FL, Vol 3710, 258-269.

Haderlein, S. B., Weissmahr, K. W., and Schwarzenbach, R. P. (1996). "Specific adsorption of nitroaromatic explosives and pesticides to clay minerals," Environ Sci Technol 30, 612-622.

Jenkins, T. F., Leggett, D. C., and Ranney, T. A. (1999). "Vapor signatures from military explosives: Part 1, Vapor transport from buried military-grade TNT," Special Report 99-21, U.S. Army Cold Regions Research and Engineering Laboratory, Hanover, NH. 
Jenkins, T. F., Walsh, M. E., Miyares, P. H., Kopczynski, J. A., Ranney, T. A., George, V., Pennington, J. C., and Berry, T. E., Jr. (2000). "Analysis of explosives-related chemical signatures in soil samples collected near buried land mines," ERDC TR-00-5, U.S. Army Engineer Research and Development Center, Vicksburg, MS.

Karimi-Loftabad, S., Pickard, M. A., and Gray, M. R. (1996). "Reaction of polynuclear aromatic hydrocarbons on soils," Environ Sci Technol 30, $1145-1151$

McGrath, C. J. (1995). "Review of formulations for processes affecting the subsurface transport of explosives," Technical Report IRRP-95-2, U.S. Army Engineer Waterways Experiment Station, Vicksburg, MS.

Pennington, J. C., and Patrick, W. H., Jr. (1990). "Adsorption and desorption of 2,4,6-trinitrotoluene by soils," J Environ Qual 19, 559-567.

Pennington, J. C., Gunnison, D., Harrelson, D. W., Brannon, J. M., Zakikhani, M., Jenkins, T. F., Clarke, J. U., Hayes, C. A., Myers, T. E., Perkins, E., Ringelberg, D., Townsend, D. M., Fredrickson, H., and May, J. H. (1999). "Natural attenuation of explosives in soil and water systems at Department of Defense sites," Technical Report EL-99-8, U.S. Army Engineer Waterways Experiment Station, Vicksburg, MS.

Phelan, J. M., and Webb, S. W. (1997). "Environmental fate and transport of chemical signatures from buried landmines-screening model formulation and initial simulations," Sandia Report SAND97-1426, UC-741, Sandia National Laboratories, Albuquerque, NM.

Phelan, J. M., Rocacy, P. J., and Barnett, J. L. (2001). "Explosive chemical signatures from military ordnance," SAND2001-0755, Sandia National Laboratories Report, Albuquerque, NM.

Price, C. B., Brannon, J. M., and Hayes, C. (1997). "Effect of redox potential and $\mathrm{pH}$ on TNT transformation in soil-water slurries," Journal of Environmental Engineering 123, 988-992.

Price, C. B., Brannon, J. M., Yost, S. L., and Hayes, C. A. (2000). "Adsorption and transformation of explosives in low-carbon aquifer soils," ERDC/EL TR-00-11, U.S. Army Engineer Research and Development Center, Vicksburg, MS.

. (2001). "Relationship between redox potential and pH on RDX transformation in soil-water slurries," Journal of Environmental Engineering $127,26-31$.

Ravikrishna, R., Valsaraj, K. T., Yost, S., Price, C. B., and Brannon, J. M. (1998). "Air emissions from exposed, contaminated sediments and dredged materials, 2, Diffusion from laboratory-spiked and aged field sediments," J Hazard Mater 60, 89-104. 
Ravikrishna, R., Yost, S. L., Price, C. B., Valsaraj, K. T., Brannon, J. M., and Miyares, P. H. (2002). "Vapor phase transport of unexploded ordnance compounds through soils," Environmental Toxicology and Chemistry 21, In Press.

Spencer, W. F., Shoup, T. D., Cliath, M. M., Farmer, W. J., and Haque, R. (1979). "Vapor pressure and relative humidity of ethyl and methyl parathion," Journal of Agricultural Food Chemistry 27, 273-278.

Thibodeaux, L. J. (1996). Environmental chemodynamics. Wiley Interscience, New York.

U.S. Environmental Protection Agency. (1994). "Nitroaromatics and nitroamines by HPLC, Second Update SW 846, Method 8330," Office of Solid Waste and Emergency Response, Washington, DC.

. (2000). "Nitroaromatics and nitroamines by HPLC, Update IV-B, SW 846, Method 8095," Office of Solid Waste and Emergency Response, Washington, DC.

Valsaraj, K. T., Ravikrishna, R., Choy, B., Reible, D. D., Thibodeaux, L. J., Price, C. B., Brannon, J. M., and Myers, T. E. (1997). "Air emissions from exposed, contaminated sediments and dredged materials, 1, Experimental data in laboratory microcosms and mathematical modeling," J Hazard Mater $54,65-87$.

. (1999). "Air emissions from exposed, contaminated sediments and dredged materials," Environ Sci Technol 32, 142-149. 


\section{Appendix A Summary of Experimental Data}




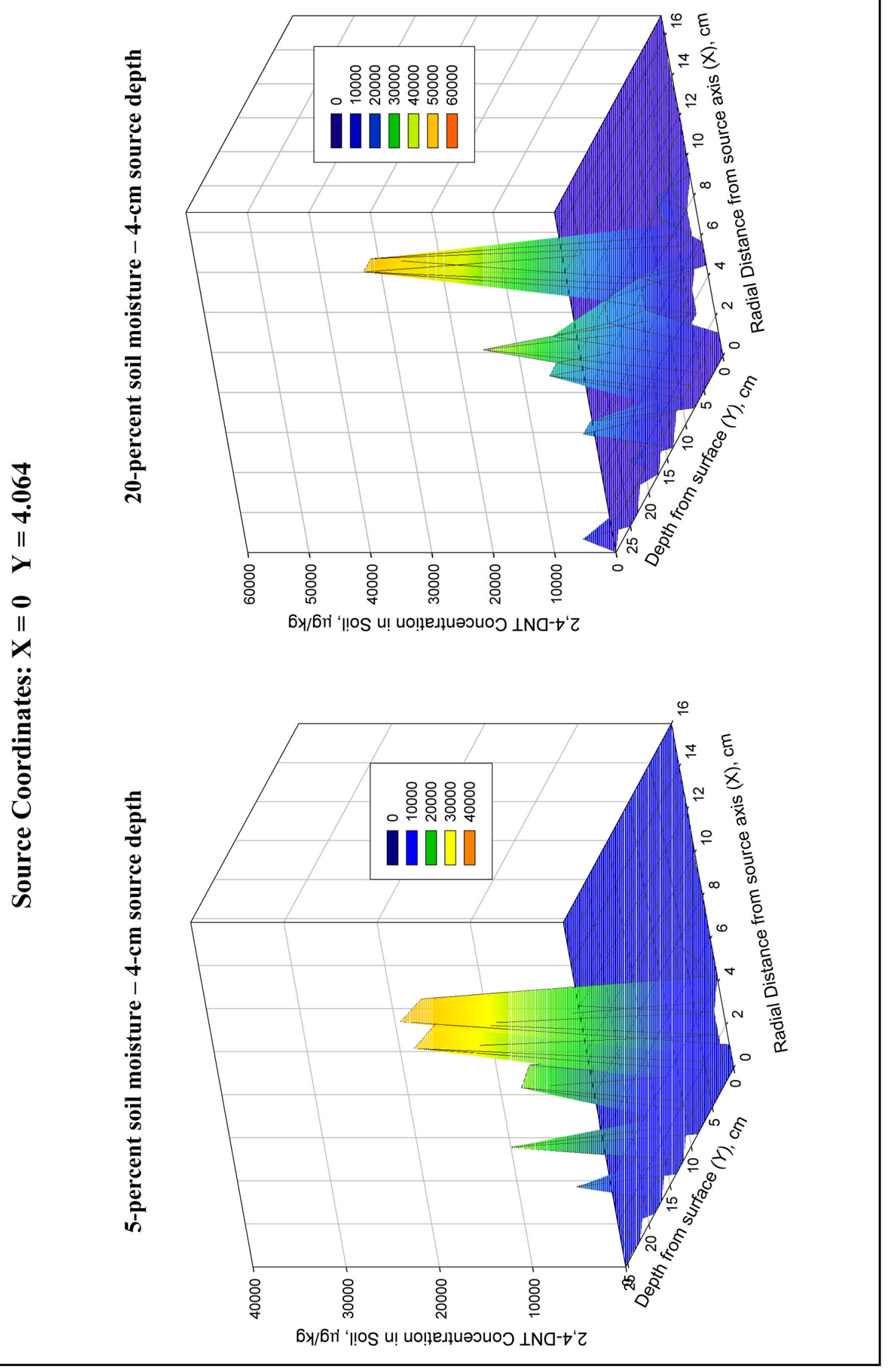

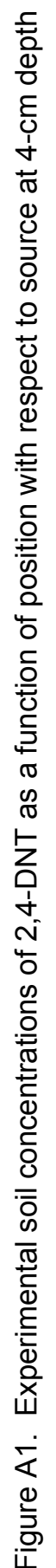




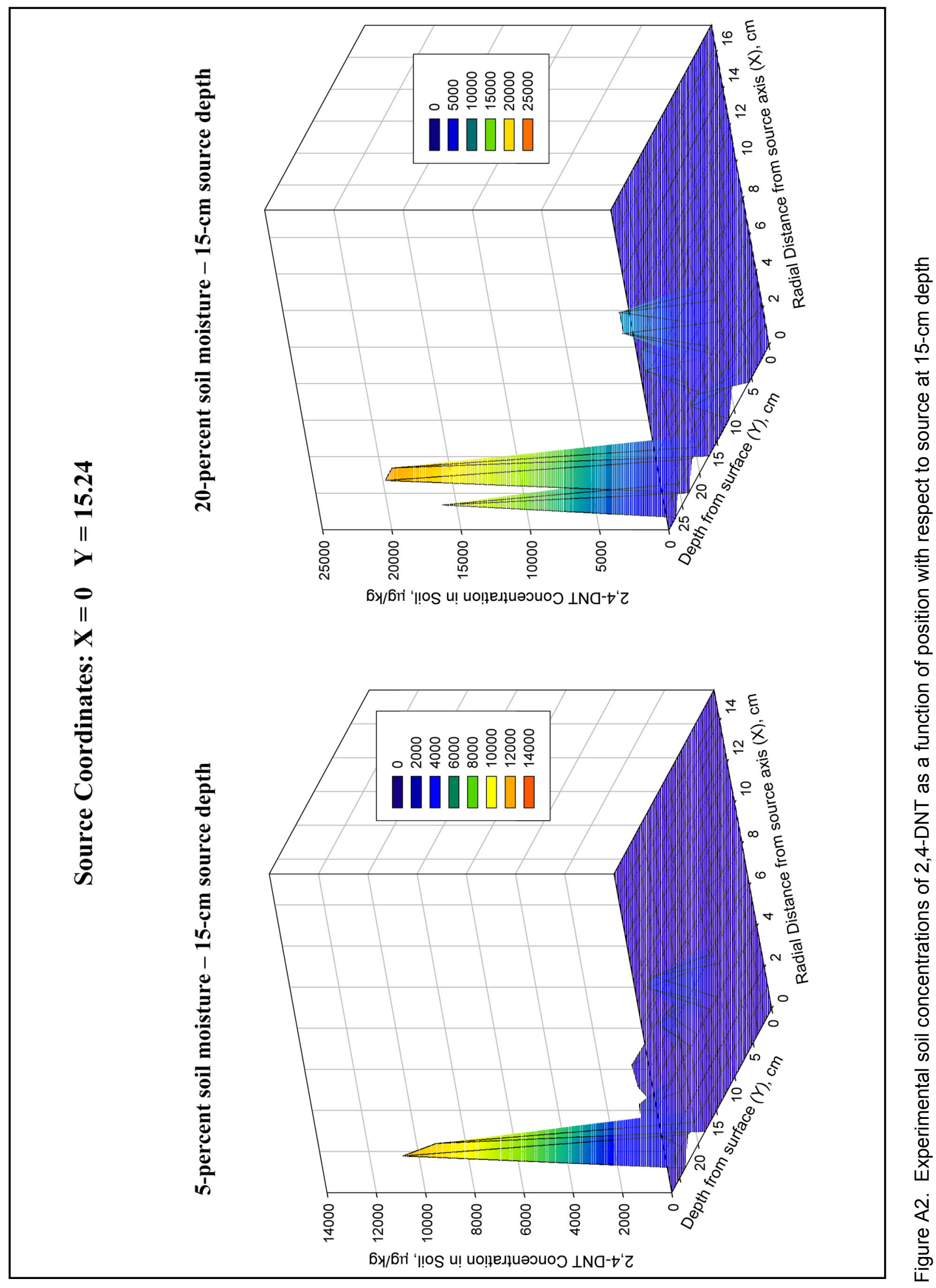




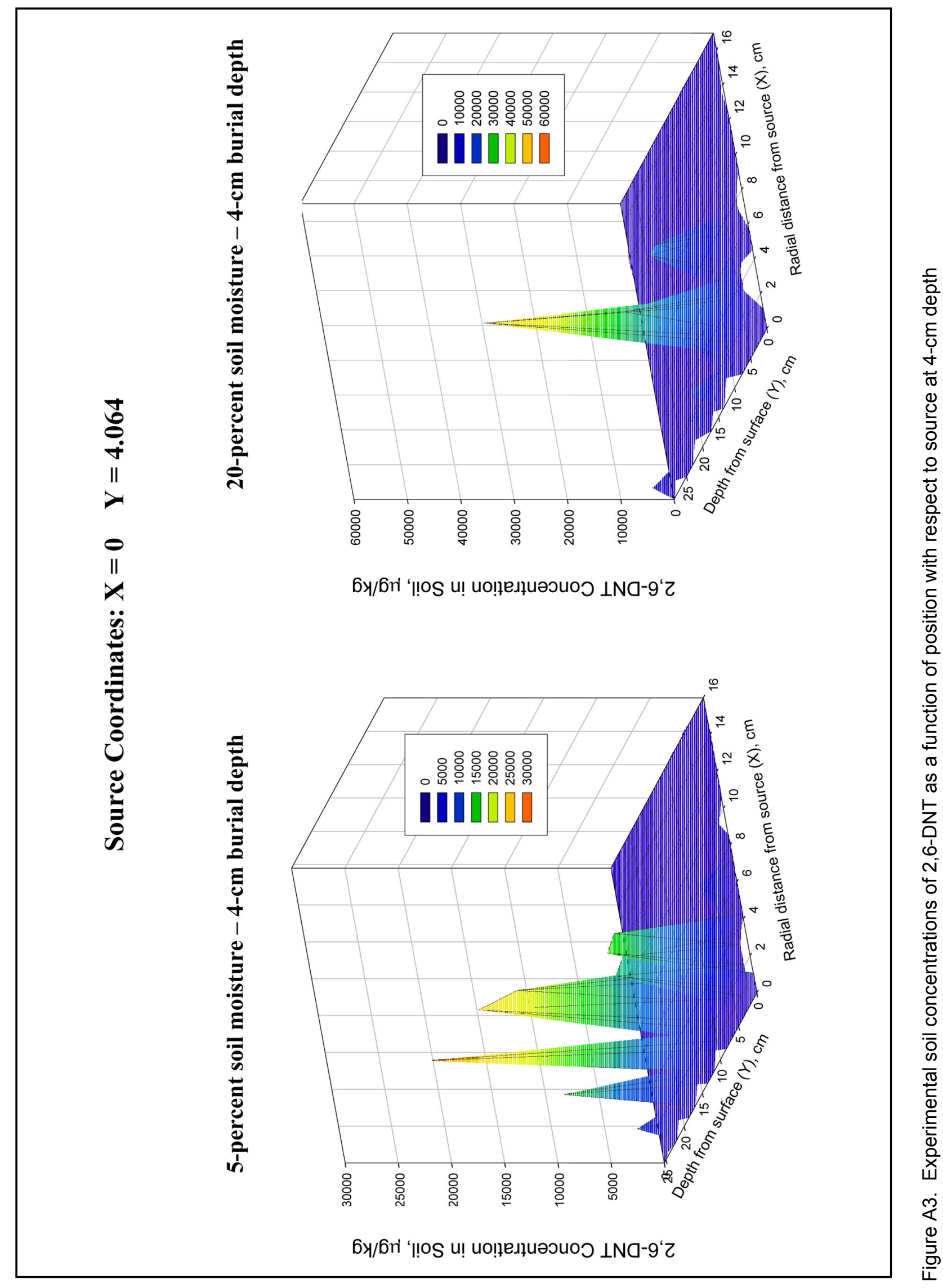




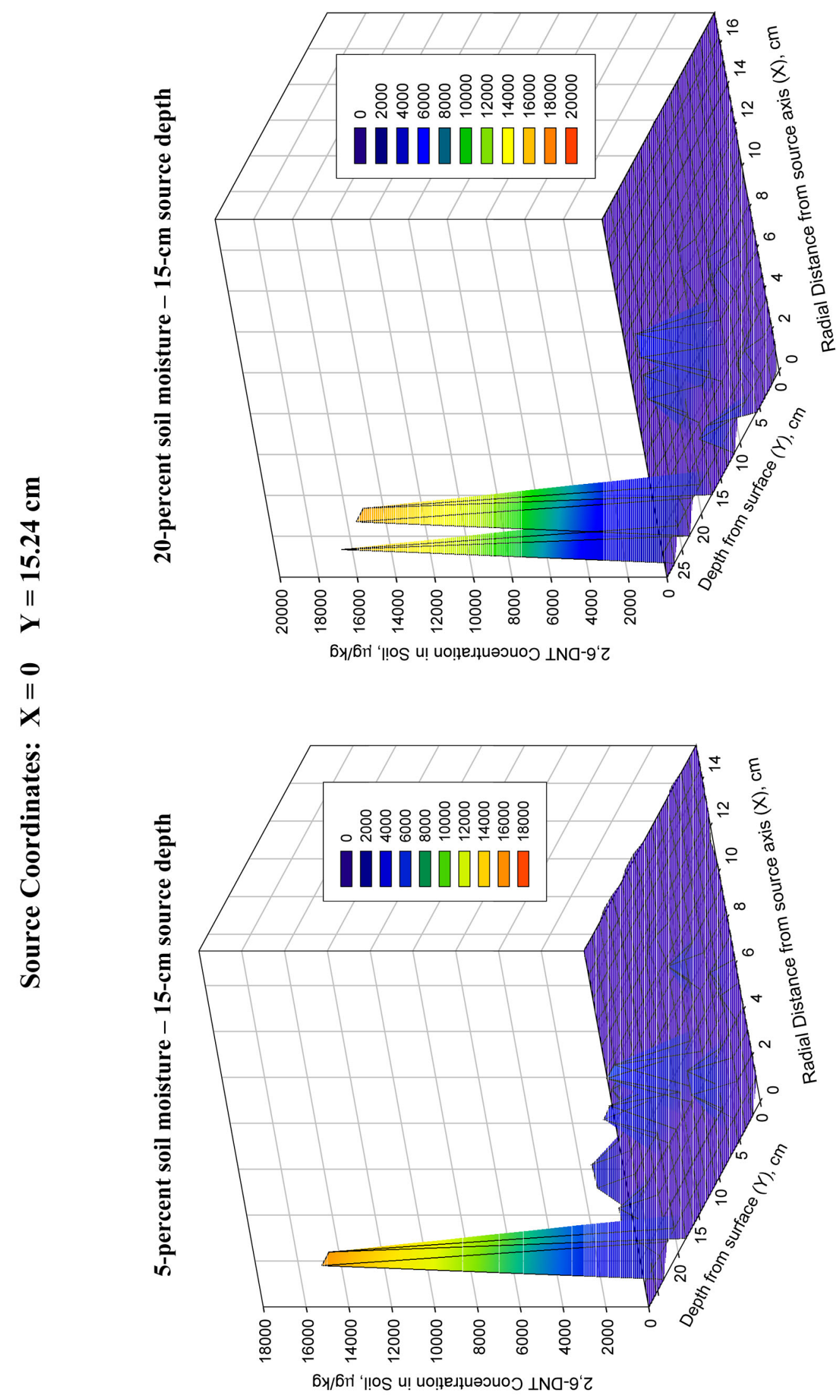

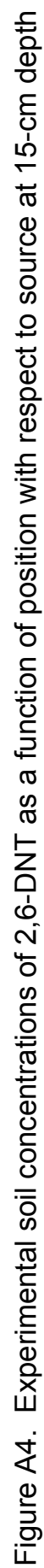




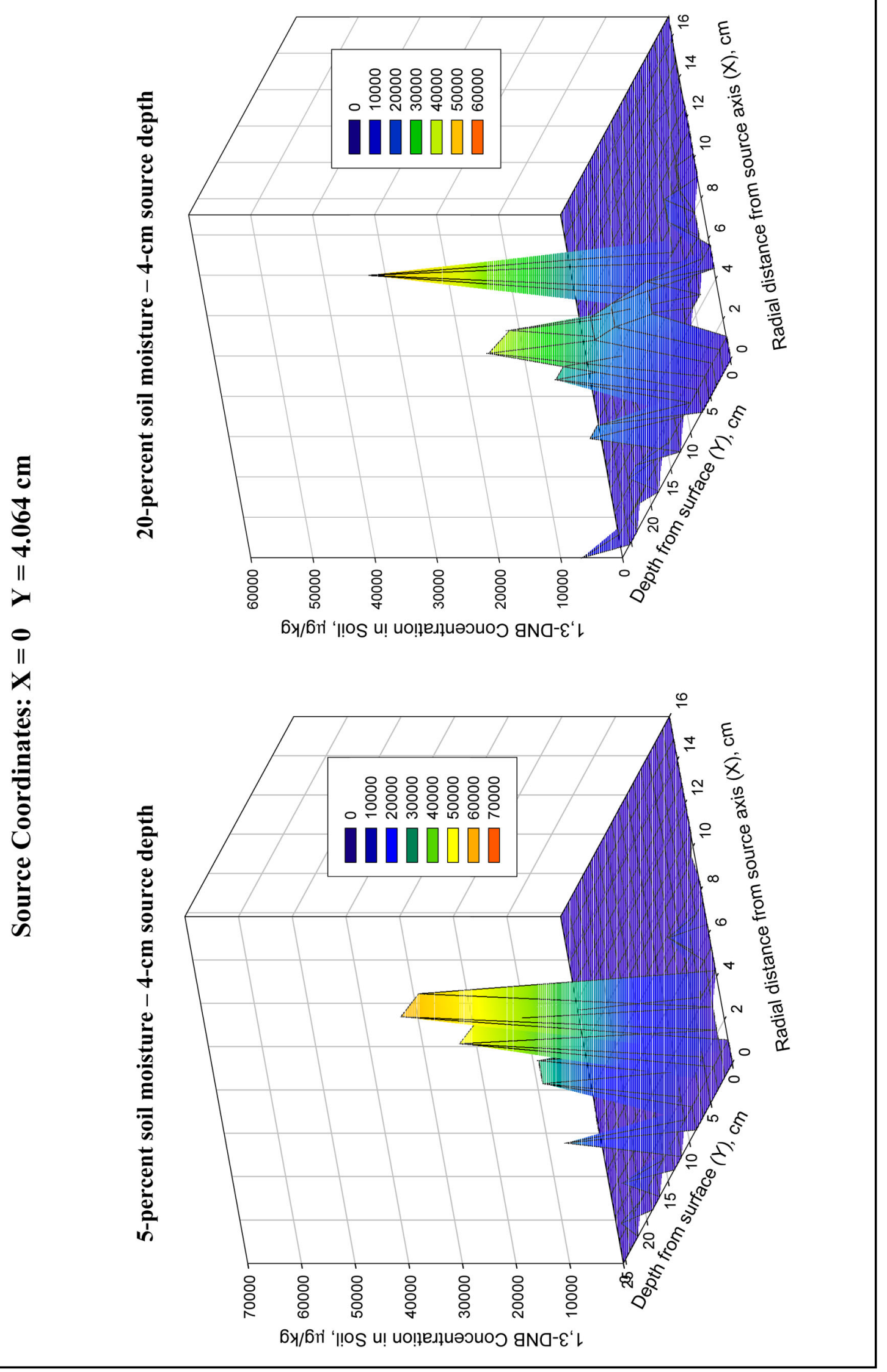

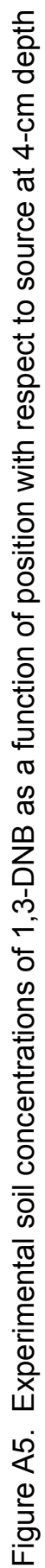




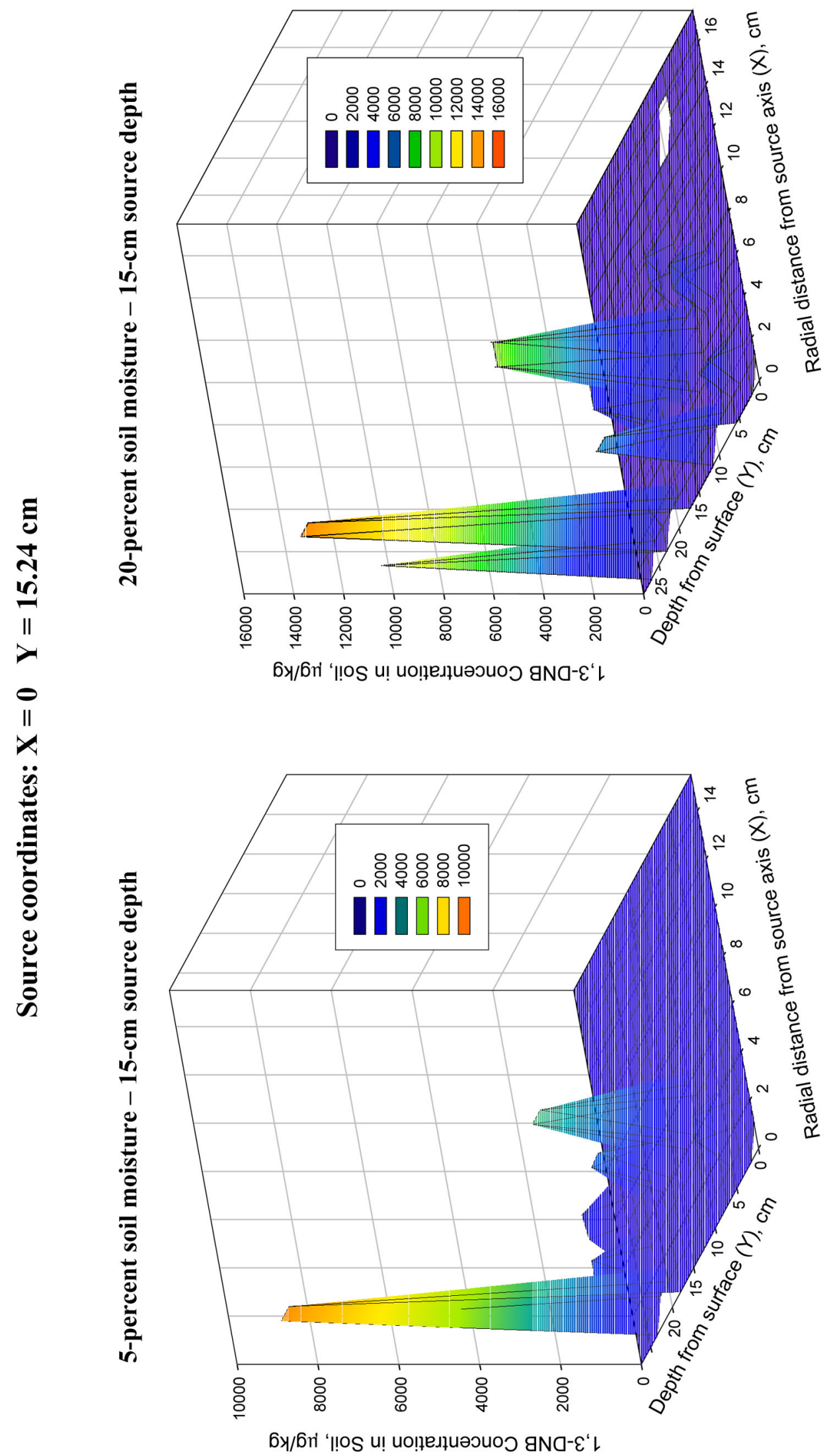

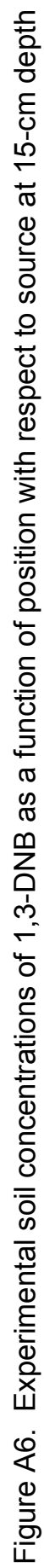




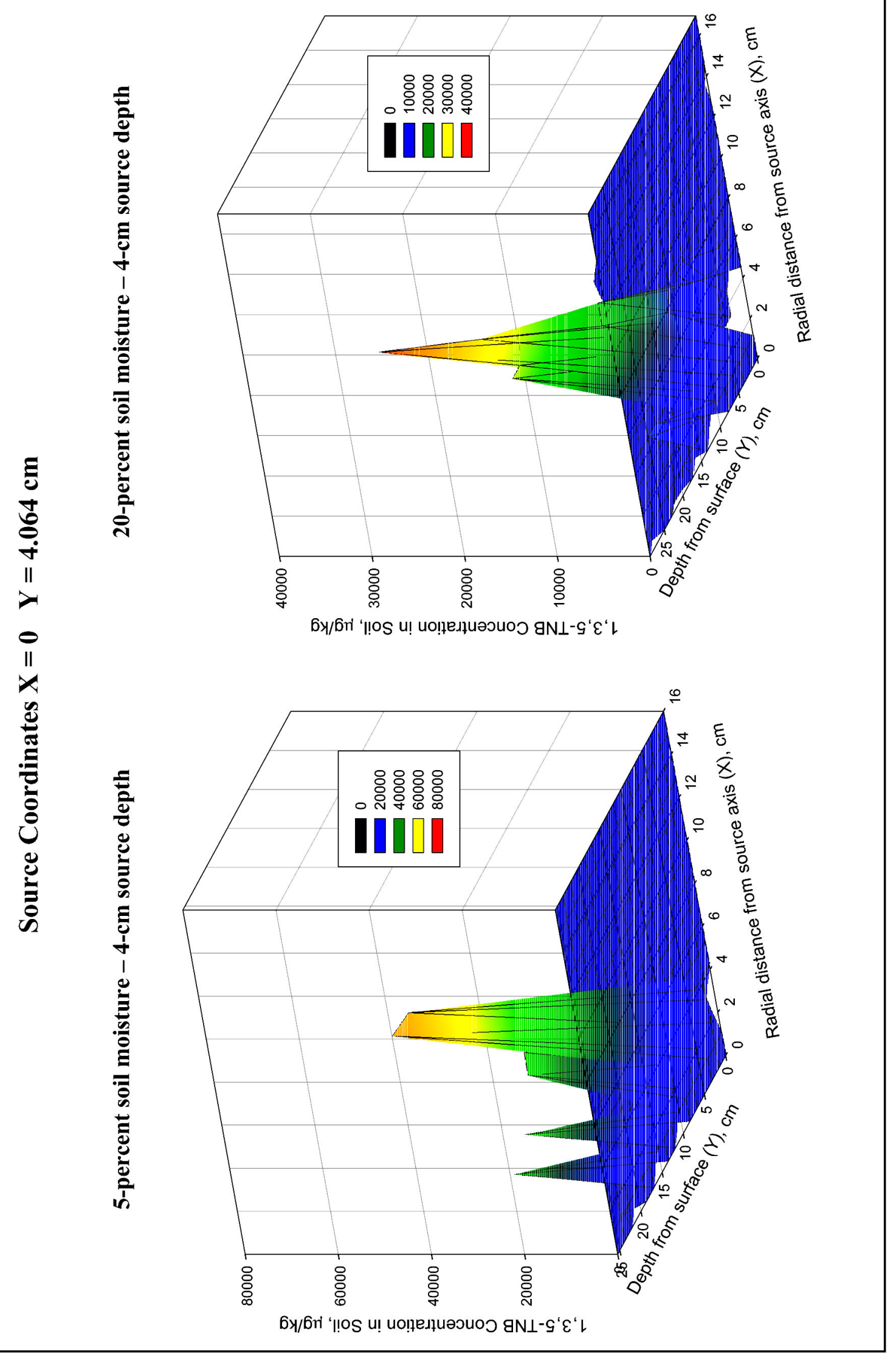

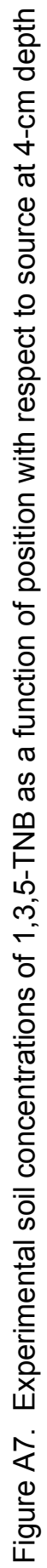




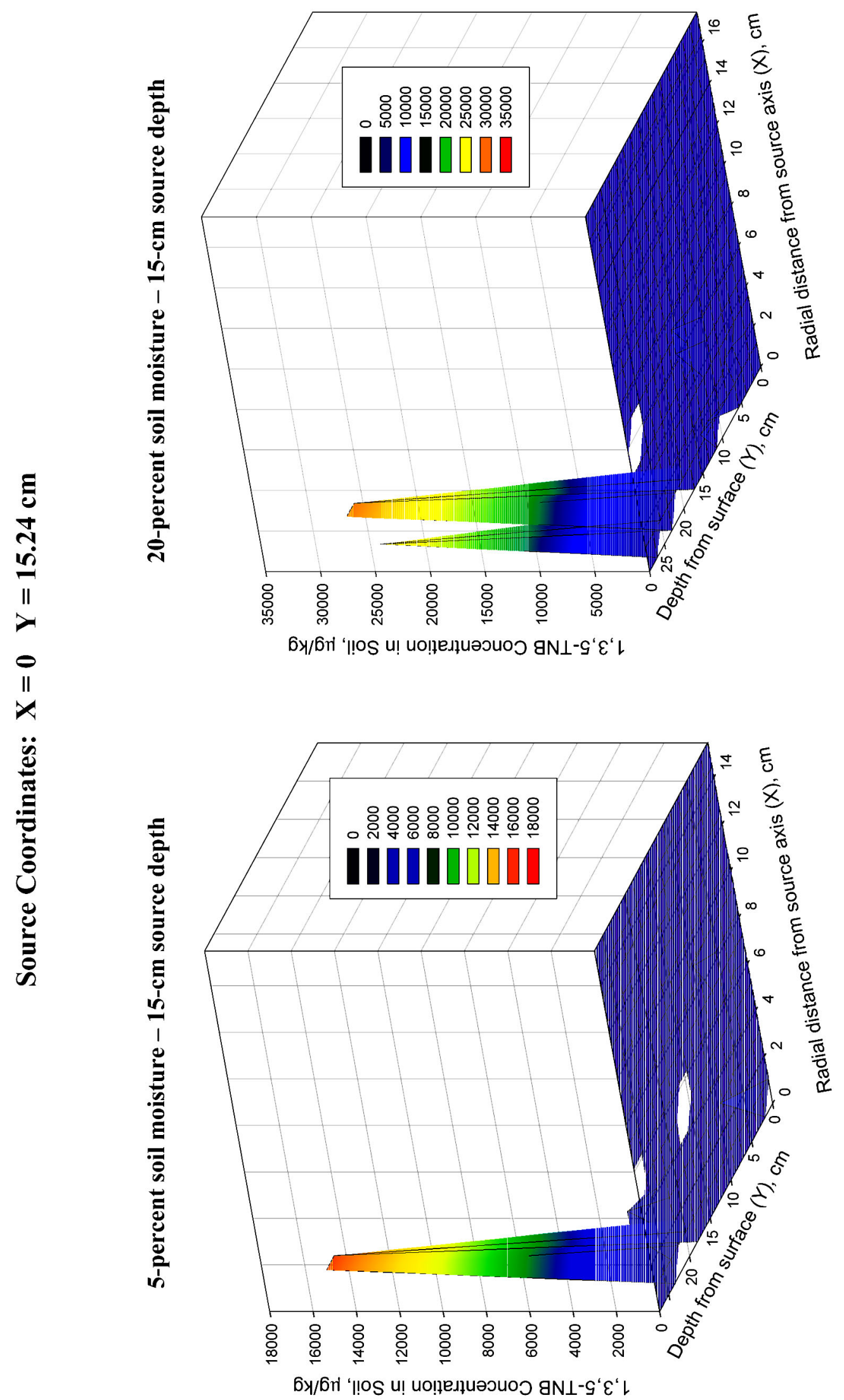

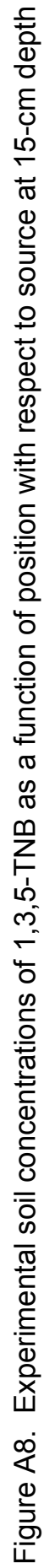




\begin{tabular}{|c|c|c|c|c|c|}
\hline \multicolumn{6}{|c|}{$\begin{array}{l}\text { Table A1 } \\
\text { Initial and Final Concentration }(\mathrm{mg} / \mathrm{kg}) \text { in Soils as a Function of } \\
\text { Temperature and Moisture }\end{array}$} \\
\hline \multirow[b]{2}{*}{ Compound } & \multirow{2}{*}{$\begin{array}{l}\text { Initial } \\
\text { Concentration }\end{array}$} & \multicolumn{2}{|c|}{$14^{\circ} \mathrm{C}$} & \multicolumn{2}{|c|}{$24{ }^{\circ} \mathrm{C}$} \\
\hline & & $5 \%$ moisture & $20 \%$ moisture & $5 \%$ moisture & $20 \%$ moisture \\
\hline \multicolumn{6}{|c|}{ LAAP-C soil following 28 days of incubation } \\
\hline $1,3,5-\mathrm{TNB}$ & $7.56 \pm 0.02$ & $7.75 \pm 0.16$ & $7.63 \pm 0.09$ & $7.12 \pm 0.16$ & $7.29 \pm 0.21$ \\
\hline 1,3-DNB & $9.98 \pm 0.12$ & $10.85 \pm 0.35$ & $10.45 \pm 0.25$ & $9.84 \pm 0.16$ & $9.63 \pm 0.37$ \\
\hline TNT & $9.97 \pm 0.13$ & $10.55 \pm 0.35$ & $10.2 \pm 0.1$ & $9.65 \pm 0.18$ & $9.60 \pm 0.33$ \\
\hline 2,6-DNT & $10.4 \pm 0.1$ & $10.23 \pm 0.57$ & $10.03 \pm 0.27$ & $9.76 \pm 0.11$ & $8.99 \pm 0.48$ \\
\hline 2,4-DNT & $10.35 \pm 0.15$ & $9.97 \pm 0.54$ & $9.84 \pm 0.04$ & $9.36 \pm 0.16$ & $9.55 \pm 0.22$ \\
\hline \multicolumn{6}{|c|}{ LAAP-D soil following 28 days of incubation } \\
\hline 1,3,5-TNB & $8.17 \pm 0.19$ & $7.87 \pm 0.26$ & $8.64 \pm 0.06$ & $7.79 \pm 0.44$ & $8.48 \pm 0.44$ \\
\hline 1,3-DNB & $10.4 \pm 0.1$ & $10.7 \pm 0.3$ & $11.85 \pm 0.05$ & $10.75 \pm 0.35$ & $11.6 \pm 0.6$ \\
\hline TNT & $10.8 \pm 0.3$ & $10.6 \pm 0.4$ & $11.65 \pm 0.05$ & $10.73 \pm 0.37$ & $11.4 \pm 0.6$ \\
\hline 2,6-DNT & $11 \pm 0.3$ & $11 \pm 0.1$ & $11.6 \pm 0.2$ & $10.7 \pm 0.5$ & $11.85 \pm 0.75$ \\
\hline 2,4-DNT & $11 \pm 0.2$ & $10.55 \pm 0.15$ & $11.5 \pm 0.1$ & $10.37 \pm 0.54$ & $11.6 \pm 0.7$ \\
\hline \multicolumn{6}{|c|}{ Yokena cay soil following 14 days of incubation } \\
\hline $1,3,5-\mathrm{TNB}$ & $7.51 \pm 0.15$ & $6.48 \pm 0.07$ & $<0.1$ & $6.09 \pm 0.11$ & $<0.1$ \\
\hline 1,3-DNB & $9.76 \pm 0.04$ & $9.70 \pm 0.02$ & $<0.1$ & $8.99 \pm 0.04$ & $<0.1$ \\
\hline TNT & $9.65 \pm 0.13$ & $8.45 \pm 0.05$ & $0.46 \pm 0.005$ & $7.57 \pm 0.13$ & $0.20 \pm 0$ \\
\hline 2,6-DNT & $10.15 \pm 0.05$ & $9.43 \pm 0.01$ & $7.96 \pm 0$ & $8.89 \pm 0.01$ & $0.26 \pm 0.02$ \\
\hline 2,4-DNT & $10.0 \pm 0$ & $10.1 \pm 0$ & $2.07 \pm 0.005$ & $9.65 \pm 0.5$ & $0.24 \pm 0.02$ \\
\hline
\end{tabular}




\begin{tabular}{|c|c|c|c|c|c|}
\hline \multicolumn{6}{|c|}{$\begin{array}{l}\text { Table A2 } \\
\text { Mass ( } \mu \mathrm{g}) \text { of Explosives from Buried Explosives at 5-Percent Soil } \\
\text { Moisture and 4-cm Burial Depth }\end{array}$} \\
\hline $\begin{array}{l}\text { Horizontal/Vertical } \\
\text { Distance from Source, cm }\end{array}$ & $1,3,5-\mathrm{TNB}$ & 1,3-DNB & TNT & 2,6-DNT & 2,4-DNT \\
\hline $0 \mathrm{~cm} / 10.2 \mathrm{~cm}$ deep & 227 & 153 & 168 & 183 & 131 \\
\hline $0 \mathrm{~cm} / 15.3 \mathrm{~cm}$ deep & 214 & 56.8 & 54.8 & 88.5 & 67.8 \\
\hline $0 \mathrm{~cm} / 20.4 \mathrm{~cm}$ deep & 18.7 & 26.3 & 10.8 & 25.2 & 15.4 \\
\hline $0 \mathrm{~cm} / 23.8 \mathrm{~cm}$ deep & 1.53 & 1.56 & 1.20 & 2.65 & 1.33 \\
\hline $2.5 \mathrm{~cm} / 0 \mathrm{~cm}$ (top cm) & 11.7 & 488 & 4.32 & 108 & 282 \\
\hline $2.5 \mathrm{~cm} / 3.4 \mathrm{~cm}$ deep & 233 & 163 & 40.6 & 39.9 & 112 \\
\hline $2.5 \mathrm{~cm} / 8.5 \mathrm{~cm}$ deep & 280 & 229 & 135.7 & 192 & 153 \\
\hline $6.5 \mathrm{~cm} / 1.7 \mathrm{~cm}$ deep & 0.142 & 40.7 & 0.063 & 20.9 & 19.5 \\
\hline $6.5 \mathrm{~cm} / 11.9 \mathrm{~cm}$ deep & 0.071 & 1.84 & 0.047 & 3.30 & 0.736 \\
\hline $6.5 \mathrm{~cm} / 17 \mathrm{~cm}$ deep & 0.066 & 1.73 & 0.038 & 1.97 & 0.694 \\
\hline $6.5 \mathrm{~cm} / 25.5 \mathrm{~cm}$ deep & 0.062 & 1.43 & 0.050 & 0.787 & 0.791 \\
\hline $9.5 \mathrm{~cm} / 0 \mathrm{~cm}$ (top cm) & 0.084 & 5.97 & 0.025 & 11.4 & 1.34 \\
\hline $9.5 \mathrm{~cm} / 6.8 \mathrm{~cm}$ deep & 0.062 & 0.414 & 0.023 & 3.29 & 0.078 \\
\hline $9.5 \mathrm{~cm} / 23.8 \mathrm{~cm}$ deep & 0.079 & 0.517 & 0.045 & 1.48 & 0.094 \\
\hline $12 \mathrm{~cm} / 1.7 \mathrm{~cm}$ deep & 0.074 & 0.588 & 0.022 & 2.75 & 0.137 \\
\hline $12 \mathrm{~cm} / 13.6 \mathrm{~cm}$ deep & 0.078 & 0.110 & 0.034 & 0.525 & 0.046 \\
\hline $16 \mathrm{~cm} / 5.1 \mathrm{~cm}$ deep & 0.062 & 0.149 & 0.023 & 1.12 & 0.062 \\
\hline $16 \mathrm{~cm} / 8.5 \mathrm{~cm}$ deep & 0.077 & 0.155 & 0.034 & 0.677 & 0.062 \\
\hline $16 \mathrm{~cm} / 20.4 \mathrm{~cm}$ deep & 0.064 & 0.061 & 0.021 & 0.165 & 0.043 \\
\hline $16 \mathrm{~cm} / 23.8 \mathrm{~cm}$ deep & 0.057 & 0.041 & 0.044 & 0.184 & 0.026 \\
\hline
\end{tabular}




\begin{tabular}{|c|c|c|c|c|c|}
\hline \multicolumn{6}{|c|}{$\begin{array}{l}\text { Table A3 } \\
\text { Mass ( } \mu \mathrm{g}) \text { of Explosives from Buried Explosives at 5-Percent Soil } \\
\text { Moisture and 15-cm Burial Depth }\end{array}$} \\
\hline $\begin{array}{l}\text { Horizontal/Vertical } \\
\text { Distance from Source, cm }\end{array}$ & 1,3,5-TNB & 1,3-DNB & TNT & 2,6-DNT & 2,4-DNT \\
\hline $0 \mathrm{~cm} / 0 \mathrm{~cm}$ (top cm) & 13.9 & 1.12 & 0.290 & 3.26 & 0.287 \\
\hline $0 \mathrm{~cm} / 20.4 \mathrm{~cm}$ deep & 214 & 123 & 158 & 212 & 153 \\
\hline $2.5 \mathrm{~cm} / 5.1 \mathrm{~cm}$ deep & 1.21 & 4.52 & 0.308 & 10.8 & 0.942 \\
\hline $2.5 \mathrm{~cm} / 23.8 \mathrm{~cm}$ deep & 13.0 & 10.4 & 3.59 & 12.2 & 11.3 \\
\hline $5.5 \mathrm{~cm} / 1.7 \mathrm{~cm}$ deep & 0.103 & 0.302 & 0.089 & 2.78 & 0.122 \\
\hline $5.5 \mathrm{~cm} / 11.9 \mathrm{~cm}$ deep & 0.112 & 28.8 & 0.108 & 29.3 & 18.6 \\
\hline $5.5 \mathrm{~cm} / 17 \mathrm{~cm}$ deep & 0.088 & 13.4 & 0.080 & 23.1 & 9.11 \\
\hline $5.5 \mathrm{~cm} / 27.2 \mathrm{~cm}$ deep & 0.076 & 4.49 & 0.044 & 8.04 & 3.80 \\
\hline $8.5 \mathrm{~cm} / 6.8 \mathrm{~cm}$ deep & 0.063 & 0.521 & 0.040 & 6.99 & 0.094 \\
\hline $8.5 \mathrm{~cm} / 23.8 \mathrm{~cm}$ deep & 0.056 & 0.816 & 0.028 & 3.99 & 0.123 \\
\hline $11.5 \mathrm{~cm} / 0 \mathrm{~cm}$ (top cm) & 0.111 & 0.144 & 0.022 & 1.15 & 0.153 \\
\hline $11.5 \mathrm{~cm} / 13.6 \mathrm{~cm}$ deep & 0.056 & 0.124 & 0.024 & 2.37 & 0.057 \\
\hline $15.5 \mathrm{~cm} / 5.5 \mathrm{~cm}$ deep & 0.055 & 0.079 & 0.022 & 0.714 & 0.059 \\
\hline $15.5 \mathrm{~cm} / 15.3 \mathrm{~cm}$ deep & 0.054 & 0.030 & 0.031 & 0.970 & 0.046 \\
\hline $15.5 \mathrm{~cm} / 20.4 \mathrm{~cm}$ deep & 0.058 & 0.112 & 0.027 & 1.21 & 0.076 \\
\hline $15.5 \mathrm{~cm} / 27.2 \mathrm{~cm}$ deep & 0.056 & 0.017 & 0.019 & 0.314 & 0.044 \\
\hline
\end{tabular}




\begin{tabular}{|c|c|c|c|c|c|}
\hline \multicolumn{6}{|c|}{$\begin{array}{l}\text { Table A4 } \\
\text { Mass ( } \mu \text { g) of Explosives from Buried Explosives at 20-Percent Soil } \\
\text { Moisture and 4-cm Burial Depth }\end{array}$} \\
\hline $\begin{array}{l}\text { Horizontal/Vertical } \\
\text { Distance from Source, cm }\end{array}$ & $1,3,5-\mathrm{TNB}$ & 1,3-DNB & TNT & 2,6-DNT & 2,4-DNT \\
\hline $0 \mathrm{~cm} / 10.2 \mathrm{~cm}$ deep & 45.6 & 99.5 & 69.8 & 46.1 & 67.0 \\
\hline $0 \mathrm{~cm} / 15.3 \mathrm{~cm}$ deep & 10.4 & 34.3 & 36.0 & 32.4 & 37.9 \\
\hline $0 \mathrm{~cm} / 20.4 \mathrm{~cm}$ deep & 3.31 & 15.6 & 18.4 & 17.6 & 21.3 \\
\hline $0 \mathrm{~cm} / 27.2 \mathrm{~cm}$ deep & 6.35 & 45.8 & 26.8 & 36.3 & 44.1 \\
\hline $2.5 \mathrm{~cm} / 0 \mathrm{~cm}$ (top cm) & 42.2 & 53.3 & 46.4 & 16.7 & 33.5 \\
\hline $2.5 \mathrm{~cm} / 1.7 \mathrm{~cm}$ deep & 79.0 & 84.5 & 76.5 & 31.2 & 52.4 \\
\hline $2.5 \mathrm{~cm} / 3.4 \mathrm{~cm}$ deep & 111 & 101 & 94.1 & 48.2 & 77.5 \\
\hline $2.5 \mathrm{~cm} / 5.1 \mathrm{~cm}$ deep & 162 & 147 & 333 & 207 & 185 \\
\hline $2.5 \mathrm{~cm} / 8.5 \mathrm{~cm}$ deep & 130 & 126 & 80.9 & 39.5 & 79.7 \\
\hline $4.5 \mathrm{~cm} / 1.7 \mathrm{~cm}$ deep & 14.3 & 39.5 & 12.9 & 12.8 & 20.4 \\
\hline $4.5 \mathrm{~cm} / 11.9 \mathrm{~cm}$ deep & 0.141 & 34.1 & 4.01 & 8.74 & 9.32 \\
\hline $4.5 \mathrm{~cm} / 17 \mathrm{~cm}$ deep & $<0.047$ & 11.6 & 1.92 & 4.63 & 4.56 \\
\hline $7 \mathrm{~cm} / 0 \mathrm{~cm}$ (top cm) & 0.087 & 40.6 & 5.41 & 9.08 & 11.4 \\
\hline $7 \mathrm{~cm} / 6.8 \mathrm{~cm}$ deep & 11.5 & 185 & 35.3 & 49.6 & 82.4 \\
\hline $7 \mathrm{~cm} / 23.8 \mathrm{~cm}$ deep & $<0.047$ & 0.059 & $<0.047$ & 0.149 & $<0.047$ \\
\hline $9.5 \mathrm{~cm} / 1.7 \mathrm{~cm}$ deep & $<0.047$ & 10.9 & 0.284 & 3.24 & 2.51 \\
\hline $9.5 \mathrm{~cm} / 13.6 \mathrm{~cm}$ deep & $<0.047$ & 2.21 & $<0.047$ & 1.21 & 0.158 \\
\hline $12 \mathrm{~cm} / 10.2 \mathrm{~cm}$ deep & $<0.047$ & 1.38 & $<0.047$ & 1.04 & $<0.047$ \\
\hline $12 \mathrm{~cm} / 20.4 \mathrm{~cm}$ deep & $<0.047$ & 0.211 & $<0.047$ & 0.248 & $<0.047$ \\
\hline $14.5 \mathrm{~cm} / 0 \mathrm{~cm}$ (top cm) & $<0.047$ & 2.56 & $<0.047$ & 2.02 & 0.789 \\
\hline $14.5 \mathrm{~cm} / 5.1 \mathrm{~cm}$ deep & $<0.047$ & 0.766 & $<0.047$ & 0.911 & $<0.047$ \\
\hline $14.5 \mathrm{~cm} / 28.9 \mathrm{~cm}$ deep & $<0.047$ & $<0.047$ & $<0.047$ & $<0.047$ & $<0.047$ \\
\hline $17 \mathrm{~cm} / 8.5 \mathrm{~cm}$ deep & $<0.047$ & 0.217 & $<0.047$ & 0.583 & $<0.047$ \\
\hline $17 \mathrm{~cm} / 17 \mathrm{~cm}$ deep & $<0.047$ & 0.073 & $<0.047$ & 0.107 & $<0.047$ \\
\hline
\end{tabular}




\begin{tabular}{|c|c|c|c|c|c|}
\hline \multicolumn{6}{|c|}{$\begin{array}{l}\text { Table A5 } \\
\text { Mass ( } \mu \mathrm{g}) \text { of Explosives from Buried Explosives at 20-Percent Soil } \\
\text { Moisture and 15-cm Burial Depth }\end{array}$} \\
\hline $\begin{array}{l}\text { Horizontal/Vertical } \\
\text { Distance from Source, cm }\end{array}$ & 1,3,5-TNB & 1,3-DNB & TNT & 2,6-DNT & 2,4-DNT \\
\hline $0 \mathrm{~cm} / 0 \mathrm{~cm}$ (top cm) & $<0.047$ & 0.716 & $<0.047$ & 0.533 & 0.175 \\
\hline $0 \mathrm{~cm} / 8.5 \mathrm{~cm}$ deep & 12.8 & 29.3 & 6.90 & 13.1 & 18.9 \\
\hline $0 \mathrm{~cm} / 20.4 \mathrm{~cm}$ deep & 142 & 70.3 & 121 & 82.6 & 105 \\
\hline $0 \mathrm{~cm} / 25.5 \mathrm{~cm}$ deep & 114 & 49.0 & 79.8 & 77.6 & 76.3 \\
\hline $2.5 \mathrm{~cm} / 5.1 \mathrm{~cm}$ deep & 3.14 & 6.83 & 0.924 & 3.67 & 3.53 \\
\hline $2.5 \mathrm{~cm} / 23.8 \mathrm{~cm}$ deep & 0.158 & 5.07 & 0.223 & 2.80 & 1.42 \\
\hline $5.5 \mathrm{~cm} / 1.7 \mathrm{~cm}$ deep & $<0.047$ & 1.09 & 0.039 & 1.10 & 0.193 \\
\hline $5.5 \mathrm{~cm} / 11.9 \mathrm{~cm}$ deep & 15.2 & 55.5 & 16.1 & 27.9 & 45.6 \\
\hline $5.5 \mathrm{~cm} / 17 \mathrm{~cm}$ deep & 0.462 & 20.7 & 7.44 & 16.2 & 23.5 \\
\hline $5.5 \mathrm{~cm} / 27.2 \mathrm{~cm}$ deep & $<0.047$ & 0.252 & 0.078 & 0.446 & 0.063 \\
\hline $7.5 \mathrm{~cm} / 6.8 \mathrm{~cm}$ deep & $<0.047$ & 7.56 & 0.140 & 4.28 & 2.34 \\
\hline $7.5 \mathrm{~cm} / 23.8 \mathrm{~cm}$ deep & $<0.047$ & 1.19 & 0.052 & 1.05 & 0.093 \\
\hline $10 \mathrm{~cm} / 0 \mathrm{~cm}$ (top cm) & $<0.047$ & 0.151 & $<0.047$ & 0.346 & $<0.047$ \\
\hline $10 \mathrm{~cm} / 13.6 \mathrm{~cm}$ deep & $<0.047$ & 6.39 & 0.778 & 3.78 & 1.69 \\
\hline $13 \mathrm{~cm} / 20.4 \mathrm{~cm}$ deep & 0.104 & 0.789 & 0.163 & 0.701 & 0.223 \\
\hline $15 \mathrm{~cm} / 3.4 \mathrm{~cm}$ deep & 0.049 & 0.039 & 0.019 & 0.229 & 0.018 \\
\hline $15 \mathrm{~cm} / 10.2 \mathrm{~cm}$ deep & 0.061 & 0.201 & 0.049 & 0.451 & 0.030 \\
\hline $15 \mathrm{~cm} / 28.9 \mathrm{~cm}$ deep & 0.073 & $<0.047$ & 0.111 & 0.049 & $<0.047$ \\
\hline $17.5 \mathrm{~cm} / 15.3 \mathrm{~cm}$ deep & $<0.047$ & 0.111 & $<0.047$ & 0.469 & 0.021 \\
\hline $17.5 \mathrm{~cm} / 23.8 \mathrm{~cm}$ deep & $<0.047$ & $<0.047$ & $<0.047$ & 0.056 & $<0.047$ \\
\hline
\end{tabular}




\title{
Appendix B Notation
}

\author{
$A_{C} \quad$ Soil-air interface area of the chamber \\ $C \quad$ Chemical concentration of reacting substance \\ $C_{A} \quad$ Concentration of chemical in pore air \\ $C_{0} \quad$ Concentration of the reactant at time 0 \\ $C_{A}^{0} \quad$ Initial equilibrium concentration of chemical in pore air $\left(\mathrm{kg} / \mathrm{m}^{3}\right)$ \\ $C_{\text {air }}^{0} \quad$ Equilibrium vapor-phase concentration of the chemical in soil \\ d Length of the airflow path \\ $D_{\text {eff }} \quad$ Effective diffusivity $\left(\mathrm{m}^{2} / \mathrm{s}\right)$ \\ $D_{A} \quad$ Diffusivity of contaminant A in air $\left(\mathrm{m}^{2} / \mathrm{s}\right)$ \\ $H_{C} \quad$ Henry's Law constant \\ $k_{a} \quad$ Air-side mass transfer coefficient $(\mathrm{m} / \mathrm{s})$ \\ $k_{a d v} \quad$ Advective velocity $\left(\mathrm{cm}^{3} / \mathrm{cm}^{2} / \mathrm{hr}\right)$ \\ $k_{1} \quad$ First-order constant for disappearance rate of chemical in soil (1/s) \\ $K_{A W} \quad$ Air-water partition constant or Henry's Law constant \\ (dimensionless) \\ $K_{S A} \quad$ Soil-air partition constant $\left(\mathrm{m}^{3} / \mathrm{kg}\right)$ \\ $K_{S W} \quad$ Soil-water partition constant $(\mathrm{L} / \mathrm{kg})$ \\ M Molecular mass \\ $N_{A} \quad$ Flux rates \\ $P \quad$ Equilibrium vapor pressure, $\mathrm{Pa}$ \\ $r \quad$ Absolute distance away from a chemical source $(\mathrm{cm})$ \\ $R \quad$ Universal gas constant \\ Re Reynolds number \\ $R_{f} \quad$ Retardation factor (dimensionless) \\ Sc Schmidt number
}




$\begin{array}{ll}t & \text { Time } \\ t_{1 / 2} & \text { Half-life } \\ T & \text { Temperature }\left({ }^{\circ} \mathrm{K}\right) \\ v & \text { Average flow velocity } \\ W_{S}(r, t) & \text { Soil concentration or loading of contaminant }(\mathrm{kg} / \mathrm{kg}) \\ W_{S}^{0} & \text { Initial soil concentration or loading of contaminant }(\mathrm{kg} / \mathrm{kg}) \\ x, y & \text { Sample coordinates } \\ X_{0}, Y_{0} & \text { Source coordinates } \\ z & \text { Vertical distance }(\mathrm{cm}) \\ \Delta H_{d e s o r p} & \text { Heat of desorption from soil to air } \\ \Delta m & \text { Mass of contaminant trapped } \\ \Delta t & \text { Duration of sampling } \\ \gamma_{a} & \text { Air-filled porosity }\left(\mathrm{m}^{3} / \mathrm{m}^{3}\right) \\ \gamma_{w} & \text { Water-filled porosity } \\ \gamma_{T} & \text { Total porosity }\left(\mathrm{m}^{3} / \mathrm{m}^{3}\right) \\ \mathrm{D}_{b} & \text { Bulk density of the soil }\left(\mathrm{kg} / \mathrm{m}^{3}\right) \\ v & \text { Kinematic viscosity of air }\end{array}$




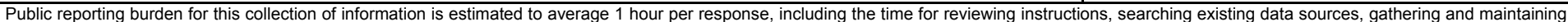

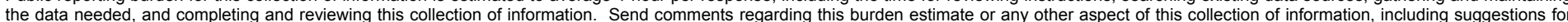

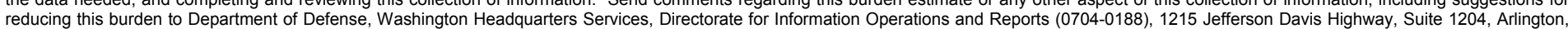

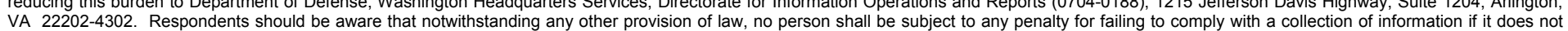
VA 22202-4302. Respondents should be aware that notwithstanding any other provision of law, no person shall be sube
display a currently valid OMB control number. PLEASE DO NOT RETURN YOUR FORM TO THE ABOVE ADDRESS.
1. REPORT DATE (DD-MM-YYYY) 2. REPORT TYPE
September 2002
Final report

\section{TITLE AND SUBTITLE}

Vapor-Phase Transport of Explosives Compounds in Soils

3. DATES COVERED (From - To)

5a. CONTRACT NUMBER

5b. GRANT NUMBER

5c. PROGRAM ELEMENT NUMBER

\section{AUTHOR(S)}

R. Ravikrishna, Sally L. Yost, Cynthia B. Price, Charolett A. Hayes, Kalliat T. Valsaraj, James M. Brannon 5d. PROJECT NUMBER

5e. TASK NUMBER

5f. WORK UNIT NUMBER

8. PERFORMING ORGANIZATION REPORT NUMBER

ERDC/EL TR-02-26

10. SPONSOR/MONITOR'S ACRONYM(S)

11. SPONSOR/MONITOR'S REPORT NUMBER(S)

\section{DISTRIBUTION / AVAILABILITY STATEMENT}

Approved for public release; distribution is unlimited.

\section{SUPPLEMENTARY NOTES}

\section{ABSTRACT}

The fate and transport of explosives in the air-filled pores within soil affect both the potential detection of buried ordnance by chemical sensors and vadose zone transport of explosives residues. The efficacy of chemical sensors and their potential usefulness for detecting buried unexploded ordnance (UXO) is difficult to determine without understanding how explosives chemical signatures are transported through soil. The objectives of this study were to quantify chemical signature transport through soils under various environmental conditions in unsaturated soils and to develop a model for chemical signature transport in unsaturated soils. Flux chambers, large soil containers, and batch testing were used to determine explosives signature movement and process descriptors for model development. This study showed that the moisture content and temperature of soils affect the flux of explosives chemical signatures from soils. Low signatures were observed for explosives under all environmental conditions. Low fluxes of even the most volatile compounds from explosives indicate that this environmental loss pathway is minimal. A model was developed that can accurately predict explosives signature movement to the surface where chemical detection can occur when the source strength is known. The model can also predict explosives signature movement and corresponding accumulation of explosives concentrations in vadose zone soils. Chemical sensors will need to be very sensitive because of low signatures. However, this may result in many false alarms because of explosives residues not associated with UXO on firing ranges. Low explosives signatures should also result in insignificant air environmental exposures.

\begin{tabular}{|c|c|c|c|c|c|}
\hline \multicolumn{2}{|l|}{ 15. SUBJECT TERMS } & $1,3-\mathrm{DNB}$ & \multicolumn{3}{|c|}{ 2,6-DNT } \\
\hline \multicolumn{2}{|l|}{ Explosives } & TNT & \multicolumn{3}{|c|}{ Vapor transport } \\
\hline Model & & 2,4-DNT & & & \\
\hline \multicolumn{3}{|c|}{ 16. SECURITY CLASSIFICATION OF: } & $\begin{array}{l}\text { 17. LIMITATION } \\
\text { OF ABSTRACT }\end{array}$ & $\begin{array}{l}\text { 18. NUMBER } \\
\text { OF PAGES }\end{array}$ & $\begin{array}{l}\text { 19a. NAME OF RESPONSIBLE } \\
\text { PERSON }\end{array}$ \\
\hline $\begin{array}{l}\text { a. REPORT } \\
\text { UNCLASSIFIED }\end{array}$ & $\begin{array}{l}\text { b. ABSTRACT } \\
\text { UNCLASSIFIED }\end{array}$ & $\begin{array}{l}\text { c. THIS PAGE } \\
\text { UNCLASSIFIED }\end{array}$ & & 66 & $\begin{array}{l}\text { 19b. TELEPHONE NUMBER (include } \\
\text { area code) }\end{array}$ \\
\hline
\end{tabular}

